\title{
Article \\ The Effect of Cobalt Catalyst Loading at Very High Pressure Plasma-Catalysis in Fischer-Tropsch Synthesis
}

\author{
Byron Bradley Govender, Samuel Ayodele Iwarere*(D) and Deresh Ramjugernath
}

Citation: Govender, B.B.; Iwarere, S.A.; Ramjugernath, D. The Effect of Cobalt Catalyst Loading at Very High Pressure Plasma-Catalysis in Fischer-Tropsch Synthesis. Catalysts 2021, 11, 1324. https://doi.org/ $10.3390 /$ catal11111324

Academic Editors: Jacek Tyczkowski and Hanna Kierzkowska-Pawlak

Received: 29 September 2021

Accepted: 30 October 2021

Published: 31 October 2021

Publisher's Note: MDPI stays neutral with regard to jurisdictional claims in published maps and institutional affiliations.

Copyright: (c) 2021 by the authors. Licensee MDPI, Basel, Switzerland. This article is an open access article distributed under the terms and conditions of the Creative Commons Attribution (CC BY) license (https:// creativecommons.org/licenses/by/ $4.0 /)$.
Thermodynamics Research Unit, Howard College Campus, School of Engineering, College of Agriculture, Engineering and Science, University of KwaZulu-Natal, Durban 4041, South Africa; byron.bg1@gmail.com (B.B.G.); ramjuger@ukzn.ac.za (D.R.)

* Correspondence: iwarere@ukzn.ac.za

\begin{abstract}
The influence of different catalyst cobalt loadings on the $C_{1}-C_{3}$ hydrocarbon product yields and energy consumption in plasma-catalytic Fischer-Tropsch synthesis (FTS) was investigated from the standpoint of various reactor operating conditions: pressure ( 0.5 to $10 \mathrm{MPa})$, current (250 to $450 \mathrm{~mA}$ ) and inter-electrode gap (0.5 to $2 \mathrm{~mm}$ ). This was accomplished by introducing a mullite substrate, coated with $2 \mathrm{wt} \%-\mathrm{Co} / 5 \mathrm{wt} \%-\mathrm{Al}_{2} \mathrm{O}_{3}, 6 \mathrm{wt} \%-\mathrm{Co} / 5 \mathrm{wt} \%-\mathrm{Al}_{2} \mathrm{O}_{3}$ or $0 \mathrm{wt} \%-\mathrm{Co} / 5 \mathrm{wt} \%-\mathrm{Al}_{2} \mathrm{O}_{3}$ (blank catalyst), into a recently developed high pressure arc discharge reactor. The blank catalyst was ineffective in synthesizing hydrocarbons. Between the blank catalyst, $2 \mathrm{wt} \%$, and the $6 \mathrm{wt} \% \mathrm{Co}$ catalyst, the $6 \mathrm{wt} \%$ improved $\mathrm{C}_{1}-\mathrm{C}_{3}$ hydrocarbon production at all conditions, with higher yields and relatively lower energy consumption at (i) $10 \mathrm{MPa}$ at $10 \mathrm{~s}$, and $2 \mathrm{MPa}$ at $60 \mathrm{~s}$, for the pressure variation study; (ii) $250 \mathrm{~mA}$ for the current variation study; and (iii) $2 \mathrm{~mm}$ for the inter-electrode gap variation study. The inter-electrode gap of $2 \mathrm{~mm}$, using the $6 \mathrm{wt} \%$ Co catalyst, led to the overall highest methane, ethane, ethylene, propane and propylene yields of $22424,517,101,79$ and $19 \mathrm{ppm}$, respectively, compared to $40 \mathrm{ppm}$ of methane and $<1 \mathrm{ppm}$ of $C_{1}-C_{3}$ hydrocarbons for the blank catalyst, while consuming 660 times less energy for the production of a mole of methane. Furthermore, the $6 \mathrm{wt} \%$ Co catalyst produced carbon nanotubes (CNTs), detected via transmission electron microscopy (TEM). In addition, scanning electron microscopy (SEM), energy dispersive $\mathrm{x}$-ray spectroscopy (EDX) and x-ray diffraction (XRD) showed that the cobalt catalyst was modified by plasma treatment.
\end{abstract}

Keywords: arc discharge; cobalt catalyst; Fischer-Tropsch synthesis; high pressure; non-thermal plasma

\section{Introduction}

Non-thermal plasma (NTP) has typically been restricted to ignition at low current ( $<1 \mathrm{~A})$ and atmospheric pressure $(\mathrm{P} \sim 1 \mathrm{MPa})$ by electric discharges, such as the dielectric barrier discharge (DBD) and corona discharge. However, within the last decade, researchers such as Fulcheri and co-workers [1] have developed an electrical arc discharge reactor which enables NTP generation at low current $(\mathrm{I}<1 \mathrm{~A})$ and very high pressure $(\mathrm{P}>1 \mathrm{MPa})$. The high pressure environment combined with the active plasma species have thus far been harnessed to undertake organic synthesis, namely hydrocarbon (Fischer-Tropsch) synthesis [2,3], dry reforming of methane [4] and fluorocarbon synthesis [5].

Fischer-Tropsch synthesis (FTS) is a well-established process which involves the hydrogenation of carbon monoxide $\left(\mathrm{CO}+\mathrm{H}_{2}\right)$ to produce synthetic hydrocarbon fuels on an industrial scale. It is a process that provides a competitive alternative to oil-derived fuels [1], considering the declining oil reserves, fluctuating oil prices and increasing energy demand. Thus, there is an increase in investment in FTS technology especially in the area of gas-to-liquid (GTL) and biomass-to-liquid (BTL) production. This is an indication that FTS technology is poised to play a significant role in the global energy mix in the upcoming decades. However, the cost associated with a large volume reaction vessel and the high temperature required for the process has led researchers to investigate the design 
of a micro-channel reactor as an alternative method. This new approach is considered to potentially reduce the limitations associated with mass and heat transfer within the reactor.

Plasma-based FTS technologies could provide a viable alternative to conventional processes as a result of the rapid reactions promoted by plasma species (milliseconds to minutes), and a reduction in space and maintenance required by the technology. Thus, few authors [2-4] in recent times have explored the use of pure plasma FTS (no catalyst) for the production of gaseous $C_{1}-C_{3}$ hydrocarbons using the arc discharge reactor at current $<1 \mathrm{~A}$. However, only a few experimental results are available in the literature for plasma-catalytic reactions applied in FTS at pressures above atmospheric conditions [6-9]. Therefore, the present study investigated the effect of catalyst loading $\left(\mathrm{Co} / \mathrm{Al}_{2} \mathrm{O}_{3}\right)$ mullite catalyst incorporated into the arc discharge for FTS.

Researchers have recently reported on the performance of cobalt catalysts pretreated with glow-discharge plasma in FTS at atmospheric pressure, with the pretreated catalyst shown to improve carbon monoxide (CO) conversion and methane selectivity [10]. Aluha et al. [11] followed the approach of inducted suspension plasma technology to synthesize nano-catalysts, and nanometric C-supported catalysts (cobalt and iron) for application in FTS [12]. Although Aluha et al. $[13,14]$ reported that plasma-synthesized catalysts were shown to have active catalytic species for FTS when Co-based and modified Co-Fe catalysts are used, Chu et al. [10] indicated that the selectivity of plasma-synthesized catalysts to longer-chain hydrocarbons $\left(\mathrm{C}_{5_{+}}\right)$is similar to those prepared through conventional techniques.

Contrary to the report by $\mathrm{Chu}$ et al. [10] on $\mathrm{C}_{5+}$ hydrocarbons, a recent review by Aluha et al. [15] covering some of the research carried out in the last four decades since the introduction of plasma techniques for catalyst synthesis highlighted that $\mathrm{Co} / \mathrm{C}$ catalyst at $493 \mathrm{~K}, 2 \mathrm{MPa}$, and $3600 \mathrm{~cm}^{3} \cdot \mathrm{h}^{-1} \cdot \mathrm{g}^{-1}$ gas hourly space velocity improved selectivity towards the longer-chain hydrocarbons.

Therefore, the present study contributes to the body of scientific knowledge in the field of catalysts at pressures $>1 \mathrm{MPa}$ for FTS using a blank catalyst, containing no cobalt $\left(0 \mathrm{wt} \%-\mathrm{Co} / \mathrm{Al}_{2} \mathrm{O}_{3}\right)$, and a $6 \mathrm{wt} \%-\mathrm{Co} / \mathrm{Al}_{2} \mathrm{O}_{3}$ catalyst, and comparing the results to those previously reported in literature [9] to further determine the influence of low cobalt loadings on plasma-catalytic FTS. Furthermore, the hydrocarbon product yields and energy consumption were compared for varying operating parameters: pressure (0.5-10 MPa), ignition current (250-450 mA) and inter-electrode gap (0.5-2 mm).

\section{Results and Discussion}

The study compares a blank, $2 \mathrm{wt} \%$ Co catalyst and $6 \mathrm{wt} \%$ Co catalysts in order to determine the contribution of different cobalt loadings to the plasma-catalytic synergistic effect. These cobalt loadings were compared using the hydrocarbon product yields and energy consumption of these systems under the scope of three varying operating parameters: pressure, ignition current and inter-electrode gap.

Trace quantities (ppm levels) of $C_{1}-C_{3}$ gaseous hydrocarbons were produced in the arc discharge reactor for both the blank, $2 \mathrm{wt} \%$, and $6 \mathrm{wt} \%$ Co catalyst systems. This was because the arc discharge active volume was estimated to be more than 10,000 times lower than the total volume of the reactor containing the catalyst $\left(\sim 1.2 \mathrm{~cm}^{3}\right)$. The large reactor/discharge volume ratio meant that $C_{1}-C_{3}$ hydrocarbons, produced within the active arc volume, were mixed with the bulk volume of unreacted syngas $\left(\mathrm{CO}+\mathrm{H}_{2}\right)$, leading to dilution of the reaction products $(<3 \mathrm{~mol} \%)$. The hydrocarbons yields were in the general order: $C_{1}$ (methane) $>>C_{2}$ (ethane + ethylene) $>C_{3}$ (propane + propylene). These products were similar to those previously reported for pure plasma FTS [3].

\subsection{Pressure Variation Study}

\subsubsection{The Influence of Pressure on FTS Product Yields}

Plasma-catalytic FTS was undertaken for varying pressures between 0.5 and $10 \mathrm{MPa}$, at a fixed current of $350 \mathrm{~mA}$ and inter-electrode gap of $1 \mathrm{~mm}$, and at different discharge times of $10 \mathrm{~s}$ and $60 \mathrm{~s}$. A full list of operating conditions for the three parametric studies are 
presented in Table 1. Prior to comparing the different cobalt loadings of $0 \mathrm{wt} \% \mathrm{Co}$ (blank), $2 \mathrm{wt} \% \mathrm{Co}$, and $6 \mathrm{wt} \%$ Co in Section $2 \mathrm{wt} \%$ and $6 \mathrm{wt} \%$ Co Catalyst, the blank catalyst was firstly compared to the pure plasma study.

Table 1. List of operating conditions used in pure plasma and plasma-catalytic FTS.

\begin{tabular}{ccccc}
\hline Operating Parameters & \multicolumn{2}{c}{ Pressure Variation Study } & $\begin{array}{c}\text { Current } \\
\text { Variation Study }\end{array}$ & Electrode Gap Variation Study \\
\hline Discharge time (s) & 10 & 60 & 60 & 60 \\
Ignition current (mA) & 350 & 350 & $250,300,350,400,450$ & 350 \\
Ignition voltage (kV) & 8 & 8 & 8 & 8 \\
Electrode gap (mm) & 1 & 1 & 1 & $0.5,1.0$, \\
Pressure (MPa) & $0.5,1,2,3,4,5,6$, & $0.5,1,2,3,4,5,6$, & 2 & 2.0 \\
$\mathrm{H}_{2}$ /CO ratio & $7,8,9,10$ & $7,8,9,10$ & $2.2: 1$ & $2.2: 1$ \\
\hline
\end{tabular}

The background: Highlights the key parameter ranges.

\section{Blank Catalyst}

A blank catalyst (mullite substrate coated with $5 \mathrm{wt} \%-\gamma-\mathrm{Al}_{2} \mathrm{O}_{3}$ ), without cobalt, was tested as a control study in order to determine the contribution of different cobalt loadings on the $\gamma-\mathrm{Al}_{2} \mathrm{O}_{3}$-coated mullite in plasma-catalysis. The studies using the blank and cobalt loaded catalysts were directly comparable as all preparation parameters were maintained.

The concentration versus pressure plots at $10 \mathrm{~s}$ and $60 \mathrm{~s}$ for the blank catalyst and the pure plasma systems are shown in Figure 1a,b. The concentration curves for methane (Figure 1a) diverged from $1 \mathrm{MPa}$ onwards compared to $4 \mathrm{MPa}$ for pure plasma. This was probably due to the improvement in bulk gas circulation at lower pressures, caused by the catalyst reducing the reactor volume by approximately $54 \%$.

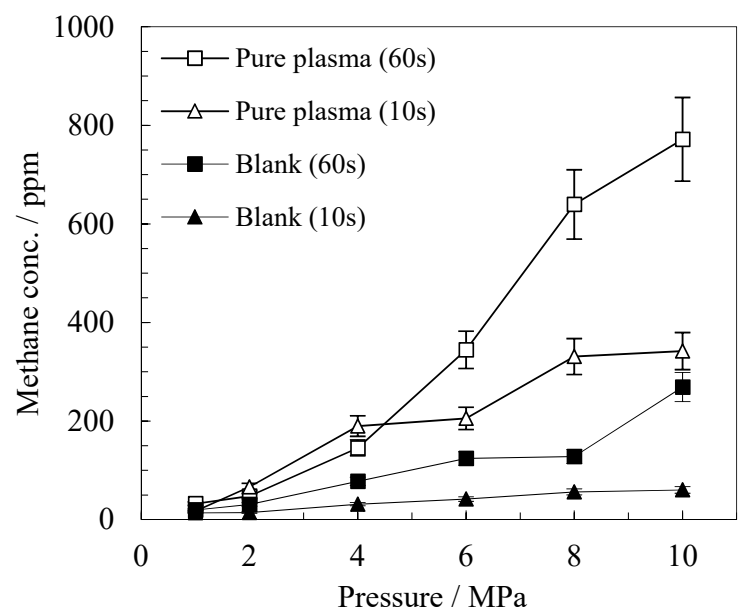

(a)

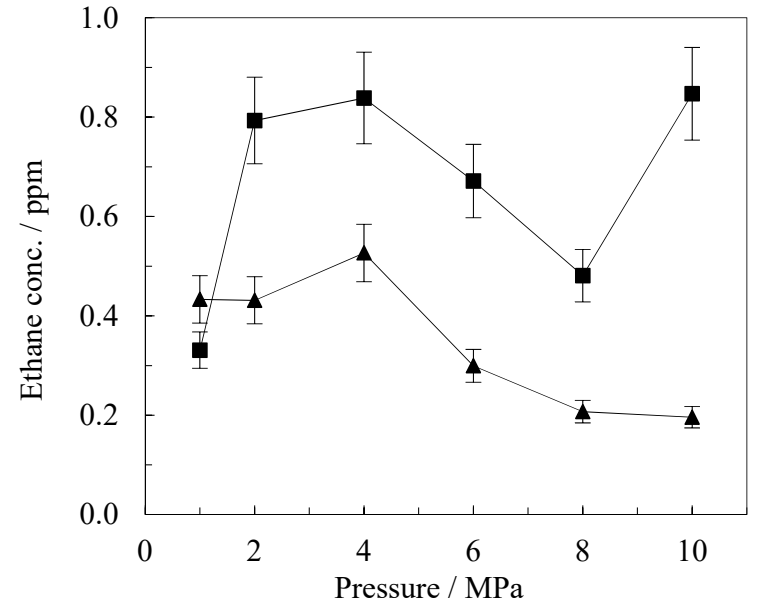

(b)

Figure 1. The influence of pressure on the hydrocarbon concentration for plasma-catalytic FTS (NTP + Blank catalyst) at discharge times of 10 and $60 \mathrm{~s}$; (a) methane and (b) ethane. Legend: $\square$ —Pure plasma (60 s); $\Delta$-Pure plasma (10 s); $\mathbf{\square}$ Blank (60 s); $\mathbf{\Delta}$-Blank (10 s). Operating conditions: Syngas ( $\mathrm{H}_{2} / \mathrm{CO}$ ) ratio: 2.2:1; current: $350 \mathrm{~mA}$; inter-electrode gap: $1 \mathrm{~mm}$; wall temperature: $25^{\circ} \mathrm{C}$. Error bars (vertical): Expanded experimental hydrocarbon concentration uncertainty of $\pm 11 \%$.

Similarly, to the pure plasma study, the pressure range of 4 to $8 \mathrm{MPa}$ for the blank catalyst was less effective for chain growth promotion as compared to 8 to $10 \mathrm{MPa}$. The qualitative trend for the blank catalyst was analogous to that of pure plasma; however, its methane concentrations were lower for the pressure range studied: at $10 \mathrm{MPa}$ and $60 \mathrm{~s}$, the 
methane concentration for the blank catalyst (269 ppm) was $\sim 2.9$ times lower than that for pure plasma (772 ppm).

Lower methane yields for the blank catalyst may infer lower CO conversions, and thus a decrease in methylene monomer production ( $\mathrm{CHx}$ )-the building blocks required for chain growth. Monomer reduction, in turn, may have been responsible for lower $C_{2}-C_{3}$ hydrocarbon yields than pure plasma, as seen by the low ethane concentrations $(<1 \mathrm{ppm})$ throughout the pressure range studied (Figure 1b). Furthermore, particularly low ethylene yields $(<0.1 \mathrm{ppm}$ ) were detected (not shown in Figure 1$)$, and $\mathrm{C}_{3}$ hydrocarbons were not synthesized (or may have been present below the gas chromatograph detection limit).

The blank catalyst was not anticipated to improve hydrocarbon production as cobalt is the active catalytic material in conventional FTS. $\mathrm{Al}_{2} \mathrm{O}_{3}$, however, has been shown to possess good catalytic activity linked to its acid/base surface properties and metal oxygen bond strength [16-19], which allows this refractory material to stimulate numerous acid catalyzed reactions $[18,20]$. Accordingly, it is possible that a decrease in FTS activity was due to the adsorptive properties of $\gamma-\mathrm{Al}_{2} \mathrm{O}_{3}$. The pressure drop ( $\Delta$ Pdrop) immediately after the discharge period of $60 \mathrm{~s}$ was assumed to be an indicator of catalytic adsorption.

In pure plasma FTS, at $10 \mathrm{MPa}$ and $10 \mathrm{~s}$, the operating pressure minutely increased by $0.01 \mathrm{MPa}(-\Delta \mathrm{Pdrop})$. This increase suggests that the extension of the inter-electrode gap from $0 \mathrm{~mm}$ (before reaction, $\mathrm{t}<0 \mathrm{~s}$ ) to $1 \mathrm{~mm}$ (at the start of reaction, $\mathrm{t}=0 \mathrm{~s}$ ) had an insignificant effect on the reactor volume and the related pressure drop. However, for pure plasma at $10 \mathrm{MPa}$ and at a longer discharge time of $60 \mathrm{~s}$, the operating pressure, instead of increasing, decreased by $0.07 \mathrm{MPa}$, probably due to an increase in the $\mathrm{C}_{1}-\mathrm{C}_{3}$ hydrocarbon yields, which possessed lower partial pressures than the $\mathrm{H}_{2}$ and $\mathrm{CO}$ reactants

An identical decreasing pressure trend was seen for the blank catalyst at $10 \mathrm{MPa}$, where the $\Delta \mathrm{P}$ drop values of 0.16 and $0.3 \mathrm{MPa}$ at 10 and $60 \mathrm{~s}$, respectively, were more than 16 and 4 times higher than the pure plasma values. However, the higher $\Delta \mathrm{P}$ drop values for the blank catalyst were not due to lower partial pressure products (as in pure plasma FTS), as considerably lower hydrocarbon yields were obtained for the blank catalyst compared to pure plasma. Therefore, it is plausible to ascribe the decrease in operating pressure to $\mathrm{CO}$ adsorption on the blank catalyst (probably in the molecular, radical or vibrationally excited states), followed by surface reactions to form carbonaceous species. This was a reasonable reaction pathway as carbon deposits (in the form of graphite) were detected via $\mathrm{x}$-ray diffraction (discussed in Section 2.4.4) on the blank, 2 and $6 \mathrm{wt} \%$ Co catalysts.

The adsorption properties of both $\gamma-\mathrm{Al}_{2} \mathrm{O}_{3}$ and mullite $\left(72 \mathrm{wt} \%-\mathrm{Al}_{2} \mathrm{O}_{3} / \mathrm{SiO}_{2}\right)$ were considered to be responsible for $\mathrm{CO}$ adsorption and its effects on synthesis. Cabrejas Manchado et al. [19] indicated that $\mathrm{CO}$ was more strongly adsorbed on $\gamma-\mathrm{Al}_{2} \mathrm{O}_{3}$ than hydrogen (present as a reactant in this work) and oxygen. This occurs through $\mathrm{CO}$ possessing both a weak carbonyl bond, which is easily converted into formate, as well as a low activation energy, which can lead to high surface coverage (up to 90\%) and possibly irreversible adsorption.

$\mathrm{CO}$ adsorption in the present study may have been further augmented by the thermal activation of the blank catalyst by the arc discharge, possibly generating radicals and vibrationally excited $\mathrm{CO}$ species that could be more readily adsorbed than ground state CO molecules.

It was shown in atmospheric pressure plasma-catalytic processes, namely dry reforming of methane and volatile organic compounds (VOCs) treatment, that the active plasma species can electrically modify the chemisorption properties of porous catalyst materials, including $\mathrm{Al}_{2} \mathrm{O}_{3}$ [21,22]. In addition, porous $\mathrm{Al}_{2} \mathrm{O}_{3}$ was indicated to increase the concentration (or pre-concentrate) of plasma species on the catalyst surface, resulting in a longer residence time in the discharge region [23]. The mentioned properties of $\mathrm{Al}_{2} \mathrm{O}_{3}$ could increase the collisional activity and promote additional surface reaction pathways [24,25], which in this work may have been translated to improved $\mathrm{CO}$ adsorption and inhibited hydrocarbon chain growth.

Hydrocarbon synthesis and chain growth would have also been impeded, apart from $\mathrm{CO}$ adsorption, by the absence of active cobalt. In classical catalysis, it has been suggested that 
hydrogen dissociates on a catalytically active metal and spills over onto the catalyst support, generating a hydrogen reservoir for synthesis processes [26,27], which would be deficient in the blank catalytic experiments owing to the absence of catalytically active cobalt.

It is therefore plausible to ascribe the low CO conversion, low methane yields, and the detection of carbonaceous (graphite) species, to both the strongly/irreversibly adsorbed $\mathrm{CO}$ and the shortage of adsorbed hydrogen (needed for precursor $\left(\mathrm{CH}_{\mathrm{x}}\right)$ hydrogenation). In addition, silica and alumina, present in mullite, could have contributed to the low $C_{2}$ and $C_{3}$ hydrocarbon yields, and possibly graphite production, as silica-alumina have been recognized to catalyze cracking reactions, which are promoted by low concentrations of water [18]. These conditions, existing during experimentation (including the detection of water, discussed later), may have caused the catalytic cracking of ethylene, which is readily susceptible to cracking [28].

The oxidative properties of $\mathrm{Al}_{2} \mathrm{O}_{3}$ could have also contributed to the low hydrocarbon concentrations. In plasma-catalytic VOCs treatment, aromatic compounds were oxidized to $\mathrm{CO}, \mathrm{CO}_{2}$, and other hydrocarbons. Oxidation was facilitated by short-lived active species, such as atomic oxygen, being adsorbed in the catalyst pores [23,24,29]. In plasma-catalytic dry reforming of methane, methane was oxidized to $\mathrm{CO}$ by combining a dielectric barrier discharge (DBD) and a $\gamma-\mathrm{Al}_{2} \mathrm{O}_{3}$ catalyst [30].

Due to the oxidative ability of $\mathrm{Al}_{2} \mathrm{O}_{3}$, the hydrocarbons produced in the arc discharge core, having similar yields to that of pure plasma FTS, may have been oxidized by excited oxygen species and oxygen radicals within the $\mathrm{Al}_{2} \mathrm{O}_{3}$ pores to produce $\mathrm{CO}$ and $/$ or $\mathrm{CO}_{2}$. This reaction pathway, however, was difficult to support as an increase in the $\mathrm{CO}$ concentration and the formation of $\mathrm{CO}_{2}$ by oxidation, if at all active, were too minute to detect by the calibrated gas chromatograph.

The reaction schemes mentioned in this section for the blank catalyst, namely $\mathrm{CO}$ chemisorption, arise from the presence of $\mathrm{Al}_{2} \mathrm{O}_{3}$ and mullite hydrogen shortage, owing to the absence of active cobalt as well as hydrocarbon cracking and hydrocarbon oxidation, may have been responsible for lower $C_{1}-C_{3}$ hydrocarbon yields and higher energy consumption for both the current and inter-electrode gap variation studies when compared to previous study on the pure plasma FTS by Govender et al. [9]. Overall, the blank catalyst's experiment involving current and interelectrode gap variation studies showed lower yields than the pure plasma experiments previously reported in the literature [9].

\subsubsection{2. $\mathrm{wt} \%$ and $6 \mathrm{wt} \%$ Co Catalyst}

In Section Blank Catalyst, it was shown that the blank catalyst produced lower yields than pure plasma [6] at all pressures. However, in this section, the influence of cobalt loadings $2 \mathrm{wt} \%$ Co catalyst and $6 \mathrm{wt} \%$ Co catalyst are discussed.

For the $6 \mathrm{wt} \%$ Co catalyst, the arc discharge was unstable above $6 \mathrm{MPa}$. This instability led to extinguishing of the arc discharge before completion of the $60 \mathrm{~s}$ treatment period, which contrasted with the blank and $2 \mathrm{wt} \%$ Co catalyst experiments, where the arc discharge was stable at all pressures investigated (1 to $10 \mathrm{MPa}$ ) and at both discharge periods of $10 \mathrm{~s}$ and $60 \mathrm{~s}$. After arc termination, instantaneous re-striking of the arc was practically impossible as cathode/anode contact was required for ignition under the low current and high pressure conditions as governed by Paschen's law.

The instability and extinguishing of the arc for the $6 \mathrm{wt} \%$ catalyst was due to the production of high water yields. Higher yields were produced due to an increase in $\mathrm{CO}$ dissociation (implying a higher availability of oxygen for water formation), which was promoted to a greater degree by the higher $6 \mathrm{wt} \%$ Co loading compared to the lower $(2 \mathrm{wt} \% \mathrm{Co})$ catalyst loading. It was the condensation of the relatively large quantities of water (seen visually as liquid droplets on the sight glass and verified using a GC-MS), which was the source of the arc extinguishing. Condensation did not occur for the lower $2 \mathrm{wt} \%$ Co loading, i.e., lower water concentrations remained in the vapor phase.

Moreover, the arc extinguished more rapidly at higher pressures: $\sim 30 \mathrm{~s}$ at $7 \mathrm{MPa}$, and $\sim 12 \mathrm{~s}$ at $10 \mathrm{MPa}$. At $10 \mathrm{MPa}$ and $\sim 12 \mathrm{~s}$ (shown in Figure 2a-e), the methane, ethane, 
ethylene, propane and propylene concentrations were 32,598 (3.2 mol\%), 268, 61, 51 and $30 \mathrm{ppm}$, respectively.

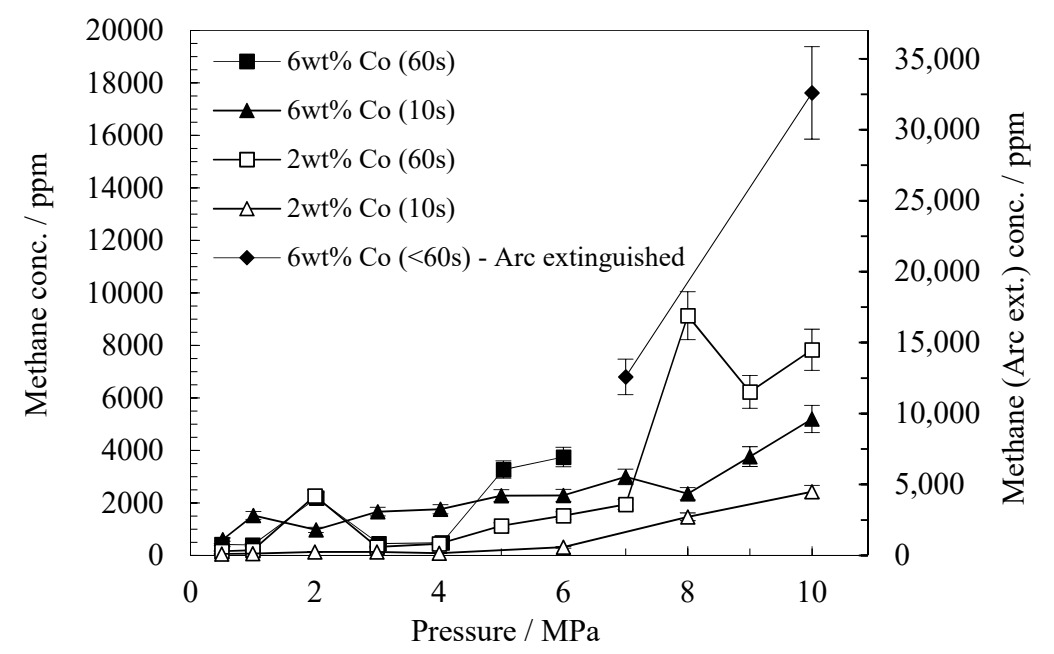

(a)

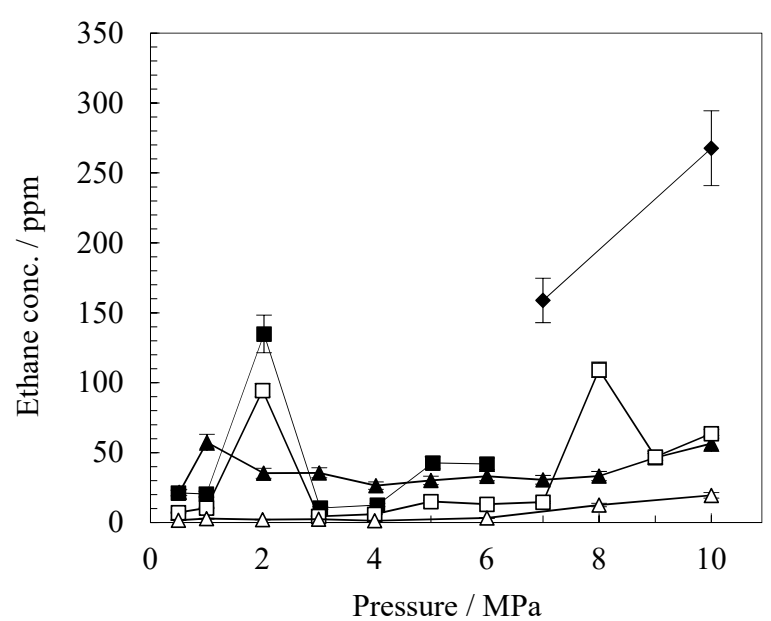

(b)

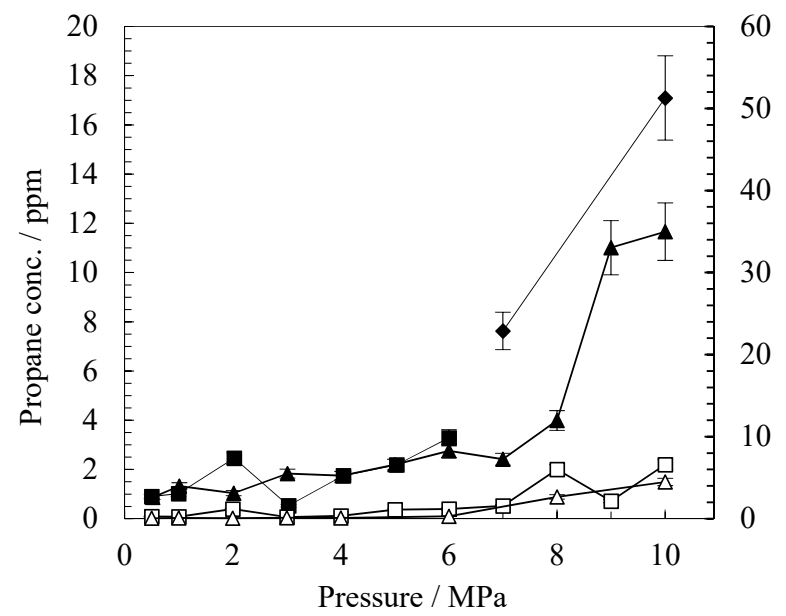

(d)

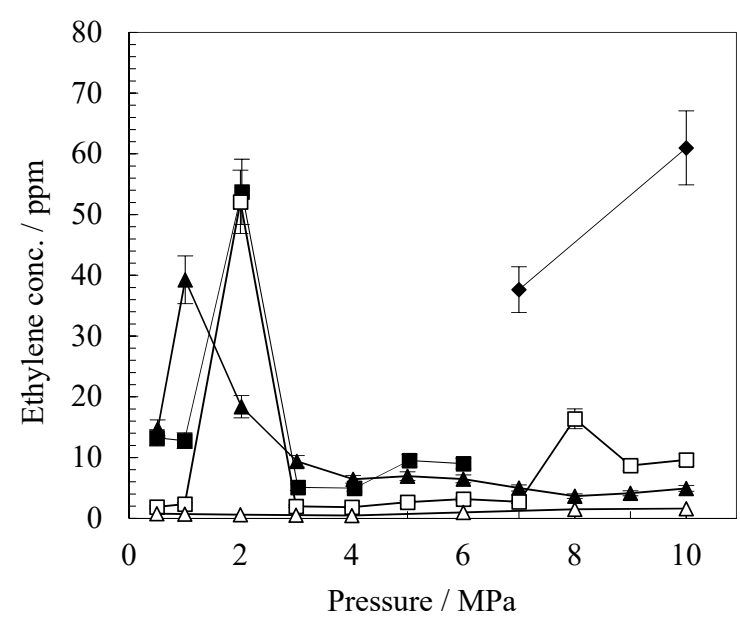

(c)

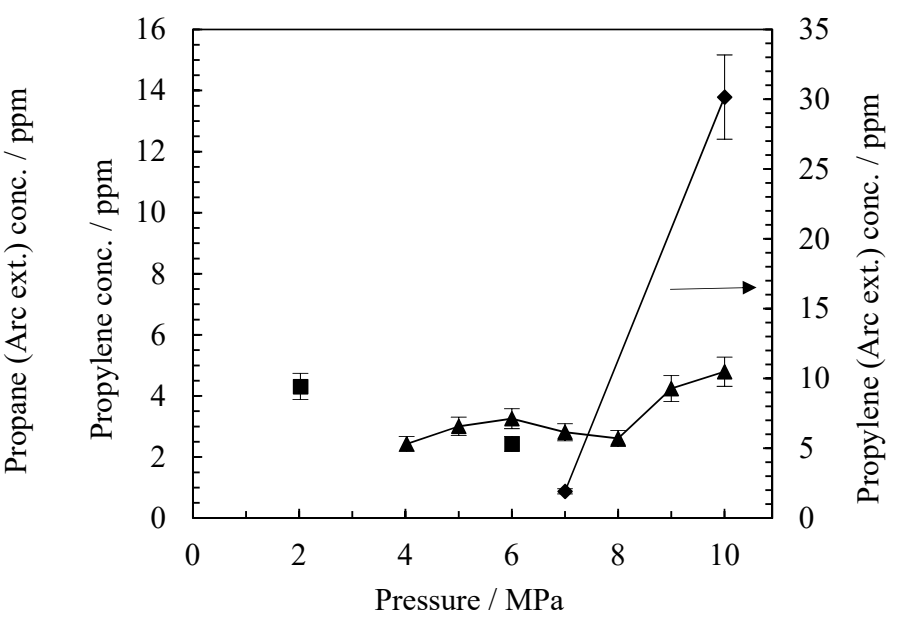

(e)

Figure 2. The influence of pressure on hydrocarbon concentration for plasma-catalytic FTS (NTP +2 or $6 \mathrm{wt} \%$ Co catalyst) at discharge times of 10 and $60 \mathrm{~s}$; (a) methane, (b) ethane, (c) ethylene, (d) propane and (e) propylene. Legend: $\square-6 \mathrm{wt} \%$ Co $(60 \mathrm{~s}) ; \boldsymbol{\Delta}-6 \mathrm{wt} \%$ Co (10 s); $\square-2 \mathrm{wt} \%$ Co $(60 \mathrm{~s}) ; \Delta-2 \mathrm{wt} \%$ Co $(10 \mathrm{~s}) ;-6 \mathrm{wt} \%$ Co (arc extinguished < $60 \mathrm{~s})$. Operating conditions: Syngas $\left(\mathrm{H}_{2} / \mathrm{CO}\right)$ ratio: 2.2:1; current: $350 \mathrm{~mA}$; inter-electrode gap: $1 \mathrm{~mm}$; wall temperature: $25^{\circ} \mathrm{C}$. Error bars (vertical): Expanded experimental hydrocarbon concentration uncertainty of $\pm 11 \%$. 
Although these were the maximum yields obtained for all systems investigated in this study, extinguishing of the arc discouraged experimentation at $10 \mathrm{MPa}$. During arc termination, the arc unhinged from its anodic root and jumped to the ceramic insulator (that securely held the cathode). Arc jumping 'burnt' the insulation material, as shown in Scheme 1, which could not be used again as it prevented ignition of the arc in subsequent experimentation: the arc continued to jump to the cathode insulator, instead of the anode, and was immediately extinguished. Consequently, a replacement insulator was required.

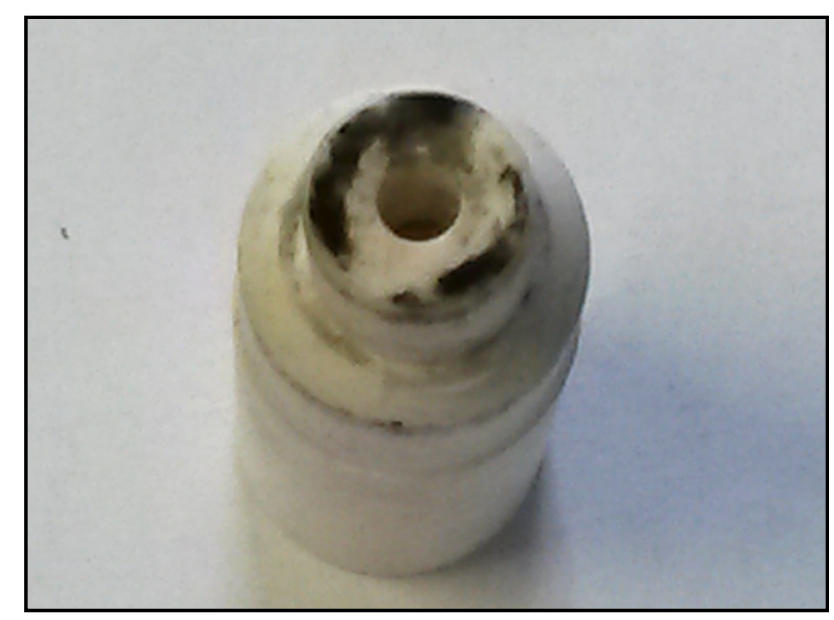

Scheme 1. Image depicting the cathode ceramic insulator (supplied by Ceradvance Engineering Ceramics), which was 'burnt' during the $6 \mathrm{wt} \%$ Co catalytic experiments at $60 \mathrm{~s}$ and between 7-10 MPa.

Due to these experimental constraints and to prevent instrumentation damage, the pressure range was restricted to $1-6 \mathrm{MPa}$ at $60 \mathrm{~s}$ for the $6 \mathrm{wt} \%$ Co catalyst. At $10 \mathrm{~s}$, however, the arc was stable from 0.5 to $10 \mathrm{MPa}$ due to lower water concentrations as a result of the shorter discharge time.

The $6 \mathrm{wt} \%$ Co catalyst produced higher hydrocarbon concentrations than the $2 \mathrm{wt} \%$ Co catalyst at both 10 and $60 \mathrm{~s}$, as shown in the concentration-pressure plots in Figure 2a-e. At $2 \mathrm{MPa}$ and $60 \mathrm{~s}$, both the 2 and $6 \mathrm{wt} \%$ Co catalysts shared a similar trend, in that a sharp increase occurred for all hydrocarbon yields.

In contrast to the other systems, where $60 \mathrm{~s}$ led to higher yields than $10 \mathrm{~s}$ throughout the pressure range, the $6 \mathrm{wt} \%$ Co catalyst displayed a reverse trend at 0.5, 1, 3 and $4 \mathrm{MPa}$. At these pressures, the $C_{1}$ to $C_{3}$ hydrocarbon yields at $60 \mathrm{~s}$ were significantly lower than that at $10 \mathrm{~s}$, implying that within the additional $50 \mathrm{~s}$, secondary reactions, namely cracking or hydrogenolysis could have occurred, thus decreasing the methane, ethane, ethylene and propane concentrations.

Apart from secondary reactions, which seem more influential for the $10 \mathrm{~s}$ study (discussed in detail later in this section), higher water yields (higher CO conversion) at the longer residence time of $60 \mathrm{~s}$ (and at 3 and $4 \mathrm{MPa}$ ) could have reduced methane production. The rationale behind this trend in conventional FTS is that water is competitive with methane for hydrogen, particularly with increasing CO conversion (longer residence time) [30-34].

For the $10 \mathrm{~s}$ study, where the arc was stable up to $10 \mathrm{MPa}$, the methane, propane and propylene yields typically increased with increasing pressure, specifically between 8 and $10 \mathrm{MPa}$. However, the ethane concentration decreased from $57 \mathrm{ppm}$ at $1 \mathrm{MPa}$ to $26 \mathrm{ppm}$ at $4 \mathrm{MPa}$, and increased to $57 \mathrm{ppm}$ at $10 \mathrm{MPa}$. Similarly, the ethylene concentration sharply decreased from $39 \mathrm{ppm}$ at $1 \mathrm{MPa}$ to $6 \mathrm{ppm}$ at $4 \mathrm{MPa}$, and decreased slightly up to $10 \mathrm{MPa}$. This $6 \mathrm{wt} \%$ Co catalyst's ethylene trend differed from the other systems at $10 \mathrm{~s}$, where the ethylene yield generally increased at higher pressures.

The decreasing trend of the ethylene (olefin) yields at $10 \mathrm{~s}$, and the $\mathrm{C} 1$ to $\mathrm{C} 3 \mathrm{hy}$ drocarbon yields at $0.5,1,3$ and $4 \mathrm{MPa}$, at $60 \mathrm{~s}$, may all be explained by the literature. 
In conventional FTS, using cobalt catalysts, the primary olefin yields decreased due to readsorption onto the catalyst surface. The readsorbed olefins, depending on the operating conditions (temperature, pressure and residence time), were then subject to secondary reactions: hydrogenation to paraffins, reinsertion into growing chains, hydrogenolysis, cracking and isomerization $[28,35]$. Hydrogenation to paraffins (causing chain termination) was shown to be dominant at $0.1 \mathrm{MPa}$ (atmospheric pressure), whereas reinsertion into growing chains was dominant at 1 and $2 \mathrm{MPa}$ (a typical FTS operating pressure) [36-39].

In this study, there may have been the secondary reinsertion of ethylene into $C_{3}$ hydrocarbon chains, especially for the $10 \mathrm{~s}$ study, which could be indicated by the decrease in ethylene yields and increase in propane and propylene yields with increasing pressure. This could have led to the maximum ethylene yields being obtained at lower pressures of $1 \mathrm{MPa}$ at $10 \mathrm{~s}$, and $2 \mathrm{MPa}$ at $60 \mathrm{~s}$.

Furthermore, high methane yields between 8 and $10 \mathrm{MPa}$, could have arisen from the hydrogenolysis of readsorbed ethylene (and other olefins)-a dominant secondary reaction above $550 \mathrm{~K}\left(277^{\circ} \mathrm{C}\right)$ in conventional FTS, which leads to a significant increase in methane selectivity with increasing CO conversion (longer residence time) [40,41]. This reaction temperature was attainable at between 8 and $10 \mathrm{MPa}$ due to greater plasma heating. On the contrary, the reaction temperature could have been considerably lowered by the active plasma species (pre-dissociated $\mathrm{H}_{2}$ and $\mathrm{CO}$ reactants) [42-55].

Amongst the olefins, ethylene, in particular, was highly susceptible to readsorption and secondary reactions due to its high surface mobility and low activation energy barrier [28]. Besides these secondary reactions, Bodke et al. [56] suggested that the micro-pores on washcoated catalysts could trap and decompose ethylene to form graphite, which was likely to occur in this study as graphite and carbon nanotubes (grown from graphite precursors) were observed on the catalyst surface using diagnostic tools (discussed in Sections 2.4.3 and 2.4.4).

So far, it has been shown that ethane, ethylene and propane were produced at all pressures for both discharge periods. However, propylene was only produced between 4 and $10 \mathrm{MPa}$ at $10 \mathrm{~s}$ (Figure 2e), indicating that chain growth was directly influenced by pressure. In addition, propylene was only produced for the $60 \mathrm{~s}$ study (Figure 2e) at 2 and $6 \mathrm{MPa}$ (maximum pressure for a stable arc), which was in agreement with the high ethane, ethylene and propane yields at these two pressures. At $60 \mathrm{~s}$, the absence of propylene at 4 and $5 \mathrm{MPa}$ and its low yield at $6 \mathrm{MPa}$ compared to the $10 \mathrm{~s}$ study, infers that propylene cracking occurred during the additional $50 \mathrm{~s}$. Similarly, in conventional FTS, longer residence times decreased olefinicity (olefin to paraffin ratio) as a result of olefin readsorption and reinsertion into growing chains [57]. Alternatively, readsorbed propylene may have been hydrogenated to paraffins, especially propane, which marginally increased by $\sim 1 \mathrm{ppm}$ from 4 to $6 \mathrm{MPa}$ (Figure 2d). Furthermore, propylene, synthesized by the $6 \mathrm{wt} \%$ Co catalyst and not by the $2 \mathrm{wt} \%$ Co catalyst, suggests that the higher cobalt loading favored chain growth as in conventional FTS [58].

In addition, carbon deposition occurred for both plasma-catalytic systems. Carbon deposits were seen at the apex of the cathode tip for the $6 \mathrm{wt} \%$ Co catalyst compared to carbon coating the entire cathode tip for the $2 \mathrm{wt} \%$ Co catalyst (as shown in Scheme 2). These observations reiterate that the $6 \mathrm{wt} \%$ Co catalyst was more selectively focused on synthesizing chain growth monomers $(\mathrm{CHx})$, whereas the $2 \mathrm{wt} \%$ Co catalyst formed more C-C chains.

\subsubsection{The Influence of Pressure on Energy Consumption}

In addition to product yields, energy was an important factor for comparing the plasma-catalytic FTS performance. The energy consumption indicators, specific input energy (SIE) and specific required energy (SRE), were determined from the input voltage and current, as described in Section 3.1.3.

The current was fixed at $350 \mathrm{~mA}$ for the pressure study, while the voltage required for arc ignition (set at an ignition voltage of $8 \mathrm{kV}$ ), was self-adjusted by the power supply. The 
average (self-adjusted) voltage, determined using Equation (5) in Section 3.1.3, is presented as a function of pressure in Figure $3 a-b$.

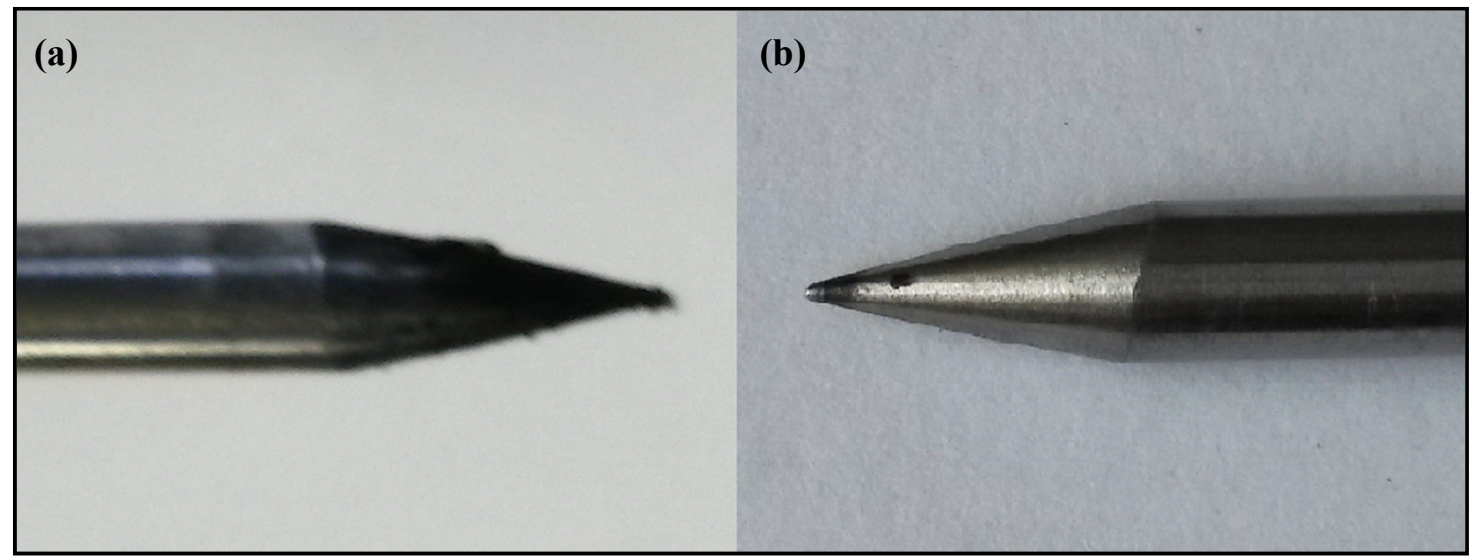

Scheme 2. Carbon deposits observed on the cathode's $60^{\circ}$ conical tip for the (a) $2 \mathrm{wt} \%$ and (b) $6 \mathrm{wt} \%$ Co catalytic systems.

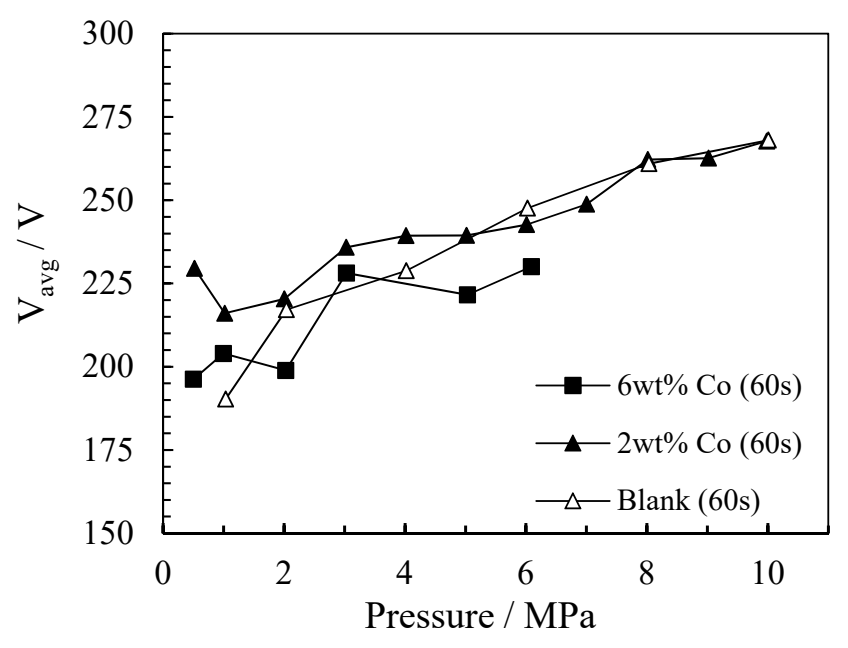

(a)

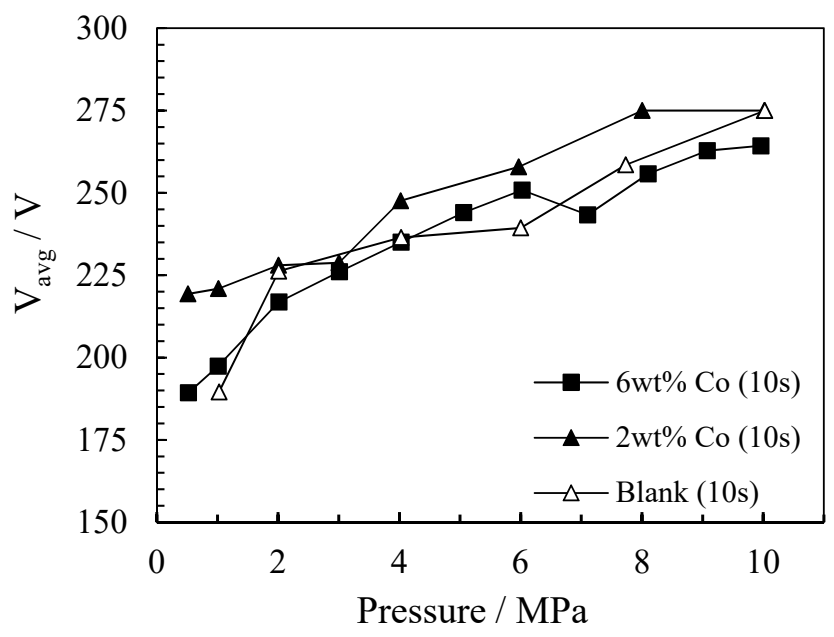

(b)

Figure 3. The influence of pressure on average voltage for plasma-catalytic FTS (NTP + Blank, 2 or $6 \mathrm{wt} \%$ Co catalyst) at discharge times of (a) $60 \mathrm{~s}$ and (b) $10 \mathrm{~s}$. Legend: $-6 \mathrm{wt} \% \mathrm{Co} ; \boldsymbol{\Delta}-2 \mathrm{wt} \% \mathrm{Co} ; \Delta-$ Blank. Operating conditions: Syngas $\left(\mathrm{H}_{2} / \mathrm{CO}\right)$ ratio: 2.2:1; current: $350 \mathrm{~mA}$; inter-electrode gap: $1 \mathrm{~mm}$; wall temperature: $25^{\circ} \mathrm{C}$. Error bars (vertical): Expanded experimental hydrocarbon concentration uncertainty of $\pm 11 \%$.

The voltage-pressure plots show an increasing for all systems investigated, characteristic of the voltage behaviour using a similar arc discharge reactor [1,3]. At higher pressures (generating a hotter arc), greater convective heat losses were encountered, which required higher voltages for maintaining the higher arc temperature, and thus sustaining the arc. The blank, 2 and $6 \mathrm{wt} \%$ Co catalytic systems required relatively similar supply voltages (power) throughout the pressure range. These trends reveal the positive influence of depositing cobalt on the mullite substrate and the contribution of a higher cobalt loading, as the $6 \mathrm{wt} \%$ Co catalyst produced greater hydrocarbon yields than the $2 \mathrm{wt} \%$ Co and blank catalysts despite using similar supply voltages.

The input voltage (power) caused the bulk gas temperature to fluctuate during the treatment period. The change in the bulk gas temperature $(\Delta \mathrm{T})$, shown in Figure 4 , is the difference between the maximum and initial temperatures recorded during the $60 \mathrm{~s}$ treatment period. 


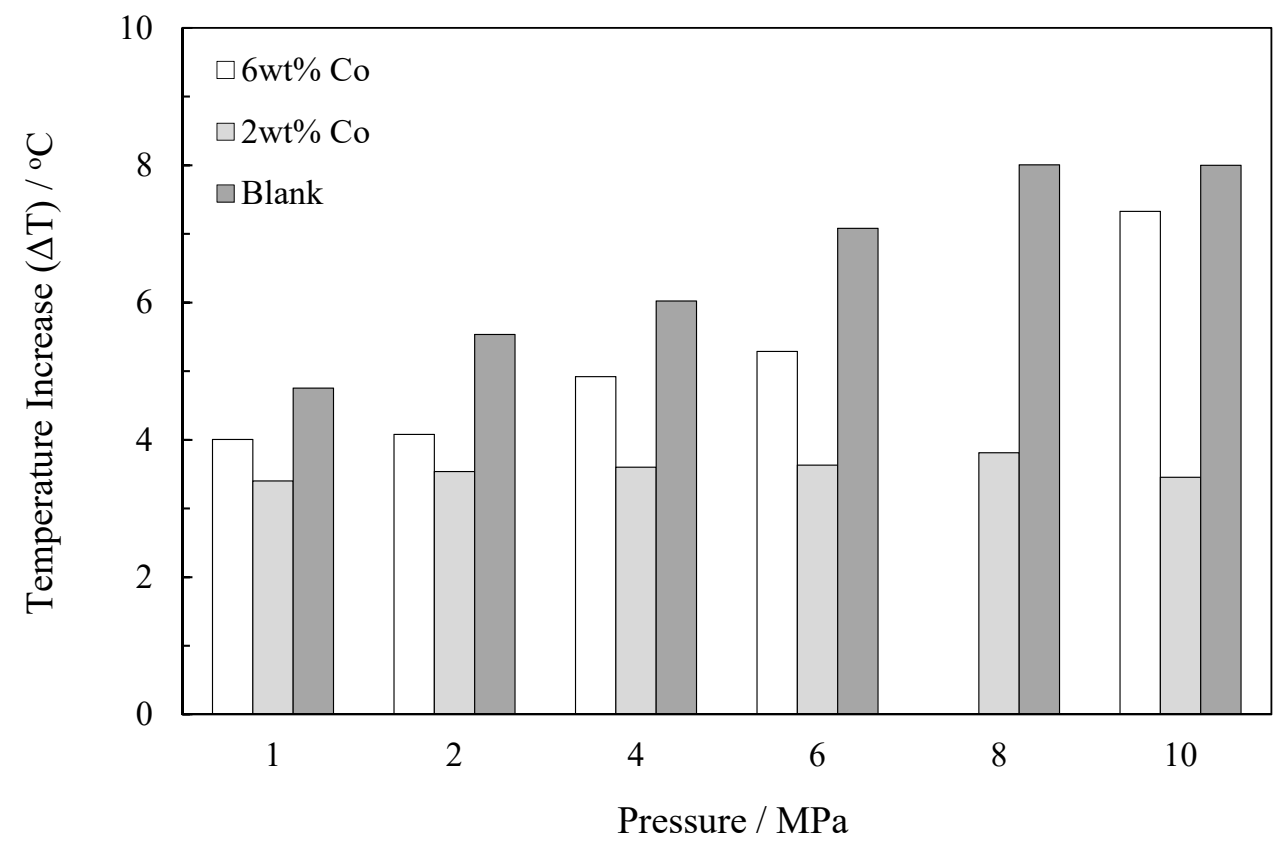

Figure 4. The temperature increase $(\Delta \mathrm{T})$ as a function of operating pressure for plasma-catalytic FTS (NTP + Blank, 2 or $6 \mathrm{wt} \%$ Co catalyst) at a discharge time of $60 \mathrm{~s}$ (N.B. the discharge time for the $6 \mathrm{wt} \%$ Co catalyst at $10 \mathrm{MPa}$ was $\sim 12 \mathrm{~s})$. Legend: $\square-6 \mathrm{wt} \% \mathrm{Co} ; \boldsymbol{\square}-2 \mathrm{wt} \% \mathrm{Co} ; \boldsymbol{\square}-\mathrm{Blank}$. Operating conditions: Syngas (H2/CO) ratio: 2.2:1; current: $350 \mathrm{~mA}$; inter-electrode gap: $1 \mathrm{~mm}$; wall temperature: $25^{\circ} \mathrm{C}$.

For instance, at $6 \mathrm{MPa}$, the blank, 6 and $2 \mathrm{wt} \%$ Co catalytic systems' $\Delta \mathrm{T}$ values were 7.1, 5.3 and $3.6^{\circ} \mathrm{C}$ respectively. These $\Delta$ T-pressure trends show that the catalyst heating (assuming that the catalyst surface temperature is a direct function of the bulk gas temperature), decreased in the order: Blank $>6 \mathrm{wt} \% \mathrm{Co}>2 \mathrm{wt} \% \mathrm{Co}$. The $6 \mathrm{wt} \% \mathrm{Co}$ catalyst was heated to a greater extent than the $2 \mathrm{wt} \%$ Co catalyst, inferring greater thermal activation. This higher catalyst temperature in conjunction with the larger catalytic cobalt sites (a result of higher cobalt loading), probably led to the highest hydrocarbon yields being produced by the $6 \mathrm{wt} \%$ Co catalyst (as shown in Figure 2).

The blank catalyst, in contrast, encountered a higher degree of heating than the 2 and $6 \mathrm{wt} \%$ Co catalysts, but produced the lowest hydrocarbon yields. As discussed in Section Blank Catalyst, lower yields for the blank catalyst were due to the absence of cobalt, the active catalytic component for synthesis, and the presence of $\gamma-\mathrm{Al}_{2} \mathrm{O}_{3}$ and mullite, which may have induced alternate reaction pathways including the stimulation of $\mathrm{CO}$ chemisorption and carbonaceous species.

Specific Input Energy (SIE)

The SIE (kJ/molsyngas)-pressure plots for pure plasma and plasma-catalysis are shown in Figure 5. Higher SIE values and lower hydrocarbon product yields at lower pressures suggest that more energy was spent on bulk gas heating instead of hydrocarbon synthesis. In contrast, at higher pressures, reverse trends are observed-lower SIE values and higher yields, suggesting that energy was more selectively focused on hydrocarbon synthesis.

\section{Specific Required Energy (SRE)}

The general trend of the SRE (MJ/molmethane, prod)-pressure plots, shown in Figure 6, shows that the energy required to produce a mole of methane decreased with increasing pressure for both the 10 and $60 \mathrm{~s}$ studies. This SRE trend and the plateauing voltage-pressure plots between 8 and $10 \mathrm{MPa}$ (Figure 1) suggest that higher pressures led to higher energy efficiency. 


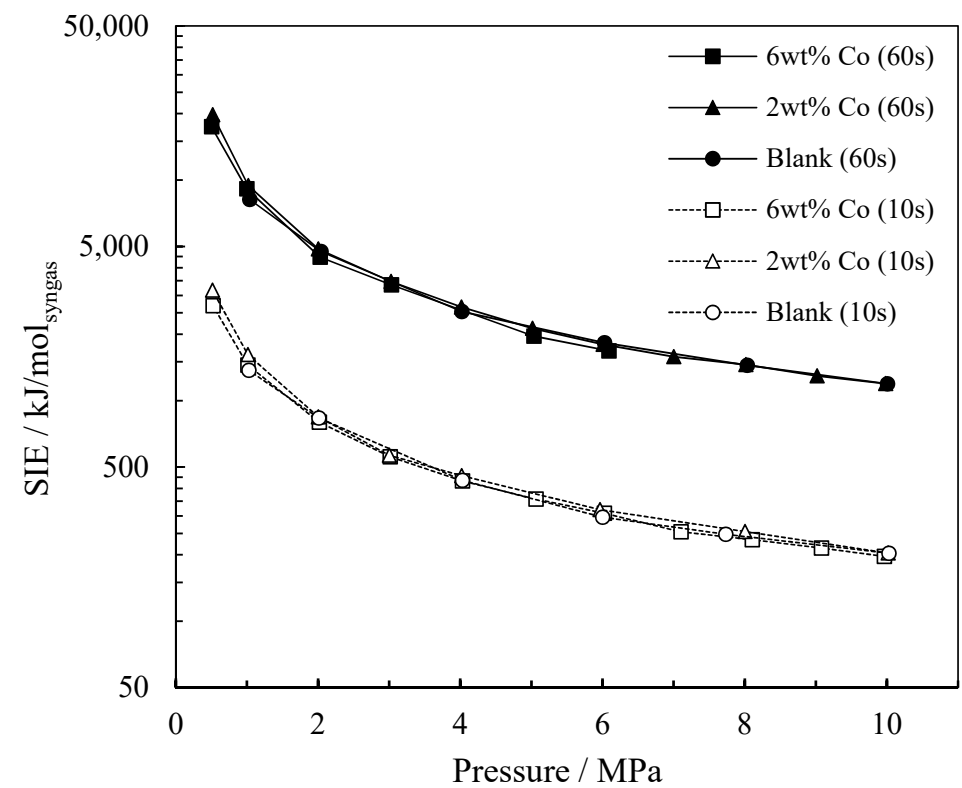

Figure 5. Specific input energy (kJ/molsyngas) as a function of pressure for plasma-catalytic FTS (NTP + Blank, 2 or $6 \mathrm{wt} \%$ Co catalyst) at discharge times of 10 and $60 \mathrm{~s}$. Legend: $\square-6 \mathrm{wt} \%$ Co (60 s); $\mathbf{\Delta}-2 \mathrm{wt} \%$ Co (60 s); •-Blank (60 s); $\square-6 \mathrm{wt} \%$ Co (10 s); $\Delta-2 \mathrm{wt} \%$ Co (10 s); $\bigcirc-B l a n k ~(10 \mathrm{~s})$. Operating conditions: Syngas $(\mathrm{H} 2 / \mathrm{CO})$ ratio: 2.2:1; current: $350 \mathrm{~mA}$; inter-electrode gap: $1 \mathrm{~mm}$; wall temperature: $25^{\circ} \mathrm{C}$.

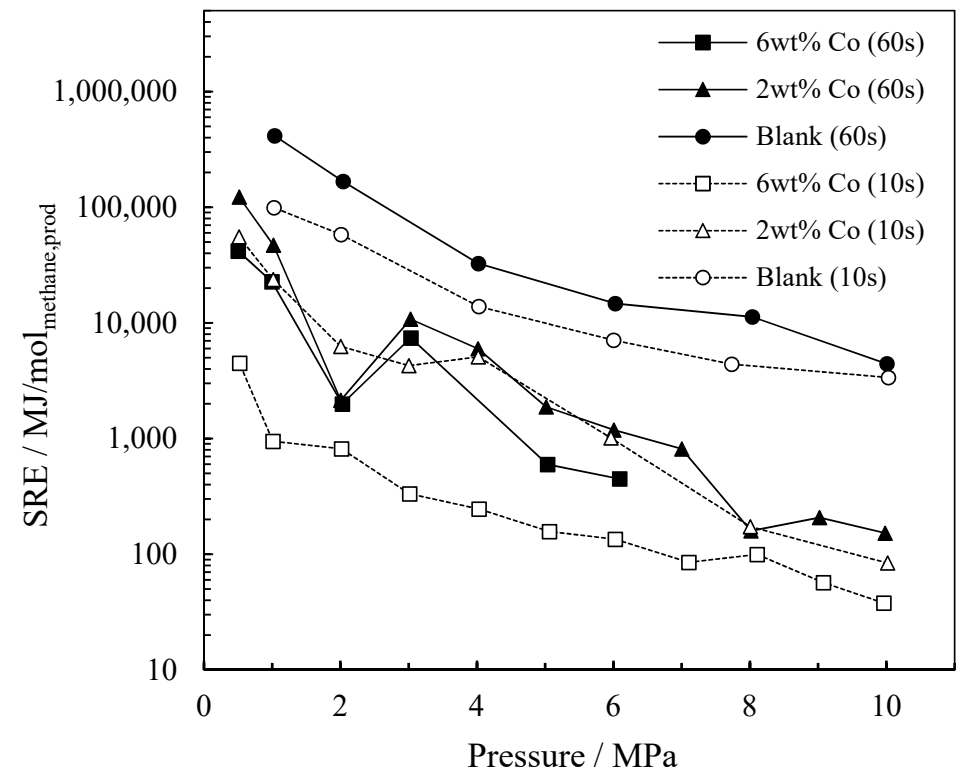

Figure 6. Specific required energy (MJ/molmethane, prod) as a function of pressure for plasmacatalytic FTS (NTP + Blank, 2 or $6 \mathrm{wt} \%$ Co catalyst) at discharge time of 10 and $60 \mathrm{~s}$. Legend: - $-6 \mathrm{wt} \%$ Co (60 s); $\mathbf{\Delta}-2 \mathrm{wt} \%$ Co (60 s); •-Blank (60 s); $\square-6 \mathrm{wt} \%$ Co (10 s); $\Delta-2 \mathrm{wt} \%$ Co (10 s); $\bigcirc$-Blank (10 s). Operating conditions: Syngas ( $\left.\mathrm{H}_{2} / \mathrm{CO}\right)$ ratio: 2.2:1; current: $350 \mathrm{~mA}$; inter-electrode gap: $1 \mathrm{~mm}$; wall temperature: $25^{\circ} \mathrm{C}$.

\subsubsection{Optimum Conditions}

In Section 2.1.1, the effects of pressure on hydrocarbon yields for the blank, $2 \mathrm{wt} \%$, and $6 \mathrm{wt} \%$ Co catalysts were discussed with a focus on the reaction pathways and discharge phenomena. This section provides a quantitative comparison of product yields and specific required energy (SRE) for the blank, 2 and $6 \mathrm{wt} \%$ Co catalysts at 10 and $60 \mathrm{~s}$, as shown in Table 2. 
Table 2. Hydrocarbon concentrations and specific required energy (SRE) values for the blank, 2 and $6 \mathrm{wt} \%$ Co catalyst systems investigated for the pressure variation study at discharge times of 10 and $60 \mathrm{~s}$. (Syngas $\left(\mathrm{H}_{2} / \mathrm{CO}\right)$ ratio: 2.2:1; current: $350 \mathrm{~mA}$; inter-electrode gap: $1 \mathrm{~mm}$; wall temperature: $25^{\circ} \mathrm{C}$; expanded experimental hydrocarbon concentration uncertainty: $\pm 11 \%)$.

\begin{tabular}{|c|c|c|c|c|c|c|c|c|c|c|c|c|}
\hline \multirow{3}{*}{ Product } & \multicolumn{6}{|c|}{ Conc. (ppm) at $10 \mathrm{~s}$} & \multicolumn{6}{|c|}{ Conc. $(\mathrm{ppm})$ at $60 \mathrm{~s}$} \\
\hline & \multicolumn{2}{|c|}{ Blank } & \multicolumn{2}{|c|}{$2 w t \%$ Co } & \multicolumn{2}{|c|}{$6 \mathrm{wt} \% \mathrm{Co}$} & \multicolumn{2}{|c|}{ Blank } & \multicolumn{2}{|c|}{$2 w t \%$ Co } & \multicolumn{2}{|c|}{$6 \mathrm{wt} \% \mathrm{Co}$} \\
\hline & $1 \mathrm{MPa}$ & $10 \mathrm{MPa}$ & $1 \mathrm{MPa}$ & $10 \mathrm{MPa}$ & $1 \mathrm{MPa}$ & $10 \mathrm{MPa}$ & $2 \mathrm{MPa}$ & $10 \mathrm{MPa}$ & $2 \mathrm{MPa}$ & $10 \mathrm{MPa}$ & $2 \mathrm{MPa}$ & $6 \mathrm{MPa}$ \\
\hline Methane & 14 & \multicolumn{11}{|c|}{$\mathrm{C}_{2}$ hydrocarbons } \\
\hline Ethane & 0.4 & 0.2 & 2,8 & 19 & 57 & 57 & 0.8 & 0.8 & 95 & 64 & 135 & 42 \\
\hline Ethylene & 0.05 & \multicolumn{11}{|c|}{$C_{3}$ hydrocarbons } \\
\hline Propane & 0.0 & 0.0 & 0.1 & 4.5 & 1.3 & 11.7 & 0.0 & 0.1 & 1.2 & 6.6 & 2.5 & 3.3 \\
\hline Propylene & 0.0 & \multicolumn{10}{|c|}{ Product ratio } & 2.4 \\
\hline $\begin{array}{l}\text { Methane/ } \\
\text { ethane }\end{array}$ & 32 & 308 & 24 & 125 & 27 & 92 & 39 & 317 & 24 & 123 & 16 & 89 \\
\hline $\begin{array}{l}\text { Ethane/ } \\
\text { ethylene }\end{array}$ & 8.7 & 2.4 & 4.0 & 12.2 & 1.5 & 11.5 & 11.1 & 10.9 & 1.8 & 6.6 & 2.5 & 4.7 \\
\hline & \multicolumn{12}{|c|}{ Specific required energy $\left(\mathrm{MJ} / \mathrm{mol}_{\mathrm{CH} 4, \text { produced }}\right)$} \\
\hline & 99,179 & 3375 & 23,666 & 84 & 950 & 38 & 167,334 & 4432 & 2148 & 152 & 1991 & 448 \\
\hline
\end{tabular}

Highlighted values mark the key findings.

At $2 \mathrm{MPa}$ and $60 \mathrm{~s}$, the $6 \mathrm{wt} \%$ Co catalyst's methane, ethane, ethylene and propane concentrations of 2194, 135, 54 and $2.5 \mathrm{ppm}$, respectively, were similar to the yields of 2266 , $95,52,1.2 \mathrm{ppm}$ for the $2 \mathrm{wt} \%$ Co catalyst, with a distinct increase of 1.4 and 2 for ethane and propane. Moreover, these $6 \mathrm{wt} \%$ Co catalyst's methane, ethane, ethylene and propane yields were 77,170 and 755 (no $C_{3}$ hydrocarbons produced) times higher, respectively, than that of pure plasma.

For the $10 \mathrm{~s}$ study, the $6 \mathrm{wt} \%$ Co catalyst was considered the optimal system in regard to chain growth and product yields, as it produced the highest $C_{3}$ hydrocarbons at $10 \mathrm{MPa}$. At $10 \mathrm{MPa}$ and $10 \mathrm{~s}$, the $6 \mathrm{wt} \%$ Co catalyst's methane, ethane, ethylene and propane concentrations of 5200, 57, 5 and $\sim 12 \mathrm{ppm}$, respectively, were 2, 3, 3 and 2 times higher than that of the $2 \mathrm{wt} \%$ Co catalyst and 86, 289 and 60 (no $C_{3}$ hydrocarbons produced) times higher, respectively, than that the blank catalyst.

Another indicator of chain growth is the methane/ethane ratio listed in Table 2. This ratio of the two main products reveals the pressure at which there was a minimum methane yield-the least desired product in conventional FTS. The methane/ethane ratio at $1 \mathrm{MPa}$ and $10 \mathrm{~s}$ for the blank catalyst, 2 and $6 \mathrm{wt} \%$ Co catalyst systems of 32, 24 and 27, respectively, were 10, 5 and 3 times lower than that at $10 \mathrm{MPa}$. The higher methane/ethane ratios at $10 \mathrm{MPa}$ were probably caused by higher arc temperatures (increasing with pressure) promoting methanation. Furthermore, the lowest ratios were achieved by the 2 and $6 \mathrm{wt} \%$ Co catalysts, suggesting the promotion of chain growth.

Furthermore, at $10 \mathrm{~s}$ study and $10 \mathrm{MPa}$, the minimum SIE and SRE values and the maximum $\mathrm{C}_{1}-\mathrm{C}_{3}$ hydrocarbon yields coincide for all systems, which is therefore considered as the optimum operating pressure. At $10 \mathrm{MPa}$ and $10 \mathrm{~s}$, the $6 \mathrm{wt} \%$ Co catalyst was the most energy efficient system as evaluated from its SRE value of $38 \mathrm{MJ} / \mathrm{molCH}$, prod (Table 2), which was $\sim 2.2$ times lower than $2 \mathrm{wt} \%$ Co catalyst $\left(84 \mathrm{MJ} / \mathrm{molCH}_{4}\right.$,prod) and 89 times lower than the blank catalyst $\left(3375 \mathrm{MJ} / \mathrm{molCH}_{4}\right.$,prod).

The longer discharge time of $60 \mathrm{~s}$ generally led to higher $C_{1}-C_{3}$ hydrocarbon concentrations (as seen in Table 2), which agreed with conventional FTS trends [59,60]. At $60 \mathrm{~s}$, the most favourable pressure for chain growth using the $6 \mathrm{wt} \%$ Co catalyst was $2 \mathrm{MPa}$, where the maximum ethane, ethylene and propylene yields were attained.

Similarly, to the $10 \mathrm{~s}$ study, a lower pressure led to a lower methane/ethane ratio for the $60 \mathrm{~s}$ study (as shown in Table 2); in this instance, $2 \mathrm{MPa}$. The methane/ethane ratio at $2 \mathrm{MPa}$ for the blank catalyst, 2 and $6 \mathrm{wt} \%$ Co catalysts systems of 39, 24 and 16, respectively, were 8,5 and 5.6 times lower than the ratios at $10 \mathrm{MPa}$. The ethane/ethylene 
ratio (representing the olefin/paraffin ratio commonly used as a performance indicator in conventional FTS), was also relatively low at $2 \mathrm{MPa}$ for the 2 and $6 \mathrm{wt} \%$ Co catalysts. This latter ratio indicates that $2 \mathrm{MPa}$ promoted olefin formation-desired in conventional FTS. Chain growth was also improved by the higher cobalt loading of $6 \mathrm{wt} \%$, which produced the maximum $\mathrm{C}_{3}$ hydrocarbons at $2 \mathrm{MPa}$.

These maximum $\mathrm{C}_{2}$ and $\mathrm{C}_{3}$ yields produced at $60 \mathrm{~s}$ and $2 \mathrm{MPa}$ by the $6 \mathrm{wt} \% \mathrm{Co}$ catalyst corresponded to a SRE value of $1991 \mathrm{MJ} / \mathrm{molCH} 4$,prod, which was 84 times lower than the blank catalyst's SRE value of $167334 \mathrm{MJ} / \mathrm{molCH} 4$,prod. However, the minimum SRE value for the $6 \mathrm{wt} \%$ Co catalyst was obtained at $6 \mathrm{MPa}$ (448 MJ/molmethane, prod). Since the main objective at this exploratory phase of FTS research is to improve product yields and chain growth, a trade-off between these factors and energy consumption favors $2 \mathrm{MPa}$ as the optimum pressure for the $60 \mathrm{~s}$ study.

\subsection{Current Variation Study}

\subsubsection{The Influence of Current on FTS Products Yields}

For the current variation study, the current was varied between 250 and $450 \mathrm{~mA}$ while fixing the other operating parameters: discharge time of $60 \mathrm{~s}$, inter-electrode gap of $1 \mathrm{~mm}$ and pressure of $2 \mathrm{MPa}$. The pressure was fixed at $2 \mathrm{MPa}$ as this lower pressure generated a stable arc discharge at lower currents $(<350 \mathrm{~mA}) .2 \mathrm{MPa}$ was also considered to be the optimum pressure for the pressure variation study: producing the maximum $C_{2}-C_{3}$ hydrocarbon yields and the lowest methane/ethane and ethane/ethylene ratios.

The blank catalyst's $C_{1}-C_{3}$ yields slightly decreased between 250 and $350 \mathrm{~mA}$ and remained relatively constant between 350 and $450 \mathrm{~mA}$, as shown in Figure 7 . This general trend of decreasing yields with increasing current is indicative of an increase in the thermal nature of the plasma, where electrons are less selectively focused on plasma-chemical reactions and more directed towards bulk gas heating i.e., the bulk gas for the blank catalyst system was heated above the initial room temperature $(\Delta \mathrm{T})$ by $5.21^{\circ} \mathrm{C}$ at $250 \mathrm{~mA}$ and $6.25^{\circ} \mathrm{C}$ at $450 \mathrm{~mA}$.

The $6 \mathrm{wt} \%$ Co catalyst led to dramatic improvements in the $\mathrm{C}_{1}-\mathrm{C}_{3}$ hydrocarbon concentrations (Figure 7). In contrast to the blank and $2 \mathrm{wt} \%$ Co catalysts, which produced an arc discharge between 250 and $450 \mathrm{~mA}$, the $6 \mathrm{wt} \%$ Co catalyst discharge behaviour was more complex: a glow-like discharge or arc-to-glow transition discharge (emitting a dim orange light at the cathode tip) was formed at 250 and $300 \mathrm{~mA}$, whereas an arc discharge (seen as a luminous blue/white arc column) was formed at 350, 400 and $450 \mathrm{~mA}$.

The glow-to-arc transition (GAT) [61] is a widely studied phenomena for glow discharges, caused by the instability of the glow discharge at near and beyond atmospheric pressure [62]. However, in this work, an inverse transition occurred-an arc-to-glow transition, in which the arc traverses further away from thermal equilibrium towards the more non-equilibrium glow region at lower currents (250 and $300 \mathrm{~mA}$ ). The occurrence of GAT in glow discharges was stated to occur by either increasing the current at a fixed pressure or increasing the pressure at a fixed current [63]. Once again, the inverse of this trend was applicable here, i.e., decreasing the current (from $350 \mathrm{~mA}$, used in the pressure variation study, to 250 and $300 \mathrm{~mA}$, used in the current variations study), at a constant pressure of $2 \mathrm{MPa}$, led to an arc-to-glow transition. Since this transitional phase was not observed for the blank and $2 \mathrm{wt} \%$ Co catalyst systems, it is therefore attributed to plasma-catalytic interactions arising from the higher cobalt loading of $6 \mathrm{wt} \%$, which is most likely to have modified the electrical characteristics of the non-thermal plasma as proposed by van Durme et al. [64] and other authors $[65,66]$. 


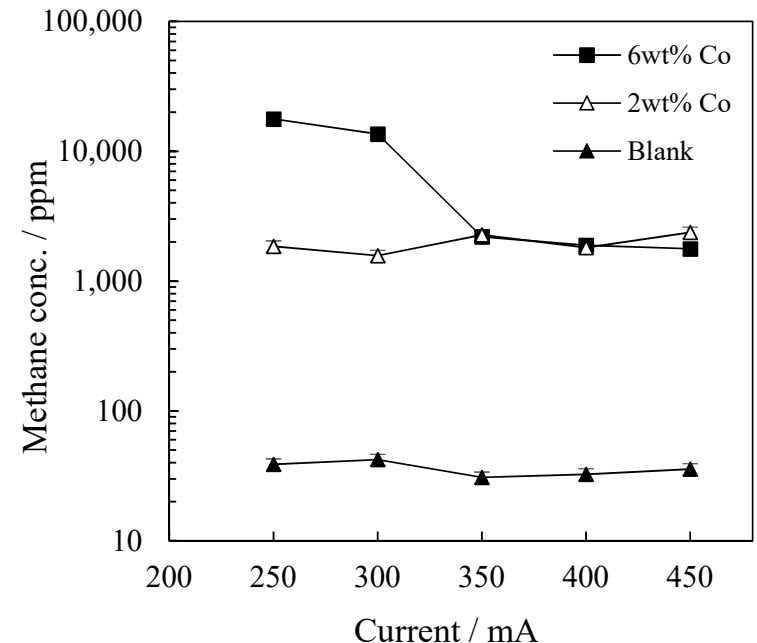

(a)

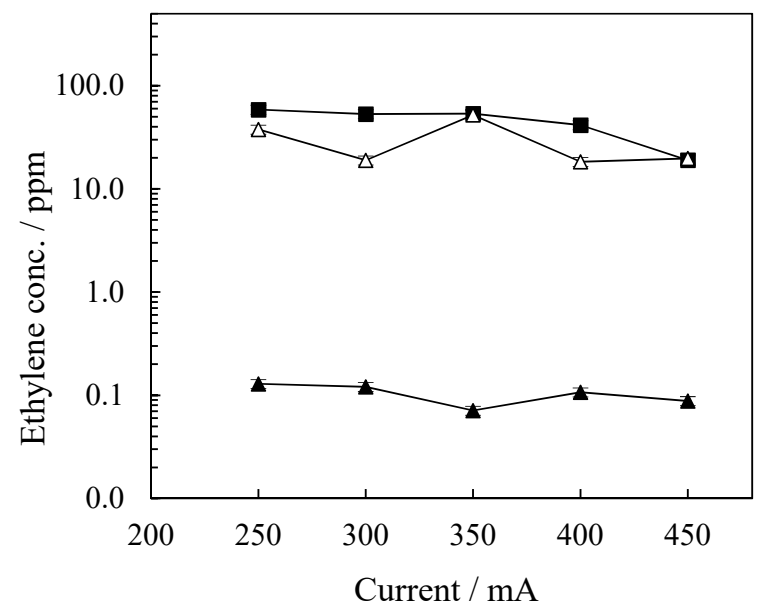

(c)

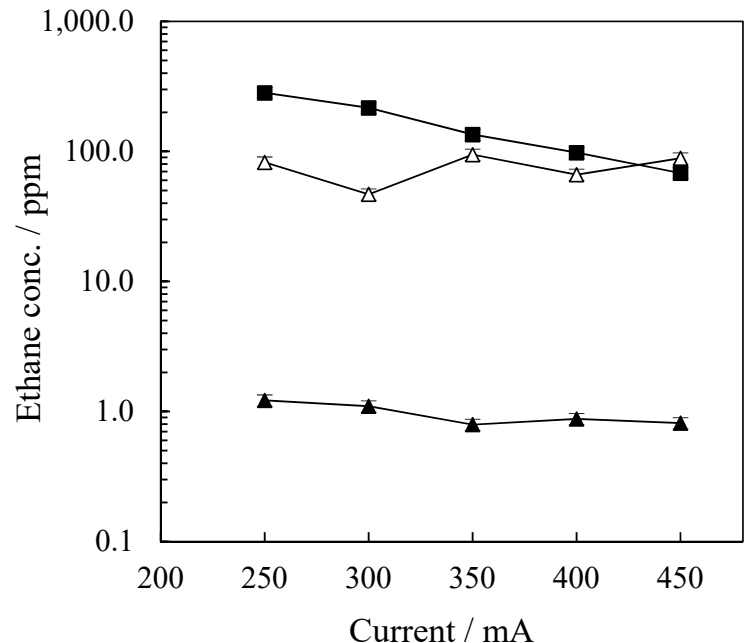

(b)

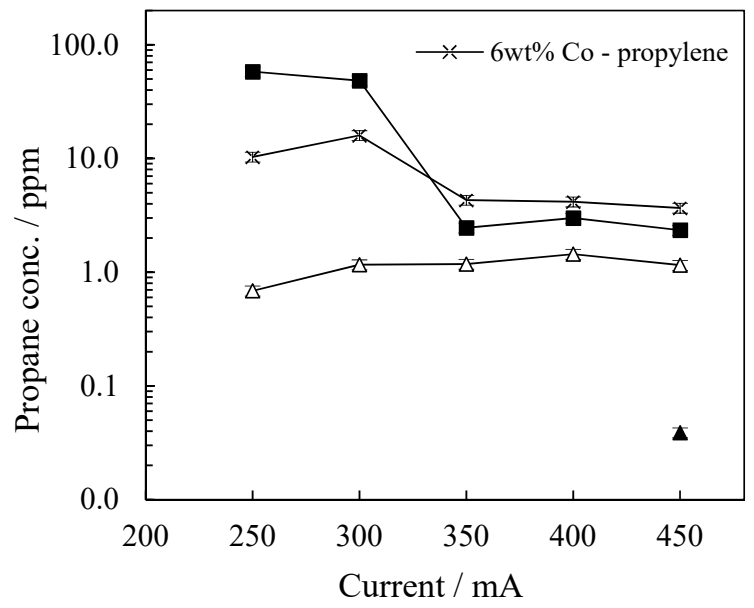

(d)

Figure 7. The influence of current on hydrocarbon concentration for plasma-catalytic FTS (NTP + Blank, 2 or $6 \mathrm{wt} \%$ Co catalyst) at a discharge time of $60 \mathrm{~s}$; (a) methane, (b) ethane, (c) ethylene and (d) propane/propylene. Legend: $\square-6 \mathrm{wt} \%$ Co; $\Delta-2 \mathrm{wt} \% \mathrm{Co} ; \boldsymbol{\Delta}-$ Blank; $\mathrm{X}-6 \mathrm{wt} \% \mathrm{Co}$ (propylene). Operating conditions: Syngas $\left(\mathrm{H}_{2} / \mathrm{CO}\right)$ ratio: $2.2: 1$; pressure: $2 \mathrm{MPa}$; inter-electrode gap: $1 \mathrm{~mm}$; wall temperature: $25^{\circ} \mathrm{C}$. Error bars (vertical): Expanded experimental hydrocarbon concentration uncertainty of $\pm 11 \%$.

In the $6 \mathrm{wt} \%$ Co catalyst study, the maximum methane (17,729 ppm), ethane (282 ppm), ethylene (59 ppm), propane (58 ppm) and propylene (10 ppm) concentrations were attained at the lowest operating pressure of $250 \mathrm{~mA}$ (glow-like or arc-to-glow discharge region). These were approximately 8, 2, 1, 24 and 2.4 times higher, respectively, than the concentrations obtained in the arc discharge region at $350 \mathrm{~mA}$, which was due to the volumetric behaviour (greater treatment volume) of the glow-like discharge. This transitional region also favored $\mathrm{C}_{3}$ hydrocarbon production, especially propane at $250 \mathrm{~mA}$ and propylene at 250 and $300 \mathrm{~mA}$. In addition, propylene was only detected for the $6 \mathrm{wt} \%$ Co catalytic system, again suggesting that the higher Co loading of $6 \mathrm{wt} \%$ promoted chain growth.

The contribution of a higher cobalt loading was also clearly seen in that the maximum methane, ethane, ethylene and propane concentrations, obtained for the $6 \mathrm{wt} \%$ Co catalyst at $250 \mathrm{~mA}$, were 9.6, 3.4, 1.6 and 85 times higher, respectively, than the $2 \mathrm{wt} \%$ Co catalyst's concentrations of 1852, 82, 38 and $0.7 \mathrm{ppm}$ (at $250 \mathrm{~mA}$ ), and 457, 232 and $456\left(\mathrm{C}_{3}\right.$ hydrocarbons not produced) times higher, respectively, than the blank catalyst's concentrations of $39,1.2$ and $0.1 \mathrm{ppm}$ (at $250 \mathrm{~mA}$ ). 


\subsubsection{The Influence of Current on Energy Consumption}

According to the rms voltage-current plots in Figure 8, all systems required higher supply voltages at lower currents for sustaining the arc discharge, with all plasma-catalysis systems requiring similar voltages. These plots conformed to the voltage-current behaviour of typical non-thermal arc discharge generated at high pressure $[1,3,67]$.

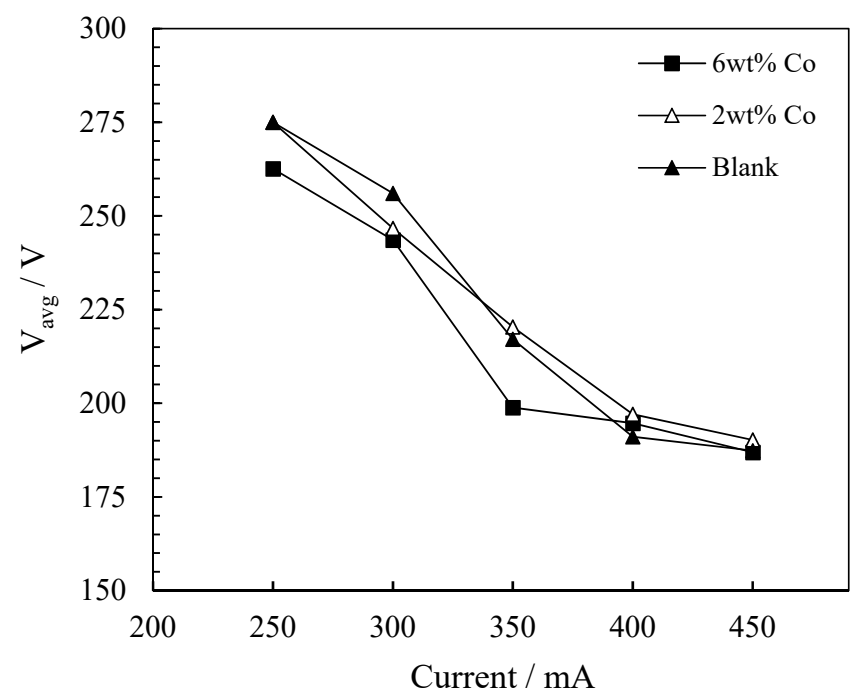

Figure 8. The influence of current on average voltage for plasma-catalytic FTS (NTP + Blank, 2 or $6 \mathrm{wt} \%$ Co catalyst) at a discharge time of $60 \mathrm{~s}$. Legend: $-6 \mathrm{wt} \% \mathrm{Co} ; \Delta-2 \mathrm{wt} \% \mathrm{Co} ; \boldsymbol{\Delta}-\mathrm{Blank}$. Operating conditions: Syngas $\left(\mathrm{H}_{2} / \mathrm{CO}\right)$ ratio: 2.2:1; pressure: $2 \mathrm{MPa}$; inter-electrode gap: $1 \mathrm{~mm}$; wall temperature: $25^{\circ} \mathrm{C}$.

The increase in current with decreasing voltage also increased the electric field energy and specific input energy (SIE) as shown in Figure 9. The more energetic field at higher currents could have produced a more thermal-natured plasma that was less selectively focused on synthesis processes, indicated by lower hydrocarbon yields at higher currents as presented in the concentration-current plots in Figure $7 \mathrm{a}-\mathrm{d}$.

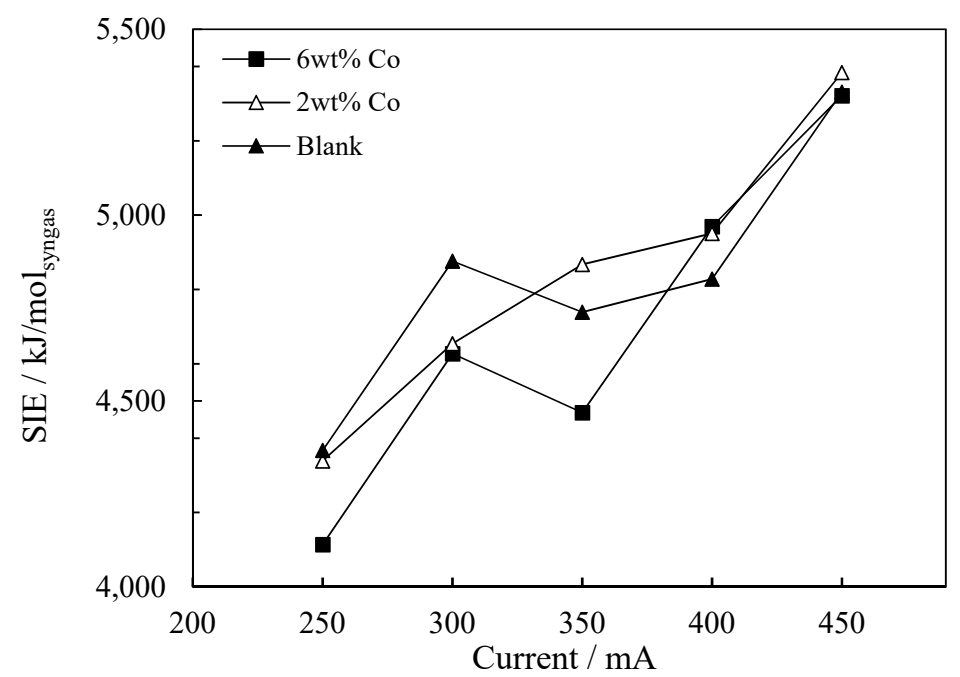

Figure 9. Specific input energy (kJ/molsyngas) as a function of current for plasma-catalytic FTS (NTP + Blank, 2 or $6 \mathrm{wt} \%$ Co catalyst) at a discharge time of $60 \mathrm{~s}$. Legend: $-6 \mathrm{wt} \% \mathrm{Co} ; \Delta-2 \mathrm{wt} \% \mathrm{Co}$; $\Delta-$ Blank. Operating conditions: Syngas $\left(\mathrm{H}_{2} / \mathrm{CO}\right)$ ratio: 2.2:1; pressure: $2 \mathrm{MPa}$; inter-electrode gap: $1 \mathrm{~mm}$; wall temperature: $25^{\circ} \mathrm{C}$. 
The specific required energy (SRE)-current plots, presented in Figure 10, show a significant increase for the $6 \mathrm{wt} \%$ Co catalyst from $232 \mathrm{MJ} /$ molmethane, prod at $250 \mathrm{~mA}$ (glow-like or arc-to-glow discharge) to $3002 \mathrm{MJ} /$ molmethane, prod at $450 \mathrm{~mA}$ (arc discharge). This result reveals the energy intensive behaviour of a discharge traversing from a glow to an arc region i.e., from a less to more thermal state. In this glow-to arc transition region for the $6 \mathrm{wt} \%$ Co catalyst, the SRE values at 250 and $300 \mathrm{~mA}$ were 10 and 8.7 times lower, respectively, than that of the $2 \mathrm{wt} \%$ Co catalyst and 485 and 339 times lower, respectively, than that of the blank catalyst. This was due to the $2 \mathrm{wt} \%$ Co catalyst's discharge remaining as an arc at all currents studied. The transition of the glow-like discharge for the $6 \mathrm{wt} \%$ Co catalytic system to a stable arc between 350 and $450 \mathrm{~mA}$ is also reflected by its SRE values mirroring those of the $2 \mathrm{wt} \%$ Co catalyst at these currents.

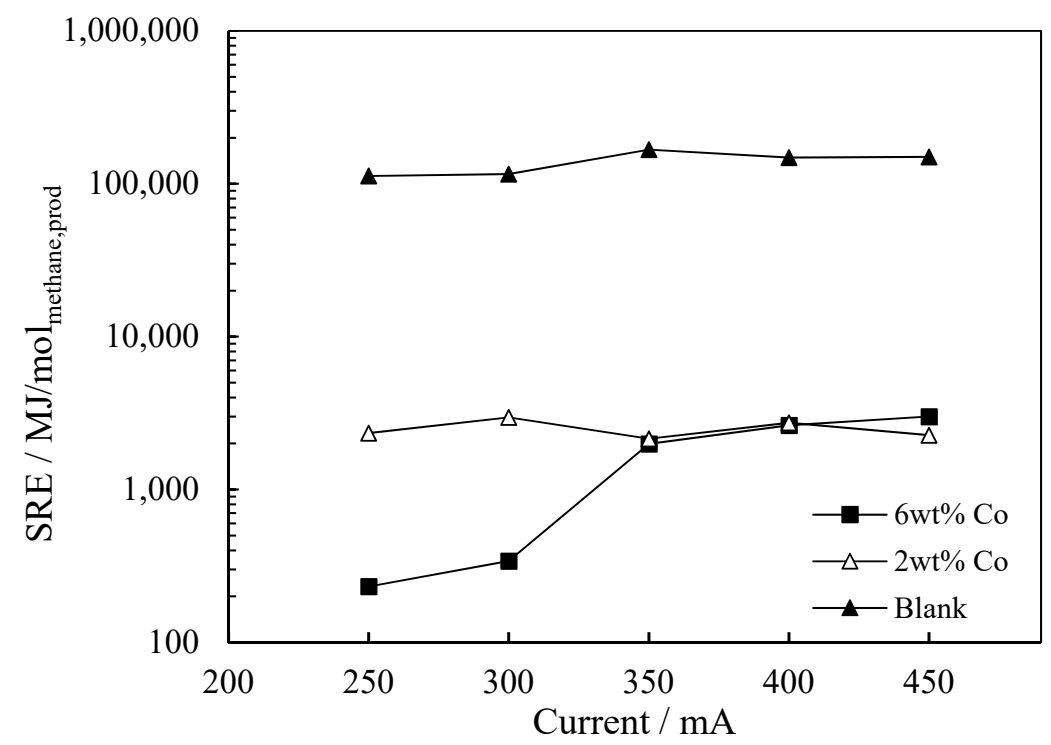

Figure 10. Specific required energy (MJ/molmethane, prod) as a function of current for plasmacatalytic FTS (NTP + Blank, 2 or $6 \mathrm{wt} \%$ Co catalyst) at a discharge time of $60 \mathrm{~s}$. Legend: $\mathbf{\square}-6 \mathrm{wt} \%$ $\mathrm{Co} ; \Delta-2 \mathrm{wt} \% \mathrm{Co} ; \mathbf{\Delta}-$ Blank. Operating conditions: Syngas $\left(\mathrm{H}_{2} / \mathrm{CO}\right)$ ratio: 2.2:1; pressure: $2 \mathrm{MPa}$; inter-electrode gap: $1 \mathrm{~mm}$; wall temperature: $25^{\circ} \mathrm{C}$.

Furthermore, the difference between the arc-to-glow transitional and stable arc states for the $6 \mathrm{wt} \%$ Co catalyst was also observed from the arc's stability, which is described by the voltage error (determined using equations 6 and 7 in Section 3.1.3). The voltage errors for the $6 \mathrm{wt} \%$ Co catalyst were approximately 9 and $6 \%$ at 250 and $300 \mathrm{~mA}$ (arc-to-glow transitional region), respectively, compared to $1.7 \%$ at $350 \mathrm{~mA}$ (stable arc region). The average voltage errors for the blank and $2 \mathrm{wt} \%$ Co catalysts, in contrast, were both $\sim 0$ and $1.9 \%$ at $250 \mathrm{~mA}$ and $300 \mathrm{~mA}$ (stable arc region), respectively. These values were much lower than the $6 \mathrm{wt} \%$ Co catalyst's errors, verifying the instability of the arc-to-glow region, and, in turn, demonstrating the more pronounced influence of the higher cobalt loading of $6 \mathrm{wt} \%$ on the electrical properties of the discharge.

\subsection{Inter-Electrode Gap Variation Study}

2.3.1. The Influence of Inter-Electrode Gap on FTS Products Yields

The final parameter studied, the inter-electrode gap, was varied from 0.5 to $2 \mathrm{~mm}$ at fixed operating conditions: pressure of $2 \mathrm{MPa}$, current of $350 \mathrm{~mA}$, and discharge period of $60 \mathrm{~s}$. These fixed conditions led to a stable arc discharge and were also the optimum conditions in the pressure variation study. The hydrocarbon yields generally increased with increasing inter-electrode gap as shown in Figure 11. 


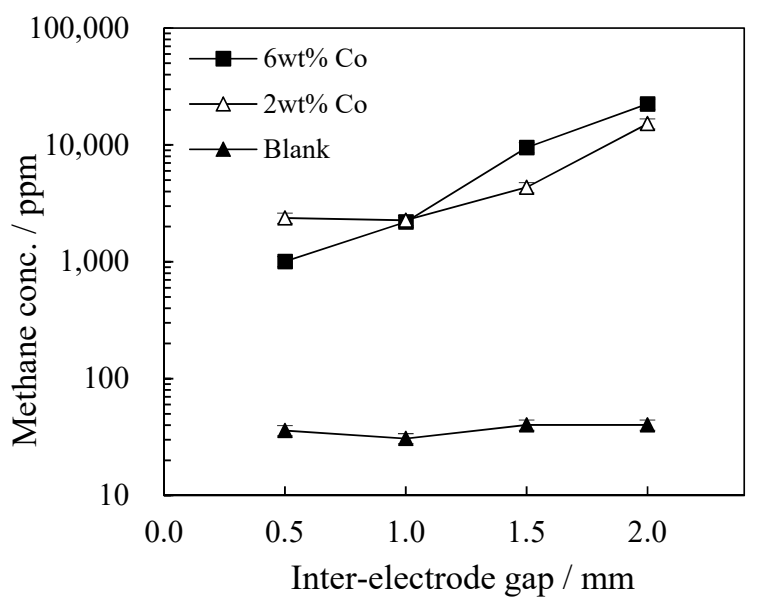

(a)

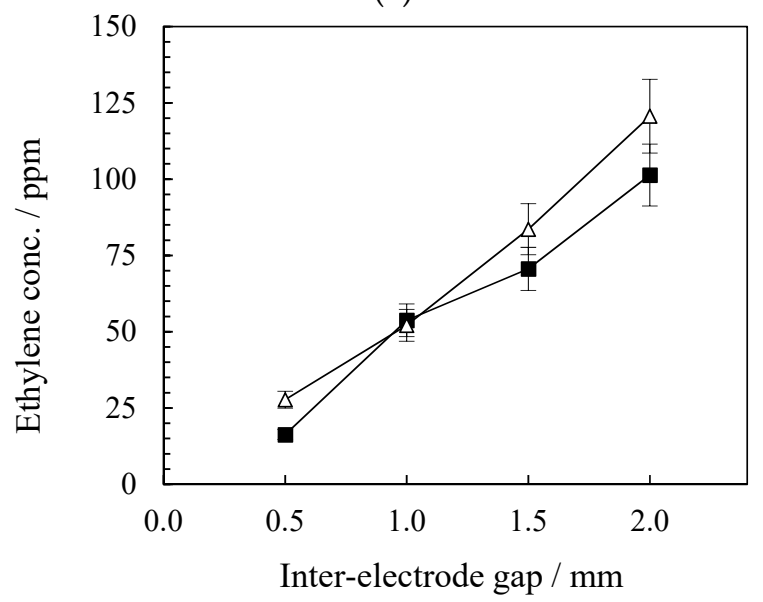

(c)

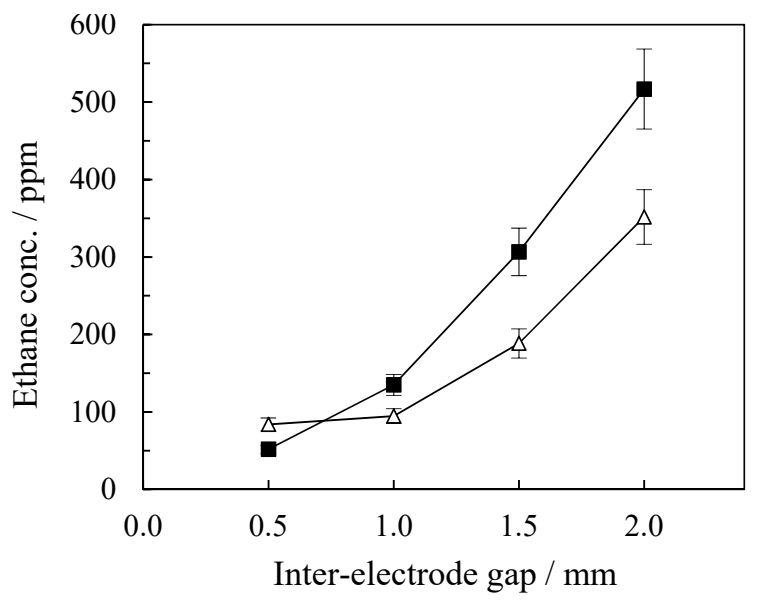

(b)

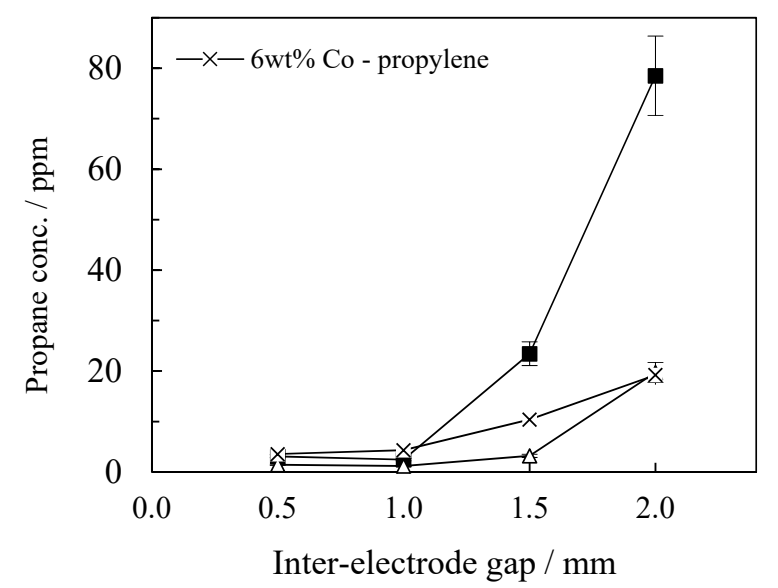

(d)

Figure 11. The influence of inter-electrode gap on hydrocarbon concentration for plasma-catalytic FTS (NTP + Blank, 2 or $6 \mathrm{wt} \%$ Co catalyst) at a discharge time of $60 \mathrm{~s}$; (a) methane, (b) ethane, (c) ethylene and (d) propane/propylene. Legend: - $6 \mathrm{wt} \% \mathrm{Co} ; \Delta-2 \mathrm{wt} \% \mathrm{Co} ; \boldsymbol{\Delta}-$ Blank; $\mathrm{X}-6 \mathrm{wt} \% \mathrm{Co}$ (propylene). Operating conditions: Syngas $\left(\mathrm{H}_{2} / \mathrm{CO}\right)$ ratio: 2.2:1; pressure: $2 \mathrm{MPa}$; current: $350 \mathrm{~mA}$; wall temperature: $25^{\circ} \mathrm{C}$. Error bars (vertical): Expanded experimental hydrocarbon concentration uncertainty of $\pm 11 \%$.

A wider inter-electrode gap produced a longer arc column, thus treating a greater volume of syngas. An increase in the discharge gap (volume) for plasma-catalysis also inferred an increase in the catalytic surface area exposed to the discharge, translating to a larger overall reaction volume for plasma-catalysis. This was observed for the $6 \mathrm{wt} \%$ Co catalyst, where the methane (22,424 ppm), ethane (517 ppm), ethylene (101 ppm), propane (79 ppm) and propylene (19 ppm) concentrations at an inter-electrode gap of $2 \mathrm{~mm}$ were approximately $22,10,6,26$ and 5 times higher, respectively, than the concentrations at $0.5 \mathrm{~mm}$. These results show that a fourfold increase in the discharge gap ( 0.5 to $2 \mathrm{~mm}$ ) produced a significantly greater reaction volume (arc discharge volume + catalyst surface area exposed to the discharge).

Although the blank catalyst had a similar reaction volume to the 2 and $6 \mathrm{wt} \%$ Co catalyst systems, its yields were considerably lower. For example, at the widest discharge gap of $2 \mathrm{~mm}$, the methane (22,424 ppm), ethane (517 ppm), ethylene (101 ppm) and propane (79 ppm) concentrations for the $6 \mathrm{wt} \%$ Co catalyst were 558, 543, 436 and 2453 times higher, respectively, than that of the blank catalyst $(40,0.95,0.23$ and $0.03 \mathrm{ppm}-\mathrm{values}$ not provided in Figure 11).

The hydrocarbon yields for the $6 \mathrm{wt} \%$ Co catalyst were generally higher than those of the $2 \mathrm{wt} \%$ Co catalyst for most discharge gaps studied. However, a reverse trend was 
observed for methane, ethane and ethylene at $0.5 \mathrm{~mm}$, which was especially apparent for ethylene between 1 and $2 \mathrm{~mm}$. The lower ethylene yields for the $6 \mathrm{wt} \%$ Co catalyst between the 1 and $2 \mathrm{~mm}$ discharge gaps may have resulted from these larger arc discharge volumes causing an elevation of the catalyst surface temperature. The catalyst temperature is related to the bulk gas temperature, which increased $(\Delta \mathrm{T})$ during the $60 \mathrm{~s}$ treatment by $3.3,5.0$, 12.5 and $25.4{ }^{\circ} \mathrm{C}$ at $0.5,1,1.5$ and $2 \mathrm{~mm}$ respectively.

The higher bulk gas/catalyst temperatures probably promoted ethylene readsorption, followed by secondary reactions, such as hydrogenation to ethane, or reinsertion into propane or propylene chains (reaction pathways discussed in the pressure variation study in Section $2 \mathrm{wt} \%$ and $6 \mathrm{wt} \%$ Co Catalyst). These reaction phenomena, describing the lower ethylene yields at 1 and $2 \mathrm{~mm}$ for the $6 \mathrm{wt} \%$ Co catalyst, were verified at $2 \mathrm{~mm}$. At this inter-electrode gap, the ethane (517 ppm) and propane (79 ppm) concentrations were 1.5 and 4 times higher, respectively, than that of the $2 \mathrm{wt} \%$ Co catalyst. In addition, the higher cobalt loading led to the exclusive production of propylene (not detected for the $2 \mathrm{wt} \% \mathrm{Co}$ catalyst system).

Furthermore, ethylene secondary reactions in the $6 \mathrm{wt} \%$ Co catalyst study appear to be more predominant at wider inter-electrode gaps than at higher pressures, as discussed in the pressure variation study in Section $2 \mathrm{wt} \%$ and $6 \mathrm{wt} \%$ Co Catalyst.

\subsubsection{The Influence of Inter-Electrode Gap on Energy Consumption}

The average voltage increased with increasing inter-electrode gap as shown in Figure 12. Higher voltages are typically required for sustaining the arc discharge at wider discharge gaps. This is due to the higher electrical resistivity (higher energy requirement) of the longer arc column, which is further from non-equilibrium than the near-electrode border zones $[1,68]$. Hence, for arc generation for the $6 \mathrm{wt} \%$ Co catalytic system, $268 \mathrm{~V}$ was required at $2 \mathrm{~mm}$ (longer arc column), whereas $157 \mathrm{~V}$ was required at $0.5 \mathrm{~mm}$ (shorter arc column).

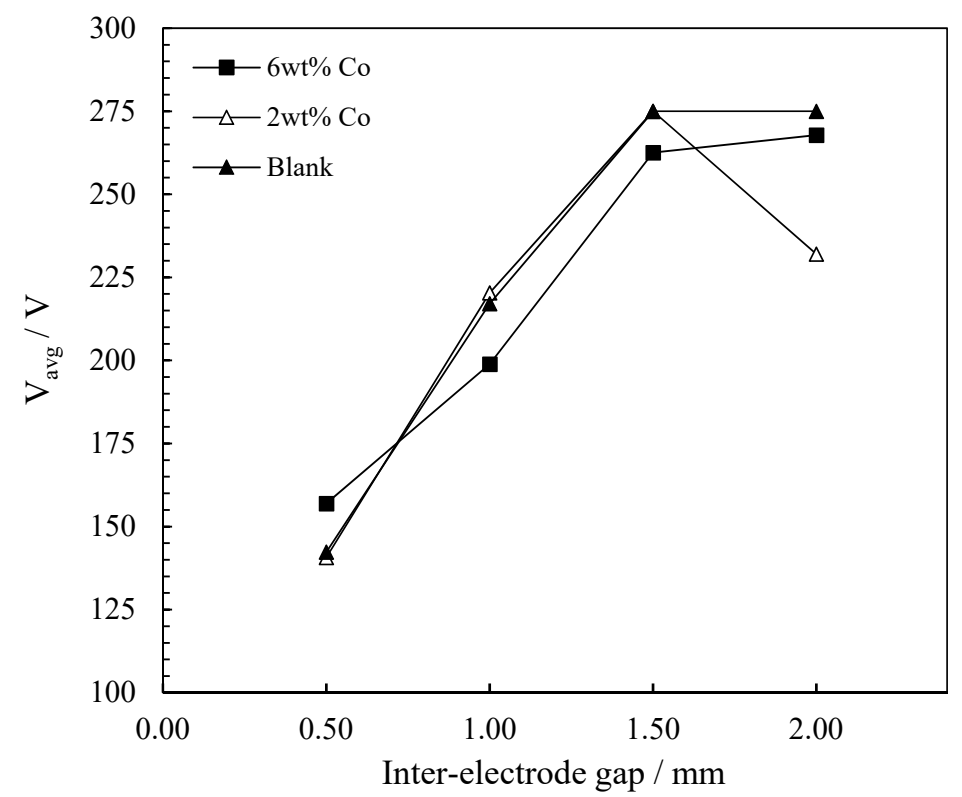

Figure 12. The influence of inter-electrode gap on rms voltage for plasma-catalytic FTS (NTP + Blank, 2 or $6 \mathrm{wt} \%$ Co catalyst) at a discharge time of $60 \mathrm{~s}$. Legend: $-6 \mathrm{wt} \%$ Co; $\Delta-2 \mathrm{wt} \%$ Co; $\boldsymbol{\Delta}-$ Blank. Operating conditions: Syngas $\left(\mathrm{H}_{2} / \mathrm{CO}\right)$ ratio: 2.2:1; pressure: $2 \mathrm{MPa}$; current: $350 \mathrm{~mA}$; wall temperature: $25^{\circ} \mathrm{C}$.

The voltage behaviour of the varying arc column width is also reflected by the specific input energy (SIE) values shown in Figure 13. The higher SIE values suggest that wider discharge gaps (longer arc columns), produced a more energy intensive (exhibited by greater bulk gas heating), and less non-equilibrium plasma. 


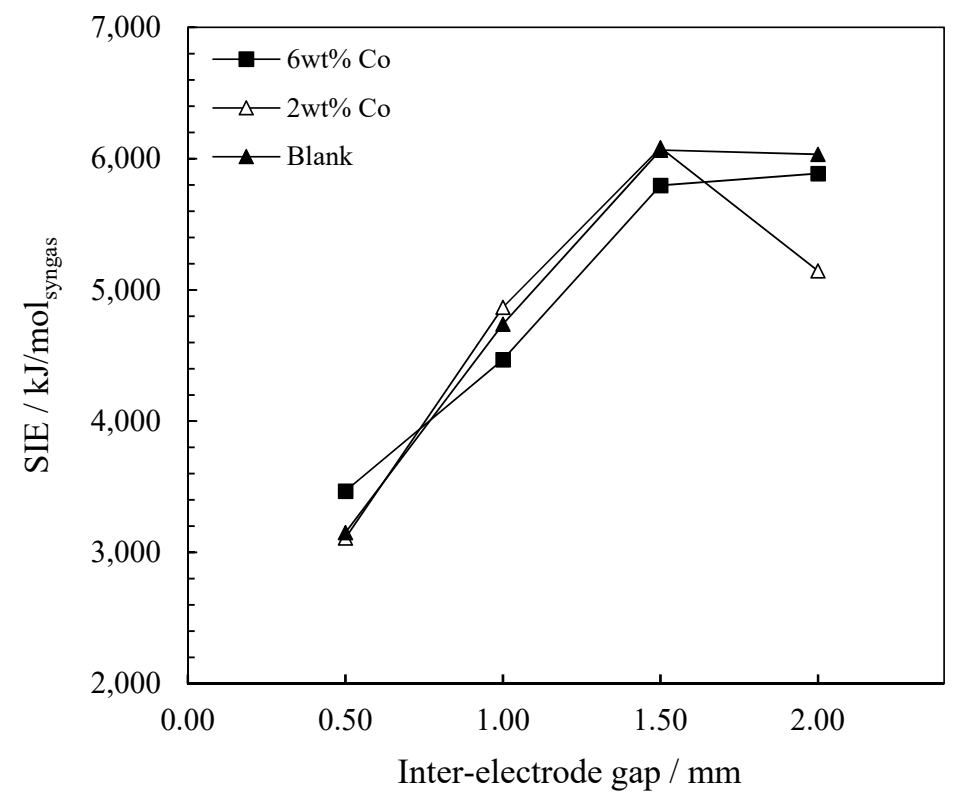

Figure 13. Specific input energy (kJ/molsyngas) as a function of inter-electrode gap for plasmacatalytic FTS (NTP + Blank, 2 or $6 \mathrm{wt} \%$ Co catalyst) at a discharge time of $60 \mathrm{~s}$. Legend: $\mathbf{\square}-6 \mathrm{wt} \%$ $\mathrm{Co} ; \Delta-2 \mathrm{wt} \% \mathrm{Co} ; \boldsymbol{\Delta}-$ Blank. Operating conditions: Syngas $\left(\mathrm{H}_{2} / \mathrm{CO}\right)$ ratio: $2.2: 1$; pressure: $2 \mathrm{MPa}$; current: $350 \mathrm{~mA}$; wall temperature: $25^{\circ} \mathrm{C}$.

The specific required energy (SRE) values, presented in Figure 14, significantly decreased between 0.5 and $2 \mathrm{~mm}$ for the 2 and $6 \mathrm{wt} \%$ Co catalysts, revealing 1.5 to $2 \mathrm{~mm}$ as the optimum inter-electrode gap range in regard to energy efficiency and hydrocarbon yields. At $2 \mathrm{~mm}$, the similar SRE values for the $2 \mathrm{wt} \%$ (224 MJ/molmethane, prod) and $6 \mathrm{wt} \%$ (265 MJ/molmethane, prod) Co catalysts were approximately 778 and 660 times lower, respectively, than that of blank catalyst (174 $451 \mathrm{MJ} /$ molmethane, prod).

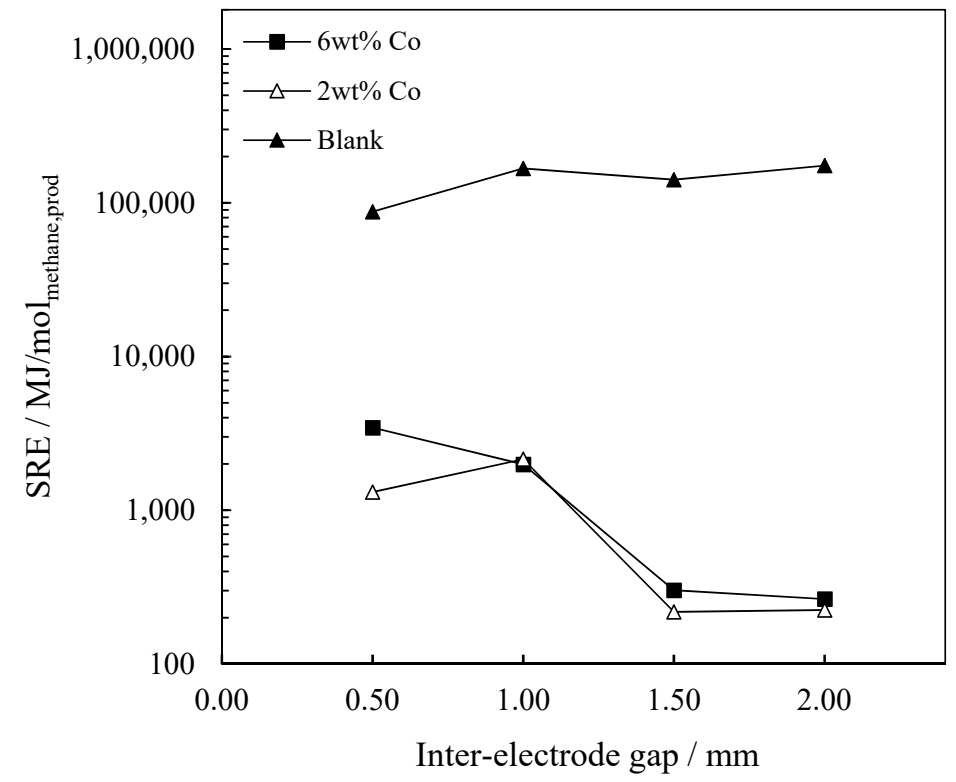

Figure 14. Specific required energy (MJ/molmethane, prod) as a function of inter-electrode gap for plasma-catalytic FTS (NTP + Blank, 2 or $6 \mathrm{wt} \%$ Co catalyst) at a discharge time of $60 \mathrm{~s}$. Legend: - $-6 \mathrm{wt} \% \mathrm{Co} ; \Delta-2 \mathrm{wt} \% \mathrm{Co} ; \boldsymbol{\Delta}-$ Blank. Operating conditions: Syngas $\left(\mathrm{H}_{2} / \mathrm{CO}\right)$ ratio: 2.2:1; pressure: $2 \mathrm{MPa}$; current: $350 \mathrm{~mA}$; wall temperature: $25^{\circ} \mathrm{C}$. 
Although the SRE value for the 2 and $6 \mathrm{wt} \%$ Co catalysts were similar at 1.5 and $2 \mathrm{~mm}$, the $6 \mathrm{wt} \%$ Co catalyst produced significantly higher quantities of $C_{1}-C_{3}$ paraffins and propylene (not detected for the other systems) in this discharge gap range. This catalyst, once again, is shown to be the most favourable for promoting chain growth. However, if higher ethylene concentrations were desired, then the $2 \mathrm{wt} \%$ Co catalyst operating between 1.5 and $2 \mathrm{~mm}$ would be preferred.

\subsection{Catalyst Characterisation}

The effects of plasma on the surface properties of the different cobalt loaded catalyst were assessed using various catalyst characterization tools, namely scanning electron microscopy (SEM), energy dispersive $x$-ray (EDX), transmission electron microscopy (TEM) and $x$-ray diffraction (XRD). These diagnostic tools and their experimental methods are described in this section.

\subsubsection{Scanning Electron Microscopy (SEM)}

The SEM micrographs, presented in Figure 15, depict the distinction between the coating layer and mullite substrate for the blank, 2 and $6 \mathrm{wt} \%$ Co catalysts. The coating layer thicknesses, measured at 20 different sites on the blank, 2 and $6 \mathrm{wt} \%$ Co catalysts, ranged between $21-49 \mu \mathrm{m}, 34-67 \mu \mathrm{m}$, and $41-75 \mu \mathrm{m}$, respectively, with average coating thicknesses of 37,49 and $51 \mu \mathrm{m}$.
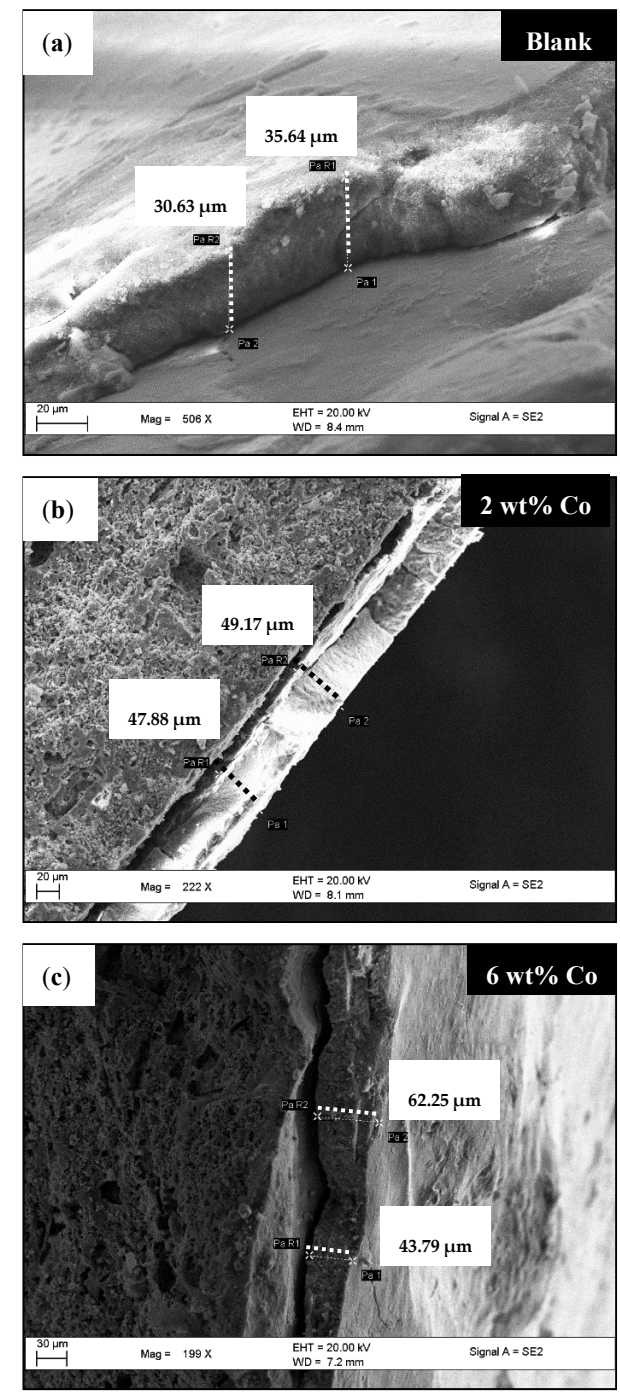

Figure 15. SEM images of catalyst coating thickness; (a) blank, (b) $2 \mathrm{wt} \% \mathrm{Co}$, (c) $6 \mathrm{wt} \%$ Co. 
The average coating thicknesses increased with increasing cobalt loading, which coincides with the increasing $C_{1}-C_{3}$ hydrocarbon yields is discussed in Sections 3.1-3.3. Bakhtiari et al. [69] observed a similar trend using a monolithic reactor (pure catalysis). They found that an increase in the coating thickness with cobalt loading, increasing from 15 to $33 \mathrm{wt} \%$, improved the $\mathrm{C}_{5+}$ selectivity. The coating thickness, although an important design factor for continuous monolith reactors-in which the diffusion length (governed by the coating thickness), directly affects the mass transfer limitations [69]-is not a significant factor for the batch process in this work.

In addition to the coating thickness, SEM was also used to analyze the surface characteristics of the catalyst i.e., the cylindrical inner surface exposed to the arc discharge. A micrograph of the fresh uncoated mullite (without $\gamma-\mathrm{Al}_{2} \mathrm{O}_{3}$ and $\mathrm{Co}$ ) is shown in Figure 16a. In contrast, $\gamma-\mathrm{Al}_{2} \mathrm{O}_{3}$ clusters are clearly visible on the fresh blank catalyst (without $\mathrm{Co}$ ) in Figure 16b.

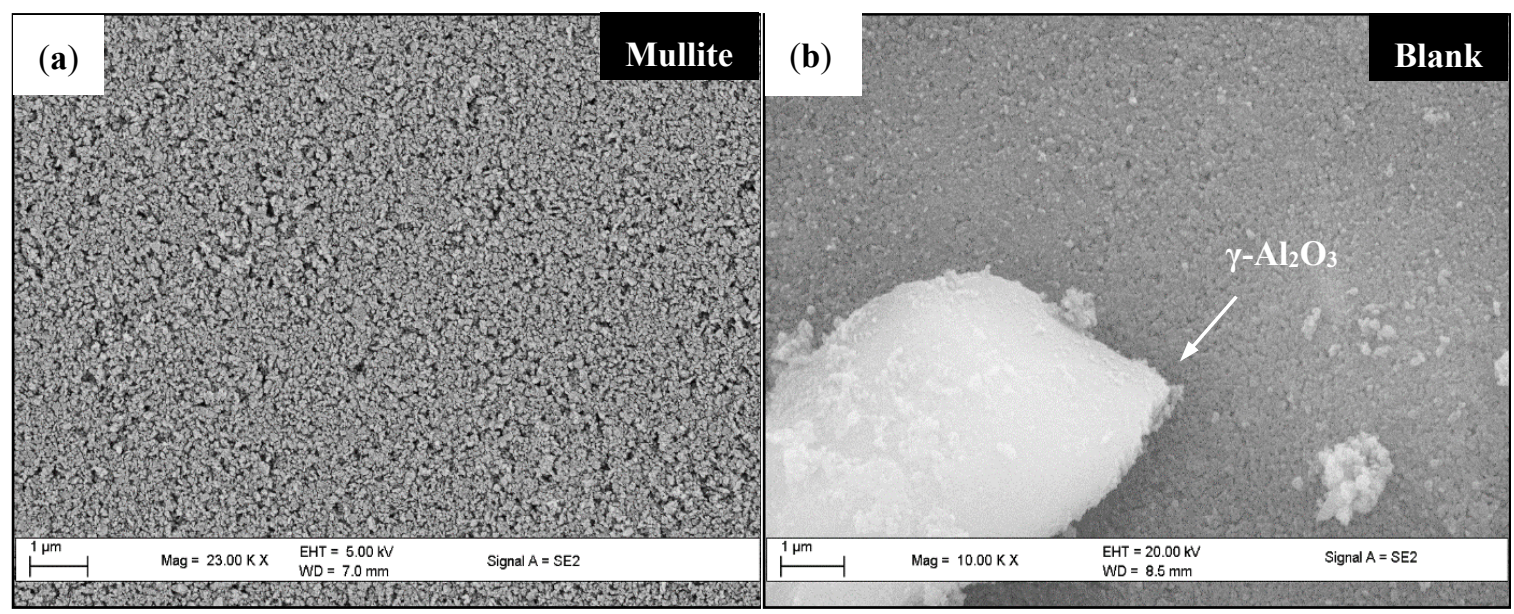

Figure 16. SEM micrographs of catalysts; (a) uncoated mullite (no $\gamma-\mathrm{Al}_{2} \mathrm{O}_{3}$ and $\mathrm{Co}$ ), (b) blank catalyst.

The SEM micrographs of inner surface of the 2 and $6 \mathrm{wt} \%$ Co catalysts, shown in Figures 17 and 18, respectively, show a vast difference between the fresh and used cobalt catalysts. Large cobalt clusters are visible on both the fresh (calcined/reduced) $2 \mathrm{wt} \%$ Co catalyst (Figure 17a) and $6 \mathrm{wt} \%$ Co catalyst (Figure 18a,b). In contrast, smaller and more highly dispersed clusters are seen on the used $2 \mathrm{wt} \%$ Co catalyst (Figure 17b) and $6 \mathrm{wt} \%$ Co catalyst (Figure 18c,d).
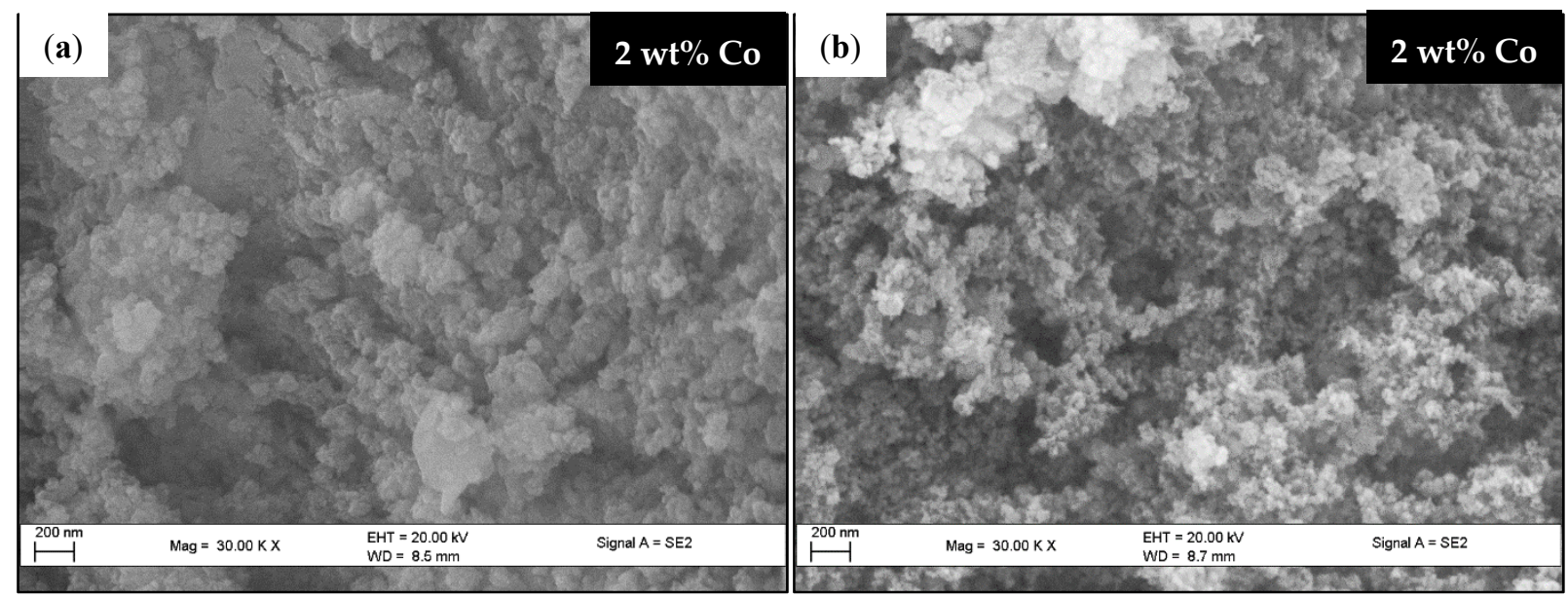

Figure 17. SEM micrographs of $2 \mathrm{wt} \%$ Co catalysts; (a) fresh catalyst, (b) used catalyst. 

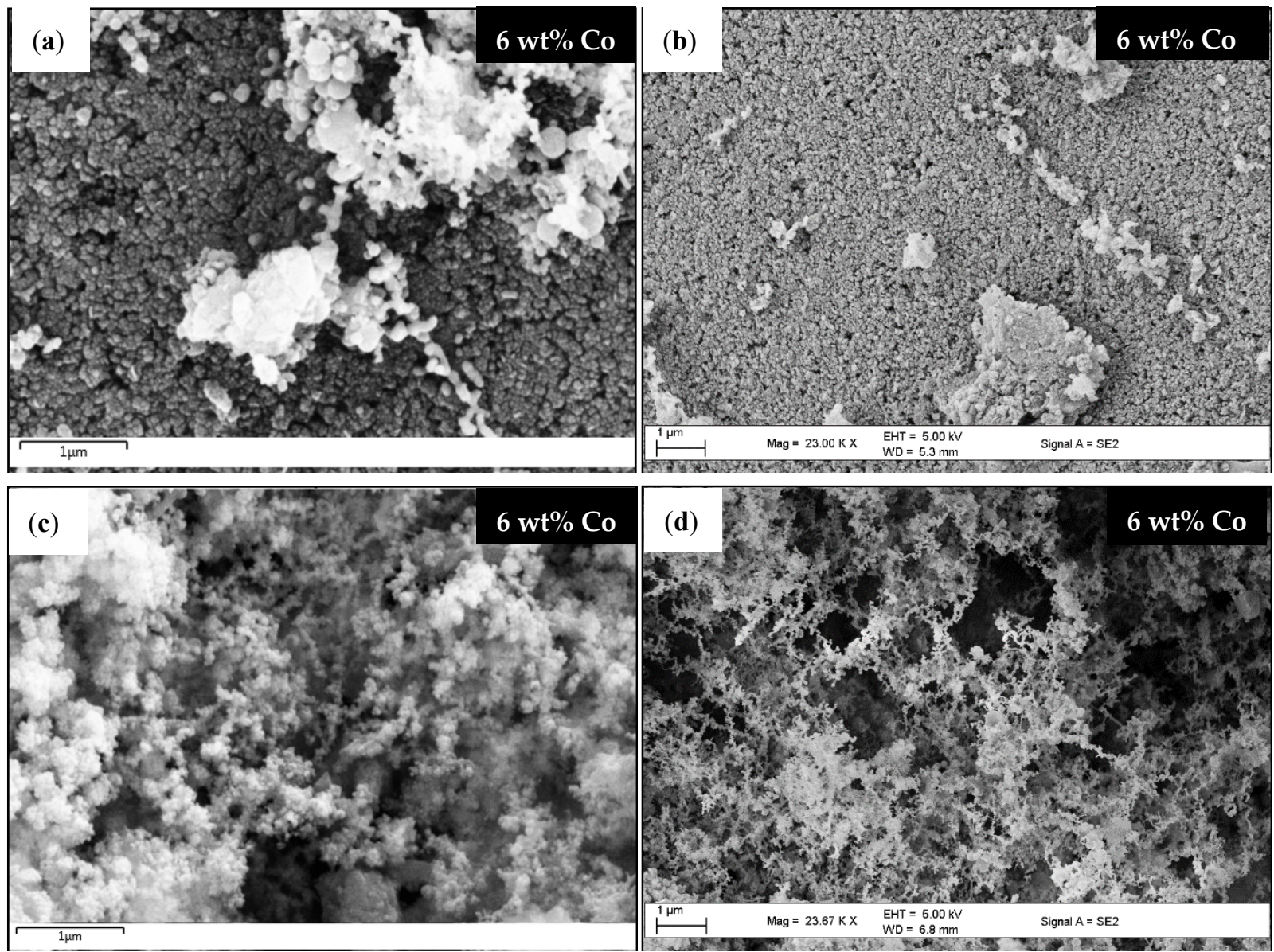

Figure 18. SEM micrographs of $6 \mathrm{wt} \%$ Co catalysts; (a,b) fresh catalyst, $(\mathbf{c}, \mathbf{d})$ used catalyst.

In conventional FTS, for a $\mathrm{Co} / \mathrm{SiO}_{2}$, an increase in cobalt dispersion-to a higher degree than that caused by $\mathrm{H}_{2}$ activation-occurred due to an increase in the operating pressure from 2 to $4 \mathrm{MPa}$ [70]. Higher pressures were suggested to promote CO chemisorption, causing cobalt cluster segregation and a larger catalytic surface area.

Therefore, higher operating pressures $(0.5-10 \mathrm{MPa})$ than that in conventional FTS, combined with the pre-dissociated CO plasma species, are factors that were probably responsible for the high cobalt dispersion shown in Figures $17 \mathrm{~b}$ and $18 \mathrm{c}, \mathrm{d}$. In addition, the reduction of unreduced Co oxides to form smaller Co metal particles, a phenomenon reported in several plasma-catalytic studies [71-74], may also explain the smaller particle sizes of the used catalysts.

Furthermore, the different cluster sizes for the used $6 \mathrm{wt} \%$ Co catalyst, shown in Figure $18 \mathrm{c}, \mathrm{d}$, were due to the different areas of the catalyst being exposed to varying discharge intensities, i.e., non-uniform plasma-heating of the catalyst surface. The smaller and more modified clusters seen in Figure 18d, suggest that this portion of the catalyst was located in closer proximity to the arc discharge (directly above the upward curved arc column). This is the most thermally intense region of the discharge, probably leading to hotspot formation, a phenomenon observed in the plasma-catalytic literature [66]. Furthermore, these catalyst's areas closest to the active arc core were likely to contribute the most to hydrocarbon production.

\subsubsection{Energy Dispersive X-ray (EDX)}

SEM-EDX dot mapping images revealing the major elemental components $(\mathrm{Co}, \mathrm{Al}$ and $\mathrm{Si}$ ) on the inner surfaces - exposed to plasma - of the used 2 and $6 \mathrm{wt} \%$ Co catalysts, are presented in Figures 19 and 20, respectively. These images show that the cobalt particles 
were uniformly distributed on both used catalyst surfaces, which was enhanced by plasma treatment as shown in SEM (Section 2.4.1) and TEM (Section 2.4.3) analysis. The images and intensity plots also verify that approximately three times more cobalt was present in the $6 \mathrm{wt} \%$ Co catalyst.

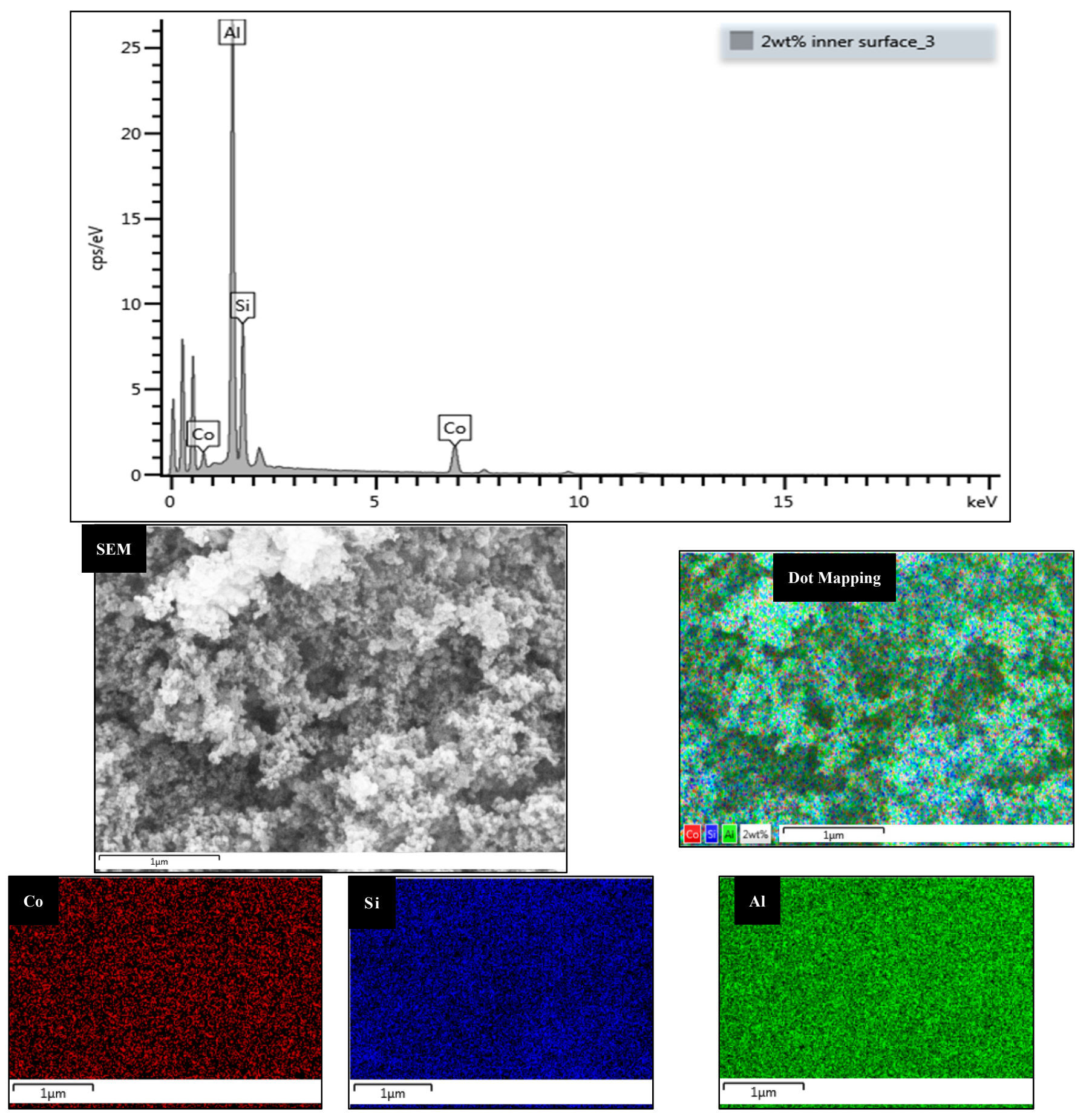

Figure 19. EDX dot mapping analysis of the surface of a used $2 \mathrm{wt} \%$ Co catalyst. 

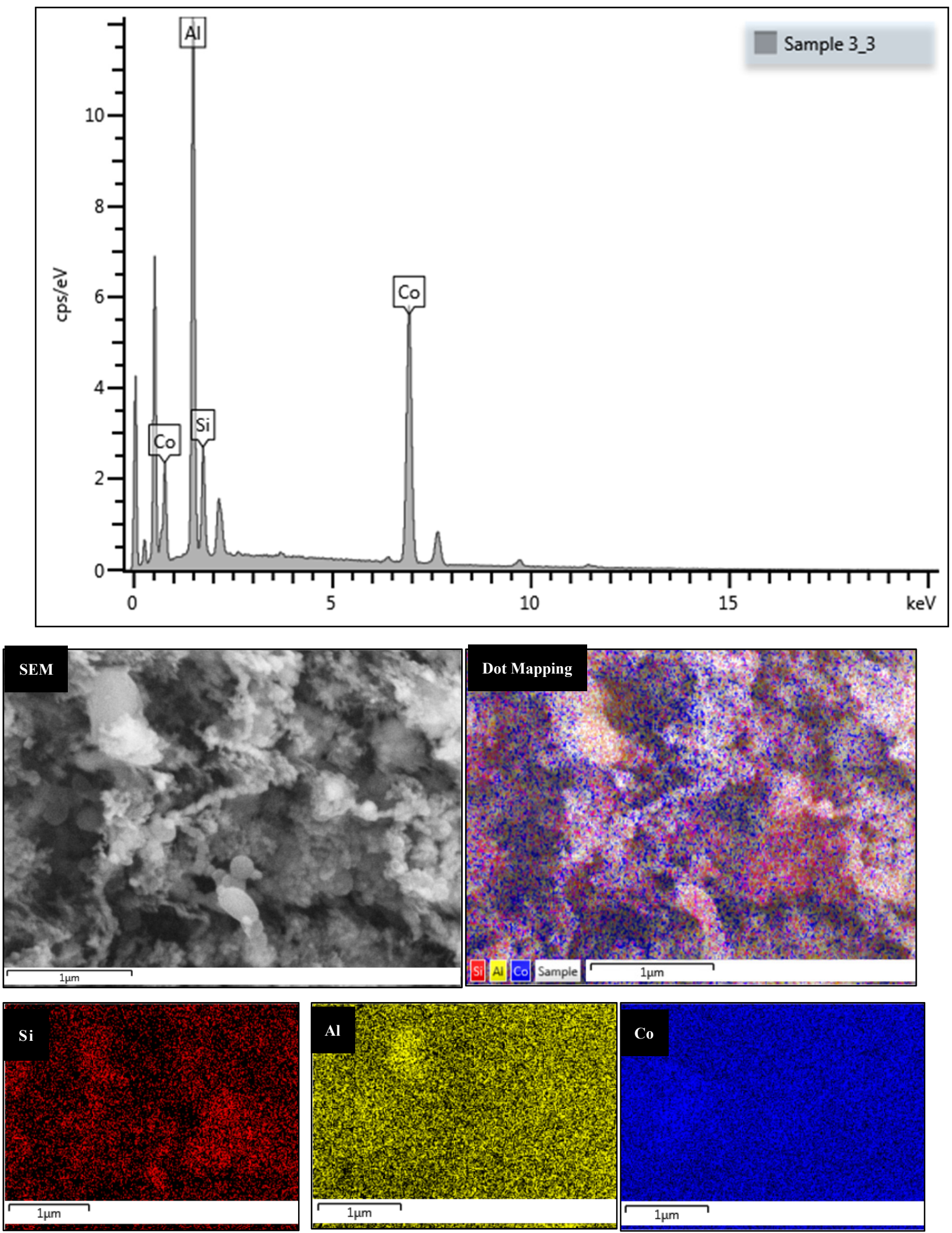

Figure 20. EDX dot mapping analysis of the surface of a used $6 \mathrm{wt} \%$ Co catalyst. 


\subsubsection{Transmission Electron Microscopy (TEM)}

Particle Size Distribution

The 2 and $6 \mathrm{wt} \%$ Co catalysts produced significantly higher product yields and a wider product distribution than the blank catalyst, which clearly indicates the contribution of cobalt in plasma-catalytic FTS. In order to better understand the influence of cobalt loading on plasma-catalytic interactions, the cobalt particle size analysis and particle distribution were examined using transmission electron microscopy (TEM).

A TEM micrograph of the blank catalyst (mullite coated with only $\gamma-\mathrm{Al}_{2} \mathrm{O}_{3}$ ) is shown in Figure 21a. Compared to the lighter $\gamma-\mathrm{Al}_{2} \mathrm{O}_{3}$ and mullite $\left(\mathrm{Al}_{2} \mathrm{O}_{3} / \mathrm{SiO}_{2}\right)$ particles seen in Figure 21a, the darker cobalt clusters, are clearly visible for the $2 \mathrm{wt} \%$ Co catalyst (Figure 21b) and $6 \mathrm{wt} \%$ Co catalyst (Figure 21c), as highlighted by the white dashed circles.
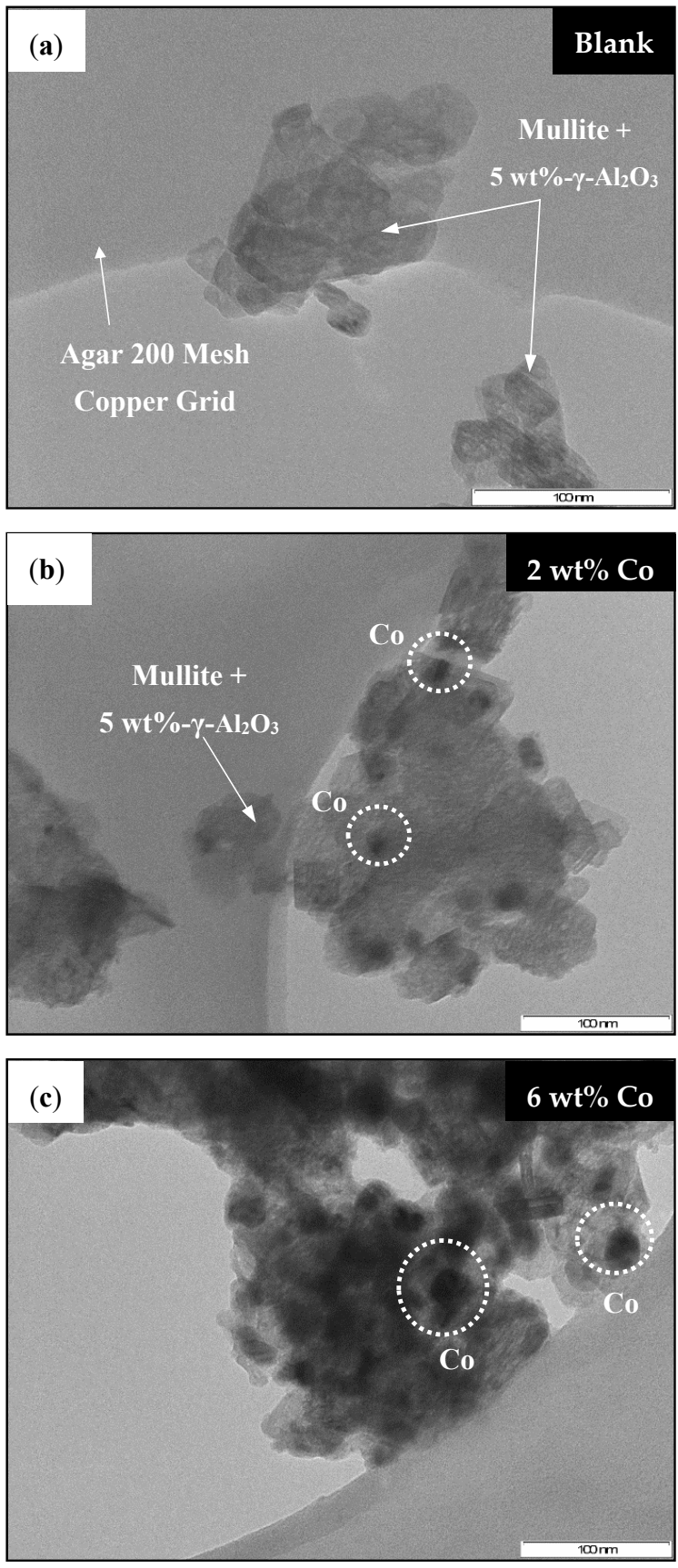

Figure 21. TEM micrographs of used catalysts; (a) blank, (b) $2 \mathrm{wt} \% \mathrm{Co}$, (c) $6 \mathrm{wt} \%$ Co. (N.B. Examples of cobalt clusters are encircled by white dashed rings). 
The cobalt particle size distribution, presented in Figure 22, was determined by measuring the approximate particle sizes of 100 cobalt clusters for both the 2 and $6 \mathrm{wt} \%$ Co catalysts using the iTEM image analysis software. The size of the $6 \mathrm{wt} \%$ Co particles spanned 6 to $57 \mathrm{~nm}$ with $84 \%$ of the particles in the range of 6 to $25 \mathrm{~nm}$. The size of the $2 \mathrm{wt} \%$ Co particles spanned 2 to $35 \mathrm{~nm}$ with $95 \%$ of the particles in the range of 2 to $19 \mathrm{~nm}$. Based on this data, the average particle sizes for the 2 and $6 \mathrm{wt} \%$ Co catalysts were estimated to be 10 and $19 \mathrm{~nm}$, respectively.

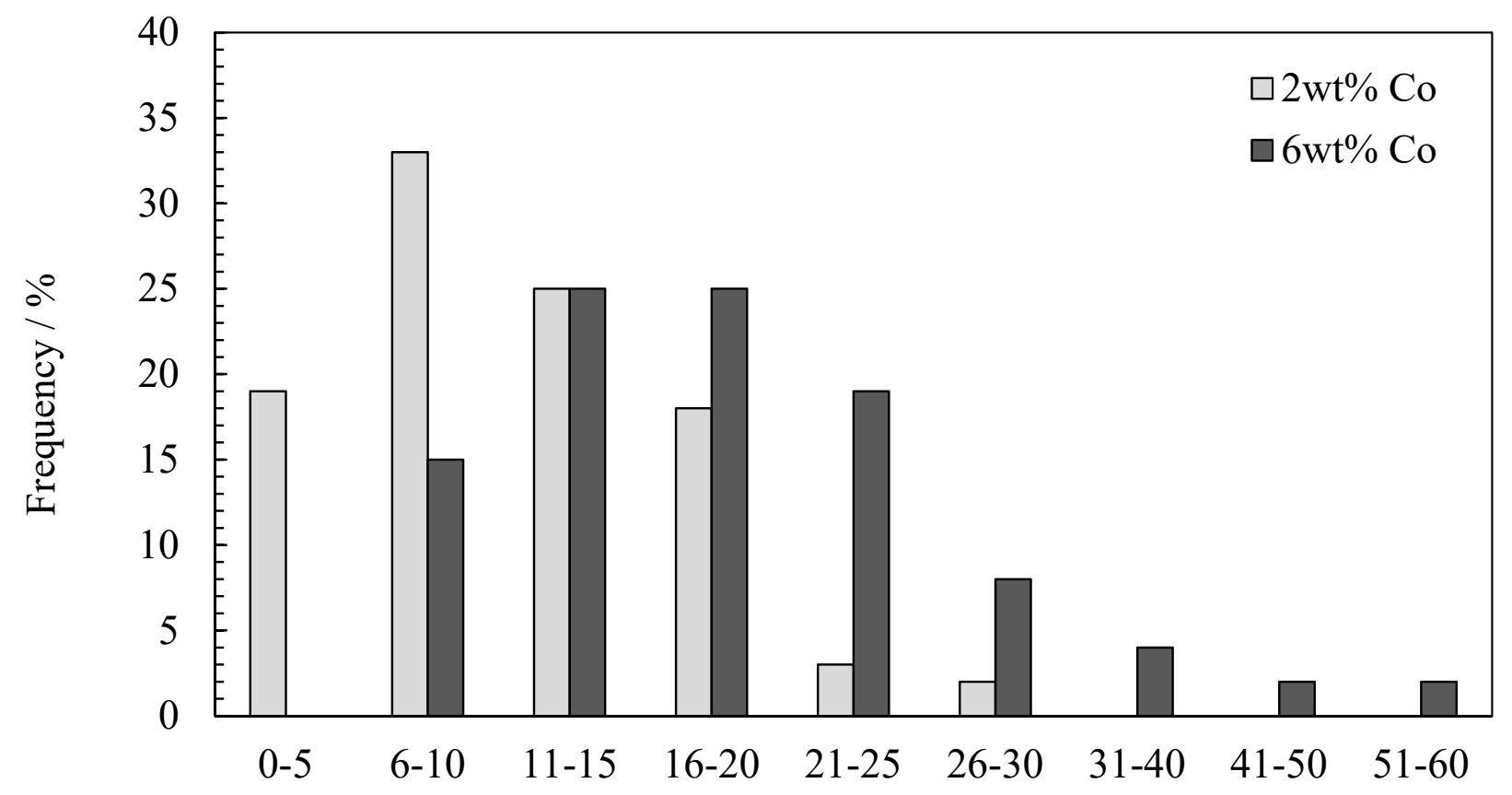

Cobalt particle size / $\mathrm{nm}$

Figure 22. Particle size histogram of the $2 \mathrm{wt} \%(\boldsymbol{\square})$ and $6 \mathrm{wt} \%$ (口) cobalt catalysts.

Tavasoli et al. [58] showed that an increase in the cobalt loading (from 8 to $40 \mathrm{wt} \%$ ) on an $\mathrm{Al}_{2} \mathrm{O}_{3}$ support, caused a higher deposition onto the same support surface, resulting in the agglomeration of cobalt crystal particles, thus forming larger clusters. Larger clusters were associated with weaker metal-support interactions, resulting in improved reducibility $[75,76]$, and thus generating more active sites (a larger catalytic surface area) for FTS reactions. It was also reported that larger clusters may reduce steric hindrance for dissociative adsorption of $\mathrm{CO}$ [58], which could promote chain growth monomer formation.

The effects of a higher cobalt loading on the FTS performance factors in this work are in agreement with the literature mentioned above $[58,75,76]$. That is, the larger cobalt particles of the $6 \mathrm{wt} \%$ Co catalyst corresponded to higher $C_{1}-C_{3}$ hydrocarbon yields. It also improved chain growth, as indicated by propylene production, which was absent for the blank and $2 \mathrm{wt} \%$ Co catalysts studies.

In addition to the cobalt particle sizes, TEM also revealed the presence of carbonaceous species on the $6 \mathrm{wt} \%$ Co catalyst in the form of carbon nanotubes (CNTs), as shown in Figure 23. This was an unexpected finding as CNTs are not synthesized in conventional FTS due to low temperature operation. The only known connection between CNTs and conventional FTS in the literature is the use of CNTs as catalyst supports [77-86].

CNT synthesis in this work is suggested to occur through similar mechanisms to that in thermal chemical vapor deposition (CVD) and/or plasma enhanced chemical vapor deposition (PECVD), as there seem to be some similarities between these processes and their products. 

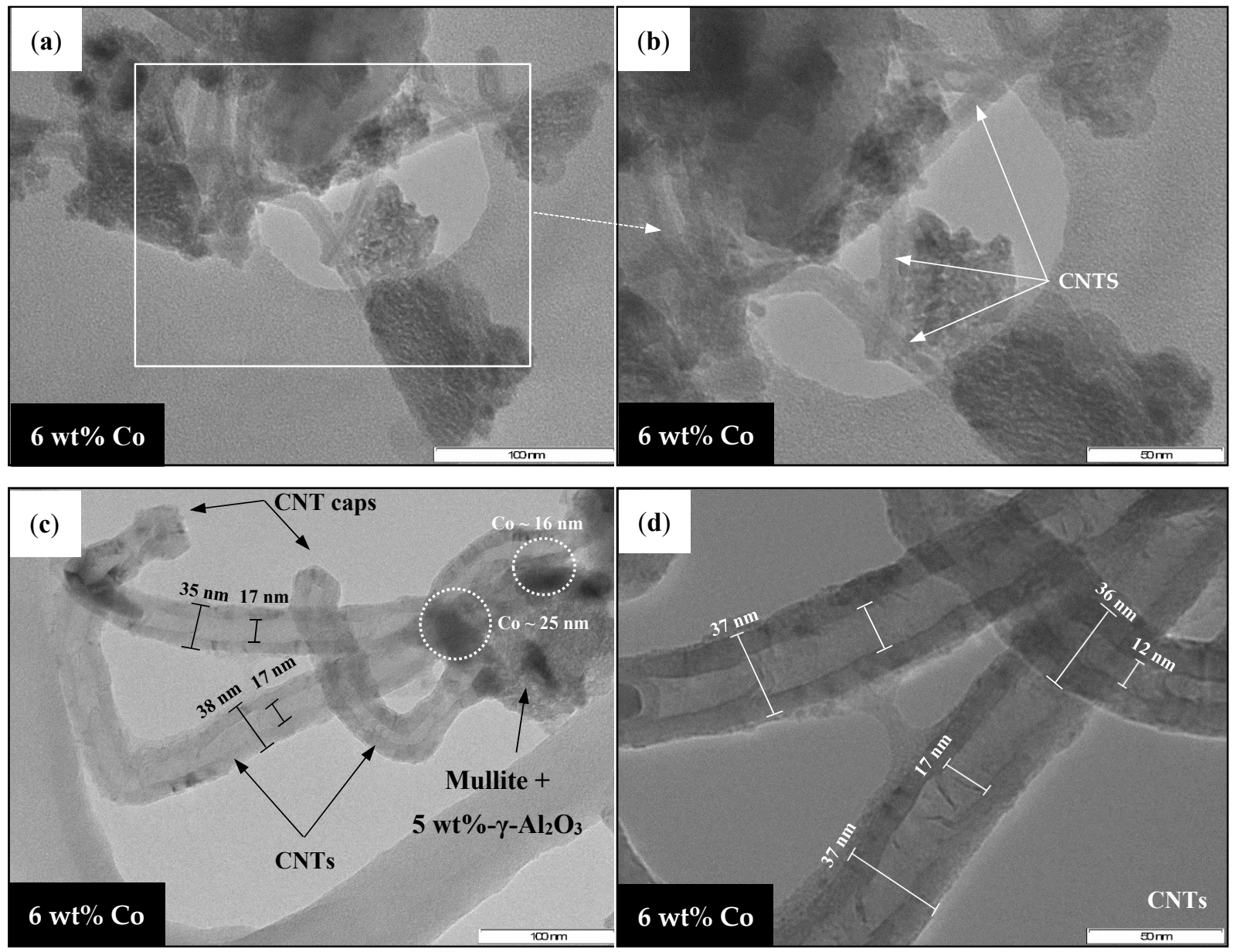

Figure 23. TEM micrographs of carbon nanotubes (CNTs) detected on the used catalyst; (a-d) $6 \mathrm{wt} \%$ Co.

Firstly, CNTs may be formed from several carbon precursors: carbon monoxide, methane, ethylene, acetylene, benzene and xylene [87-89]. Carbon monoxide was the obvious carbon precursor in this work, with prospective contributions from the $\mathrm{C} 1-\mathrm{C} 3$ hydrocarbon products. Secondly, CNT growth usually occurs via precursor decomposition on the catalyst surface at high temperatures [90]. Here, precursor decomposition could have been induced by CVD and/or PECVD routes: molecular CO and hydrocarbons decomposed on the cobalt surface between 600 and $1200{ }^{\circ} \mathrm{C}$, which is similar to thermal CVD (less likely due to the high temperature requirements), or PECVD (where carbonplasma, pre-dissociated $\mathrm{CO}$, was deposited on the cobalt surface at temperatures as low as $\left.120^{\circ} \mathrm{C}\right)[89,91]$.

The PECVD route for CNT synthesis was more likely to occur due to the ability of the active plasma species to reduce the temperature requirement by lowering the activation barrier, a phenomena reported in other plasma-catalytic applications $[78,79]$. However, the CNTs structure resembled the "curly" or "spaghetti-like" structure of CVD-CNTs [88,89], as opposed to the vertically aligned assembly of PECVD-CNTs $[89,91]$. In addition, CNTs may have been modified during the grinding of the $6 \mathrm{wt} \%$ Co catalyst into powder (the form required for TEM analysis); however, the effect of grinding on these nano-sized structures are not known. Therefore, a precise CNT mechanism cannot be deciphered at this exploratory stage of experimentation.

Furthermore, the appearance of these CNTs resembled that of multi-walled CNTs (MWCNTs) [87,92]. The MWCNTs had inner diameters between 12-17 $\mathrm{nm}$ and outer diameters between $36-38 \mathrm{~nm}$, visually measured from the TEM images in Figure 26 using the iTEM software. The dimensions were in the general MWCNT diameter range of 2 to $100 \mathrm{~nm}$ [93], with the tubes diameters increasing proportionally with the catalyst particle 
size, a relationship reported in the PECVD literature [88] i.e., larger catalyst particles formed CNTs with larger tube diameters, vice versa. The average diameters of at least $10 \mathrm{~nm}$ for the cobalt particles in this study, corresponded to the range (of tens of nanometers) reported in the literature for MWCNTs. In contrast, a few nanometers $(\leq 3 \mathrm{~nm})$ were reported for single-walled CNTs (SWCNTs) [60,94]. Furthermore, the lower temperature range of 600 to $900{ }^{\circ} \mathrm{C}$ for MWCNT synthesis was more likely to occur than the range of 900 to $1200{ }^{\circ} \mathrm{C}$ for SWCNT synthesis [60].

In regard to the growth mechanism, it appears that a MWCNT originated at the surface of a cobalt cluster (firmly rooted to the $\gamma-\mathrm{Al}_{2} \mathrm{O}_{3} /$ mullite support), and as it grew, protruded away from the cobalt cluster. This growth process conforms to the base-growth mechanism, which occurs due to the strong interaction between $\mathrm{Co}$ and $\gamma-\mathrm{Al}_{2} \mathrm{O}_{3}$. In contrast, moderate interactions between $\mathrm{Co}$ and $\mathrm{TiO}_{2}$, and weak interactions between $\mathrm{Co}$ and $\mathrm{SiO}_{2}$ [31]-other oxide supports used in FTS-would probably be described by the tip-growth mechanism. In this mechanism, the graphitic cylinder evolves between the metal and support, pushing the metal upwards.

\subsubsection{X-ray Diffraction (XRD)}

A powder XRD apparatus equipped with a cobalt radiation source was used to classify the molecular compounds comprising the blank, 2 and $6 \mathrm{wt} \%$ Co catalysts. The catalyst spectra, shown in Figure 24a, were identified by comparison to reference peak patterns (Figure 24b). The reference peaks were sourced from the HighScore Plus database, which listed potential compound matches and their order of probability. The highest reference peak in each reference spectra in Figure 24b, corresponds to $100 \%$ intensity, with the outstanding peaks having relative intensities.

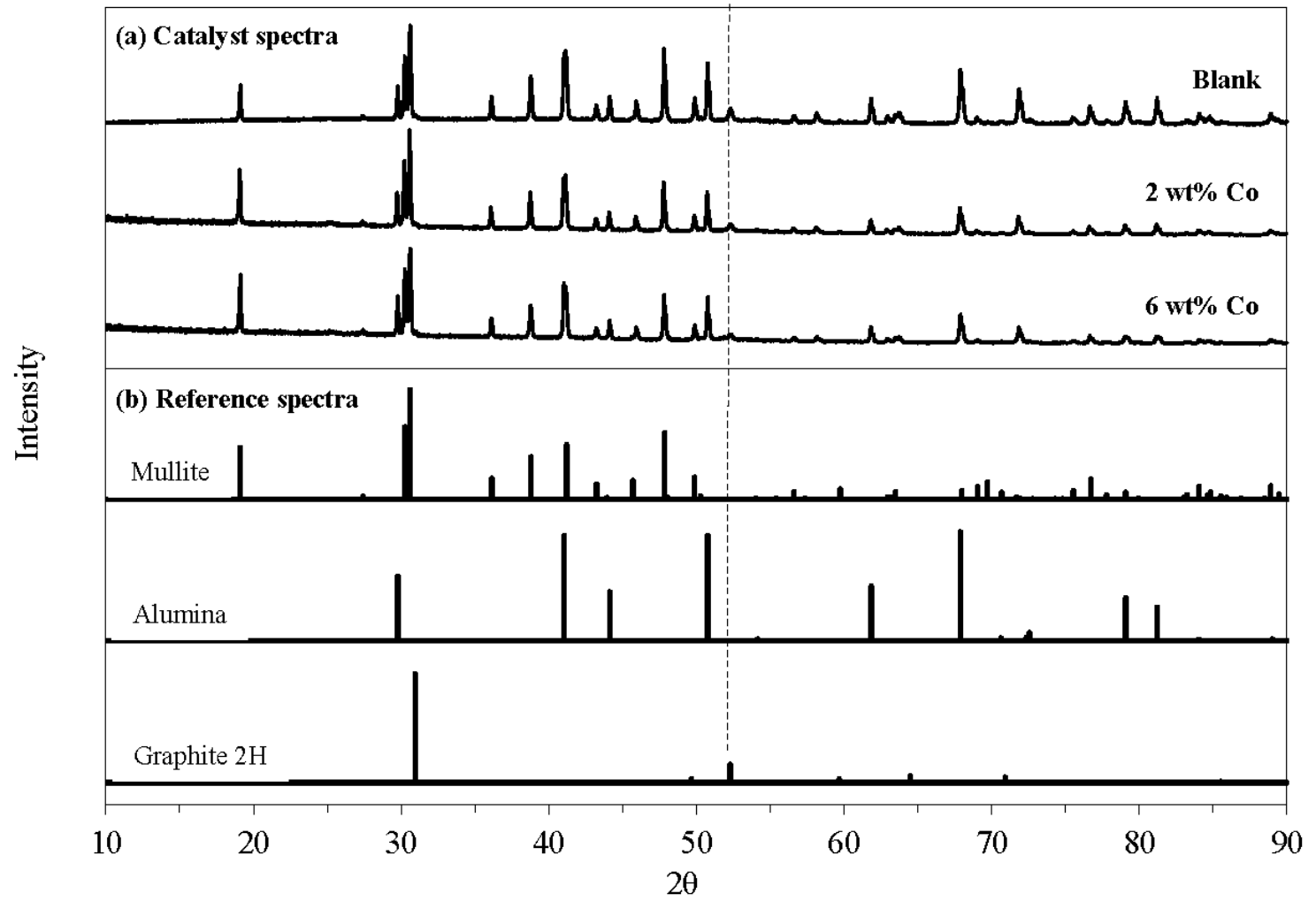

Figure 24. XRD plots of (a) catalyst peaks and (b) reference peak patterns.

The reference peak patterns show that mullite and alumina are the dominant components of the blank, 2 and $6 \mathrm{wt} \%$ Co catalysts, as these patterns matched the catalyst spectra with the highest probability. Furthermore, the 2 and $6 \mathrm{wt} \%$ Co catalysts' spectra for mullite and alumina display relatively similar peak intensities, but the mullite/alumina peaks at 
$62^{\circ}, 63^{\circ}, 67^{\circ}, 71^{\circ}, 76^{\circ}, 79^{\circ}, 81^{\circ}, 84^{\circ}$ and $89^{\circ}$ for the blank catalyst have a slightly higher intensity, which is probably due to more mullite and alumina being present in the absence of cobalt. Moreover, the prominence of mullite and alumina might have also swamped the detection of cobalt for the Co-loaded catalysts.

In addition to mullite and alumina, graphite (more specifically graphite $2 \mathrm{H}$ [95]) was detected in all three catalysts. The graphite reference peaks at $\sim 31^{\circ}, 49^{\circ}, 59^{\circ}$ and $71^{\circ}$ intersect those of mullite, with the graphite peak at $71^{\circ}$ closely corresponding to alumina, thus making it difficult to distinguish graphite. However, the peak at $52^{\circ}$ (highlighted by the dashed line), absent in alumina and mullite, suggests that graphite was formed on all three catalysts.

The deposition of graphite on the catalysts may be confirmed by it being a precursor in the synthesis of carbon nanotubes (CNTs), which were detected using TEM (discussed Section 2.4.3) i.e., CNTs are fundamentally cylindrical graphene sheets, where graphene is a single layer of graphite. Graphite formation may be further verified by the intersection of temperatures required to synthesize these carbonaceous compounds: graphite forms above $400{ }^{\circ} \mathrm{C}$ [96-100], whereas CNT growth occurs above $600^{\circ} \mathrm{C}$ by thermal CVD and above $120^{\circ} \mathrm{C}$ by PECVD $[60,89,91]$. These high temperatures, 400 to $600{ }^{\circ} \mathrm{C}$, usually lead to surface carbon being converted into more stable carbon species that possess a lower affinity for hydrogenation [100].

\subsubsection{Carbon Deposition on Electrodes}

In addition to the catalyst surface, carbon deposits were also seen on the cathode and anode surfaces for the $2 \mathrm{wt} \%$ Co catalyst system, as shown in Scheme 2 in Section $2 \mathrm{wt} \%$ and $6 \mathrm{wt} \%$ Co Catalyst. These deposits were seen to destructively interfere with the arc stability. Apart from visual observation, the stability was also evaluated based on the voltage errors (signifying voltage fluctuations) [1], as discussed in Section 3.1.3. The voltage errors for the blank catalyst, 2 and $6 \mathrm{wt} \%$ Co catalysts systems were 1.2, 2.9 and $1.4 \%$ respectively.

The $2 \mathrm{wt} \%$ Co catalyst exhibited the highest voltage error (highest arc fluctuation), confirming that the carbonaceous species on the electrodes had a negative influence on the arc stability. The arc fluctuation/deformation probably occurred by the arc unhinging from the anodic root, jumping, and re-hinging onto the electrically conductive [101] carbon species, which were coated on the electrodes. Furthermore, these arc jumps, caused by the carbon species, led to the arc interacting with the internal reactor components, which was problematic as it hindered the operability and performance of the arc reactor. These findings, in addition to higher yields and lower energy consumption, favors the application of the $6 \mathrm{wt} \%$ Co catalyst in plasma-catalytic FTS, and necessitates the investigation of higher cobalt loadings [58].

\section{Materials and Methods}

\subsection{Arc discharge Reactor}

\subsubsection{Reactor Set-Up}

Fischer-Tropsch synthesis was explored using a tip-to-plane arc discharge (batch) reactor previously reported by Fulcheri et al. [1] and Iwarere et al. [3] with capability to operate at low current and high pressure (up to $20 \mathrm{MPa}$ ). A schematic illustrating the process flow of the reactor and its peripheral equipment are illustrated in Figure 25.

The reactor was equipped with two axially-positioned tungsten electrodes. The stationary cathode was fixed in position by a ceramic holder, fabricated by Ceradvance Engineering Ceramics, Pretoria, South Africa. The mobile anode was moved using a hand wheel, enabling an adjustable inter-electrode gap. This was an innovative feature of the reactor, as contact of the electrodes (inter-electrode gap $=0 \mathrm{~mm}$ ) minimized the electrical resistance of the high pressure gas, thus enabling the ignition of an arc discharge, and ultimately circumventing the high pressure limitations prescribed by Paschen's law $[68,102-104]$. 
The electrodes and electrode holders were fitted with O-rings, ensuring a leak tight discharge chamber. The arc discharge could be viewed via two face-to-face borosilicate Pyrex $^{\mathrm{TM}}$ sight glasses, Sophia Antipolis, France. The reactor was equipped with a thermocouple for measuring the bulk gas temperature, which was positioned at around 8.5 to $9 \mathrm{~mm}$ away from the conical tip of the cathode (the origin of arc discharge). The reactor operating pressure was measured by a WIKA E-10 flameproof pressure transmitter (0-25 MPa) (WIKA Instruments Pty Ltd., Durban, South Africa). Due to the high temperature arc, the room temperature bulk gas was regulated using a water-cooled cooling jacket.

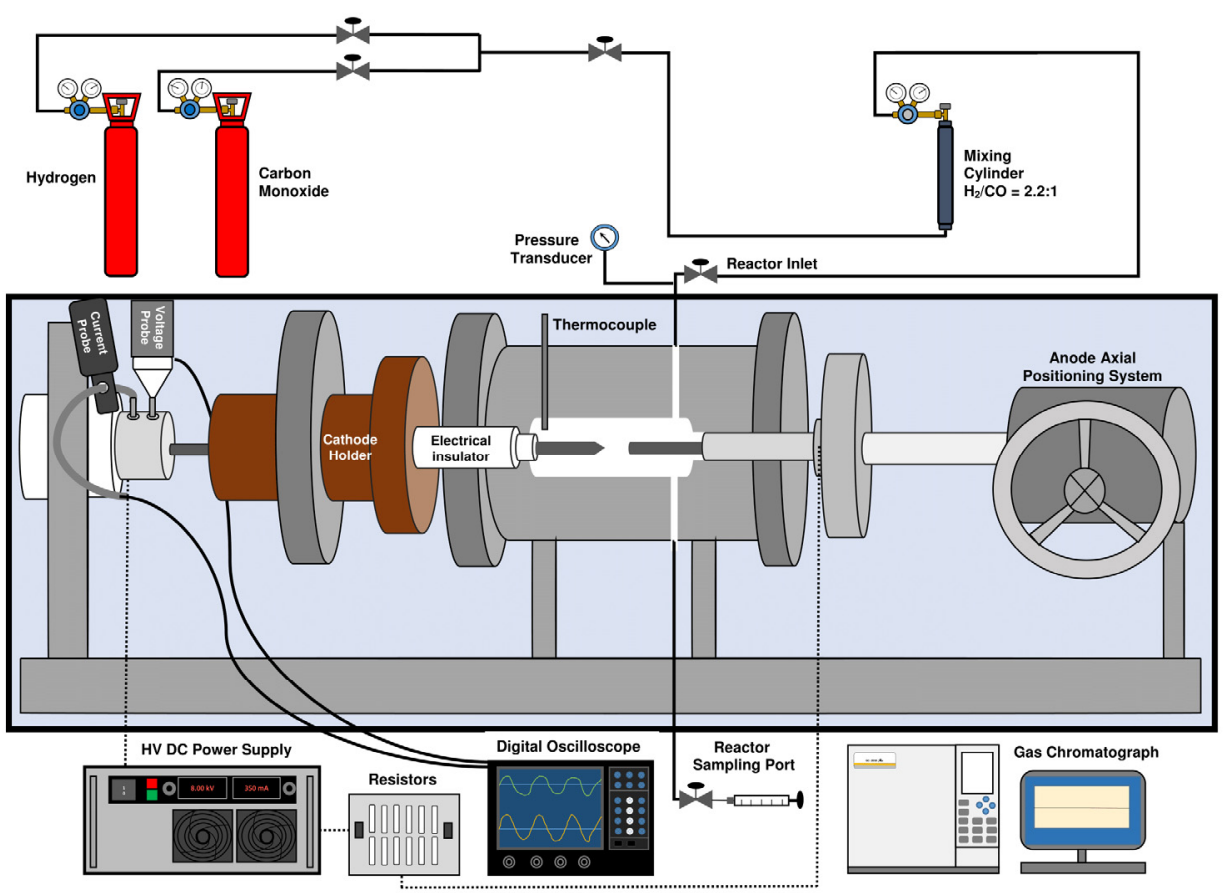

Figure 25. Schematic of the high pressure arc discharge reactor used in this study [9].

A high voltage DC power supply (Technix-SR-15-R-10,000 model, Technix, Créteil, France) was used to ignite the discharge between the electrodes. The cathode was attached to the negative polarity and the anode to the neutral point of the power supply, which had a maximum supply voltage of $10 \mathrm{kV}$ and current of $500 \mathrm{~mA}$. The operator could pre-set the current, whereas the power supply automatically self-adjusted the voltage. As a safety precaution, two $1 \mathrm{k} \Omega$ resistors were inserted in series between the power supply and reactor in order to limit the supply current. A similar power supply and its electrical design were previously described by Fulcheri et al. [1].

Apart from the reactor and power supply, the equipment setup incorporated peripheral equipment, which included a syngas mixing vessel and reactor feed system, a products sampling port, and control and data (temperature, pressure, voltage and current) acquisition tools (as illustrated in Figure 25).

\subsubsection{Reactor Experimental Procedure}

The $\mathrm{H}_{2}$ and $\mathrm{CO}$ reactant gases (both $99.999 \mathrm{~mol} \%$ purity)), acquired from Afrox (Durban, South Africa), were mixed to form syngas with a $\mathrm{H}_{2} / \mathrm{CO}$ ratio of 2.2:1. Composition analysis using a Shimadzu 2010 Plus gas chromatograph (Kyoto, Japan), prior to experiments, showed that only methane (up to $15 \mathrm{ppm}$ ) was present as an impurity in the syngas. Before every experiment, the reactor was purged with helium and evacuated using an Edwards vacuum pump in order to remove product impurities from previous experiments.

After purging, the syngas mixture was delivered to the reactor at the desired operating pressure (between 0.5 and $10 \mathrm{MPa}$ ). The mobile electrode (anode) was then moved along an axial axis, using a positioning system, until it contacted the fixed electrode (cathode). 
Electrode continuity was confirmed by a multimeter. Direct tip-to-plane contact of the electrodes was compulsory in order to reduce the gas resistivity and overcome the restrictions enforced by Paschen's Law under the low current $(\leq 450 \mathrm{~mA})$ and high pressure $(\geq 1 \mathrm{MPa})$ operating conditions.

Subsequent to electrode contact, the high voltage DC power supply was switched on. The power supply was pre-set to the required supply current (between 250 and $450 \mathrm{~mA}$ ) and ignition voltage $(8 \mathrm{kV})$. Once the power supply was activated, the mobile anode was immediately retracted from the fixed cathode, instantaneously forming a luminous arc discharge. The anode was retracted until an inter-electrode gap of $1 \mathrm{~mm}$ (between the electrodes) was acquired. The discharge was maintained at this electrode gap, at which syngas treatment proceeded for a pre-determined period of either 10 or $60 \mathrm{~s}$. After this discharge period, the power supply was switched off, instantaneously extinguishing the arc discharge. As a safety measure, an insulated copper wire was utilized to transmit residual charge from the arc discharge reactor to ground.

Thereafter, the products were sampled from the reactor and analyzed off-line using a Shimadzu 2010 Plus Gas Chromatograph (Kyoto, Japan). The GC was fitted with a thermal conductivity detector (TCD), calibrated to detect $\mathrm{CO}$ and $\mathrm{H}_{2}$, and a flame ionization detector (FID), calibrated to detect $C_{1}$ to $C_{3}$ hydrocarbons using the same GC operating parameters previously reported in literature [9]. A standard method in literature [9] was followed to determine the hydrocarbon product concentrations via the following equations:

$$
\begin{aligned}
\mathrm{n}_{\mathrm{i}}(\text { mols })= & (\text { GC Calibration slope })_{\mathrm{i}} \times(\text { GC peak area })_{\mathrm{i}} \\
\mathrm{C}_{\mathrm{i}}(\mathrm{ppm})= & \left(\frac{\mathrm{n}_{\mathrm{i}}}{\sum_{\mathrm{i}=1}^{\mathrm{tot}} \mathrm{n}_{\mathrm{i}}+\mathrm{n}_{\mathrm{CO}}+\mathrm{n}_{\mathrm{H} 2}}\right) \times 1,000,000 \mathrm{ppm} \\
& \mathrm{C}_{\mathrm{i}, \text { prod }}(\mathrm{ppm})=\mathrm{C}_{\mathrm{i}, \text { final }}-\mathrm{C}_{\mathrm{i}, \text { initial }}
\end{aligned}
$$

where i represents the $C_{1}-C_{3}$ hydrocarbon species, $C_{i}$ denotes the concentration of species $i$ present in the gas mixture prior to and after reaction, and $C_{i, p r o d}$ is the concentration of species i produced by the reaction.

The expanded experimental uncertainty $(U)$ of $\pm 11 \%$ for $C_{i, p r o d}$ was evaluated from the uncertainty contributions of two major error sources: sample measurement ( $\left.\mathrm{u}_{\mathrm{rep}}\right)$ and GC calibration ( $\left.\mathrm{u}_{\text {calib }}\right)$.

$$
\mathrm{U}(\mathrm{ppm})=\mathrm{f}\left(\mathrm{u}_{\text {rep }}, \mathrm{u}_{\text {calib }}\right) \approx \pm 11 \%
$$

The expanded uncertainties are signified by the vertical error bars in the concentration versus operating parameter (pressure, current or inter-electrode gap) plots.

\subsubsection{Reactor Energy Analysis}

The electrical energy efficiency for plasma-catalytic FTS, in conjunction with product yields, were used to determine the optimal operating conditions. The energy efficiency of each system was assessed from the current and voltage. A current of $350 \mathrm{~mA}$ was used for the pressure and inter-electrode variation studies, but was varied for the current study. The ignition voltage was fixed at $8 \mathrm{kV}$ for all parametric studies. The voltage, much higher than the breakdown voltage, was set as a precautionary measure in the event of a voltage surge.

The constant-current direct current (DC) power supply automatically self-adjusted the voltage between the electrodes throughout the discharge period. This maintained the current at its original setpoint. The varying voltage signal (consisting of up to 10,000 and 60,000 voltage values at 10 and $60 \mathrm{~s}$ respectively) were recorded using a digital oscilloscope. These voltage signal values were used to calculate the average voltage using Equation (5) (also applicable to the average current $\left(\mathrm{I}_{\mathrm{avg}}\right)$ ).

$$
\mathrm{V}_{\mathrm{avg}}=\sum_{\mathrm{i}=1}^{\mathrm{n}} \frac{\mathrm{V}_{\exp }}{\mathrm{n}}
$$


where $\mathrm{V}_{\text {avg }}$ is the voltage attained from the oscilloscope response data, and $\mathrm{n}$ is the number of voltage value between 10,000 and 60,000 at 10 and 60 s respectively.

Furthermore, the average voltage and voltage signal, comprised of 60,000 voltage values for the $60 \mathrm{~s}$ study, were used to determine the voltage error $\left(\mathrm{V}_{\mathrm{err}}(\%)\right)$ for each operating parameter setpoint (pressure, current and inter-electrode), using equations 6 and 7 . The average voltage error, describing the fluctuations in the voltage signal, was used to assess the arc stability.

$$
\begin{gathered}
\sigma_{\mathrm{V}}=\sqrt{\frac{\sum_{1}^{\mathrm{n}}\left|\mathrm{V}-\mathrm{V}_{\mathrm{avg}}\right|^{2}}{\mathrm{n}}} \\
\mathrm{V}_{\mathrm{err}}(\%)=\left(\sigma_{\mathrm{V}} / \mathrm{V}_{\mathrm{avg}}\right) \times 100 \%
\end{gathered}
$$

where $\mathrm{V}$ is the voltage attained from the oscilloscope response data, $\mathrm{n}$ refers to 60,000 voltage values for the $60 \mathrm{~s}$ study, $\mathrm{V}_{\mathrm{avg}}$ is the rms voltage, and $\sigma_{\mathrm{V}}$ is the standard deviation error.

The average voltage $\left(\mathrm{V}_{\text {avg }}\right)$, representative of the gas breakdown voltage when the electrodes were in contact (for negligible gas resistivity), was used with the average current to determine the energy consumption. Energy was evaluated in the form of the specific input energy (SIE), input energy required per mole of syngas, and the specific required energy (SRE), energy required to produce a mole of methane (the main synthesis product) as previously reported in the literature [9].

$$
\begin{gathered}
\mathrm{E}(\mathrm{kJ})=\mathrm{V}_{\text {avg }} \mathrm{I}_{\text {avg }} \Delta \mathrm{t} \\
\mathrm{SIE}\left(\mathrm{kJ} / \mathrm{n}_{\text {syngas }}\right)=\frac{\mathrm{E}}{\mathrm{n}_{\text {syngas }}}, \text { where } \mathrm{n}_{\text {syngas }}=\frac{\mathrm{PV}_{\text {reactor }}}{\mathrm{RT}} \\
\operatorname{SIE}\left(\mathrm{kJ} / \mathrm{n}_{\mathrm{CH}_{4, \text { produced }}}\right)=\frac{\mathrm{E}}{\mathrm{n}_{\mathrm{CH}_{4, \text { after }}}-\mathrm{n}_{\mathrm{CH}_{4, \text { before }}}}
\end{gathered}
$$

where $\mathrm{V}_{\text {avg }}$ and $\mathrm{I}_{\mathrm{avg}}$ denote the average voltage and current, respectively; $\Delta \mathrm{t}$ is the discharge period of 10 or $60 \mathrm{~s}$; $E$ is the electrical energy delivered by the power supply to ignite the arc discharge; $\mathrm{n}_{\text {syngas }}$ is the moles of syngas, which is a function of the universal gas constant $(\mathrm{R})$, syngas volume $\left(\mathrm{V}_{\text {reactor }}\right)$, pressure $(\mathrm{P})$, and (room) temperature $(\mathrm{T})$; and finally, $\mathrm{n}_{\mathrm{CH} 4}$ is the concentration of methane in the reactor before and after the discharge period.

All the plasma-catalytic FTS processes utilized the experimental apparatus and procedure discussed above. The preparation and configuration of the catalyst within the reactor are discussed in Section 3.2.

\subsection{Catalyst Preparation}

\subsubsection{Catalyst Design and Configuration}

$\mathrm{A} \mathrm{Co} / \mathrm{Al}_{2} \mathrm{O}_{3}$ catalyst, representative of an industrial Fischer-Tropsch synthesis (FTS) catalyst, was used in plasma-catalytic FTS. Due to several factors, namely the high temperature $(10,000$ to $20,000 \mathrm{~K})$ of the arc discharge [105] (contrasting with its ambient bulk gas), the low reactor volume $\left(2.56 \mathrm{~cm}^{3}\right)$, and a labyrinth of internal reactor components (electrodes and electrode insulators), the catalyst could not be inserted into the reactor according to the conventional plasma-catalytic (DBD or corona discharge) methods. In these atmospheric pressure discharge reactors, a catalyst, prepared in various forms [55,64,106,107], is usually inserted into the reactor via two different configurations, namely, in plasmacatalysis (IPC) $[23,49,108-112]$ or post-plasma catalysis (PPC) $[23,109,110]$.

In lieu of the complexities of the arc discharge reactor, an alternate catalyst configuration was implemented. The reactor catalyst configuration utilized in the gliding arc discharge reactor $[113,114]$, in which active cobalt is coated onto a ceramic substrate and positioned near (but not directly contacting) the discharge, was adapted for this work. This configuration was combined with the catalyst preparation method used for preparing monolithic catalysts [69,115-122]. 
The combination of these methods resulted in a catalyst consisting of a pre-formed LINE-OX $^{\circledR}$ (CERadvance Engineering Ceramics Pty Ltd., Pretoria, South Africa) porous mullite (sintered $72 \mathrm{wt} \%-\mathrm{Al}_{2} \mathrm{O}_{3} / \mathrm{SiO}_{2}$ ) ceramic substrate, coated with $\gamma-\mathrm{Al}_{2} \mathrm{O}_{3}$ (high surface area support) and cobalt (active FTS material).

The mullite substrate design, illustrated in Figure 26, enabled the mobile anode to axially move and freely contact the fixed cathode within the annulus of the catalyst whilst preventing direct contact of the electrodes and arc discharge with the catalyst's inner surface, as illustrated in Figure 27. This was achieved due to a sufficient clearance of approximately $1.5 \mathrm{~mm}$ between the catalyst's inner surface and electrodes' outer surfaces, and approximately $3.5 \mathrm{~mm}$ between the catalyst's inner surface and cathode tip (where the arc originated). Other design factors were also considered: firstly, the catalyst substrate fitted precisely into the reactor chamber due to an outer diameter of $\sim 12 \mathrm{~mm}$ (dimensions shown in Figure 26), which also provided adequate radial support at high pressures (0.5 to $10 \mathrm{MPa}$ ); secondly, face-to-face perforations of $5 \mathrm{~mm}$, aligned with the two circular sight glasses of the reactor, permitting visualization of the arc discharge; and finally, three $2.5 \mathrm{~mm}$ semi-circular cut-outs (wedges) at the boundaries of the substrate, housing the thermocouple line, and reactor inlet and outlet (sampling) lines.

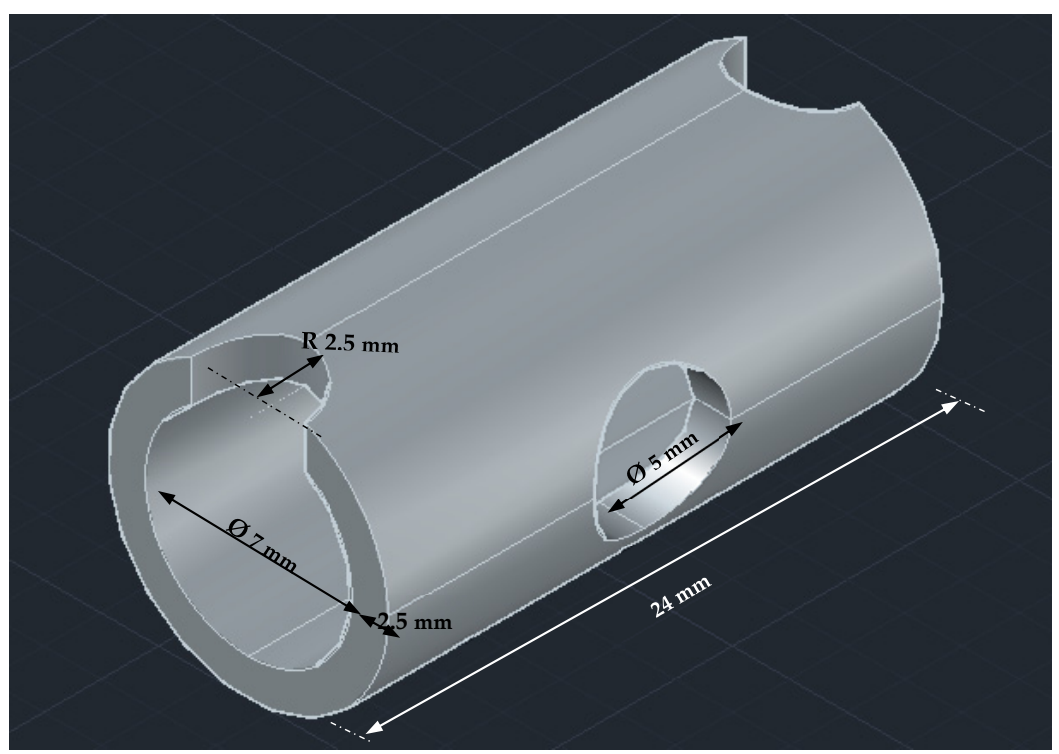

Figure 26. SW Isometric view of the LINE-OX ${ }^{\circledR}$ porous mullite substrate.

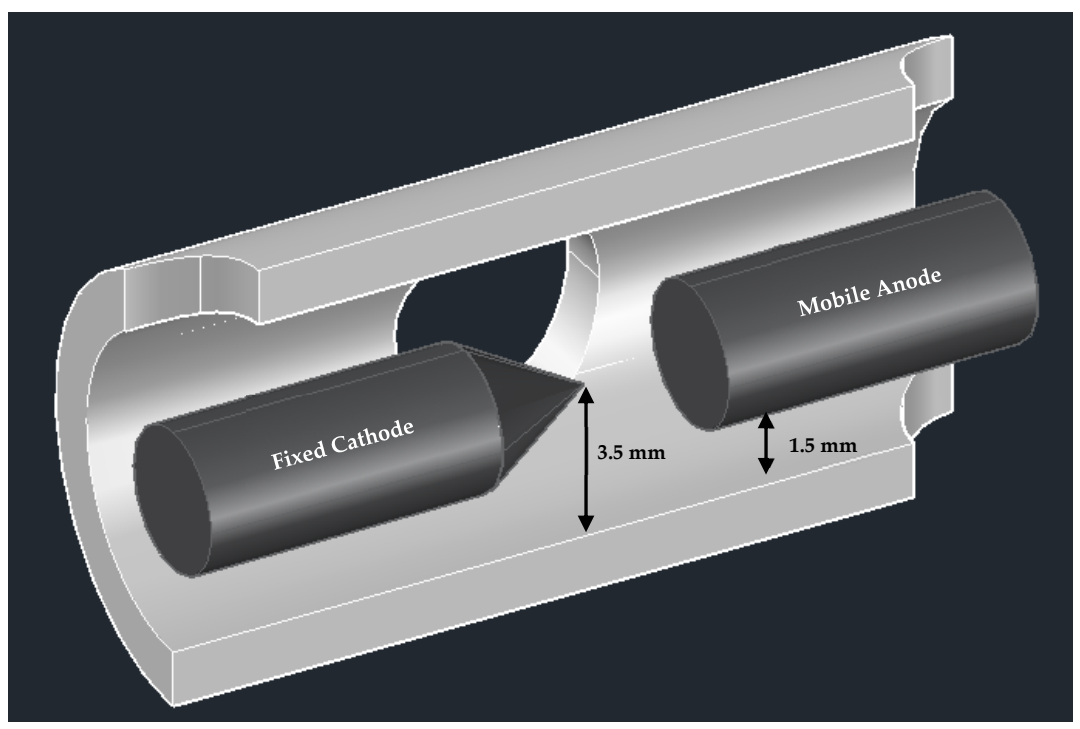

Figure 27. Isometric cross-sectional view of the LINE-OX ${ }^{\circledR}$ porous mullite substrate with electrodes. 
Mullite was considered as a more suitable substrate material for this application (instead of the commonly used cordierite), due to its excellent thermo-physical properties (listed in Table 3): thermal stability [123], mechanical strength [123], porous structure, electrical resistivity [124], and the availability of oxygen vacancies [125]. Mullite as a catalyst support, has been used in limited applications [126-128].

Table 3. Thermo-mechanical properties of mullite supplied by Ceradvance Engineering Ceramics.

\begin{tabular}{cccc}
\hline \multicolumn{2}{c}{ Mechanical } & \multicolumn{2}{c}{ Thermal } \\
\hline Alumina content & $72 \mathrm{wt} \%$ & Max. temperature & $1400^{\circ} \mathrm{C}$ \\
Other constituents & Silica (bound) & Thermal conductivity & $5 \mathrm{Wm}^{-1} \mathrm{~K}^{-1}$ \\
Bulk density & $2.7-2.8 \mathrm{~g} / \mathrm{cm}^{3}$ & Thermal expansion: & \\
Porosity & $15 \%$ & at $400^{\circ} \mathrm{C}$ & $4.68 \times 10^{-6}{ }^{\circ} \mathrm{C}^{-1}$ \\
Water absorption & $6-8 \%$ & at $800^{\circ} \mathrm{C}$ & $5.54 \times 10^{-6}{ }^{\circ} \mathrm{C}^{-1}$ \\
Modulus of rupture & $100 \mathrm{MPa}$ & at $1000^{\circ} \mathrm{C}$ & $5.88 \times 10^{-6}{ }^{\circ} \mathrm{C}^{-1}$ \\
Modulus of elasticity & $140 \mathrm{GPa}$ & - & - \\
\hline
\end{tabular}

\subsubsection{Catalyst Preparation Procedure}

$\mathrm{Al}_{2} \mathrm{O}_{3}$ and Cobalt were coated in succession onto the surface of a pre-formed LINE$\mathrm{OX}^{\circledR}$ porous mullite substrate, manufactured by Ceradvance Engineering Ceramics (Pretoria, South Africa). Successive coatings, as opposed to coating a mixture of $\mathrm{Co} / \mathrm{Al}_{2} \mathrm{O}_{3}$, was shown to produce higher conversions and $\mathrm{C}_{5+}$ selectivity in classical FTS using a monolithic reactor [69].

The $\gamma-\mathrm{Al}_{2} \mathrm{O}_{3}$ was coated using the washcoating method developed by Villegas et al. [129]. Thereafter, cobalt was deposited using the preparation technique for coating monoliths in FTS $[69,115,118,119,121,130]$. Both methods were modified for this application.

For the first coating layer, the $\gamma-\mathrm{Al}_{2} \mathrm{O}_{3}$ powder $(3 \mu \mathrm{m}$ average particle size procured from Alpha-Aesar, Haverhill, Massachusetts, United States) was added to water to form a slurry $\left(\mathrm{Al}_{2} \mathrm{O}_{3} / \mathrm{H}_{2} \mathrm{O}=25 \mathrm{wt} \%\right)$. Nitric acid $\left(\mathrm{HNO}_{3} / \mathrm{Al}_{2} \mathrm{O}_{3}=2.2 \mathrm{~mol} . \mathrm{g}^{-1}\right)$ was added to assist alumina dispersion. The slurry was mixed for $15 \mathrm{~h}$ at room temperature using a magnetic stirrer. A mullite substrate was dipped vertically into the slurry for $15 \mathrm{~min}$. After this immersion period, compressed air was utilized to remove the excess slurry. The alumina-coated substrate was dried in a static furnace for $15 \mathrm{~min}$ at $600{ }^{\circ} \mathrm{C}$. Finally, the substrate was weighed. The coating procedure (dipping and drying) was repeated until a $5 \mathrm{wt} \% \gamma-\mathrm{Al}_{2} \mathrm{O}_{3}$ washcoat was obtained. The $5 \mathrm{wt} \% \gamma-\mathrm{Al}_{2} \mathrm{O}_{3}$ coated onto mullite (and not containing cobalt), was referred to as the blank catalyst. The blank was used as a control study to determine the contribution of cobalt loading in plasma-catalytic FTS.

For the cobalt-based catalyst, the alumina-coated mullite substrate was dipped for $15 \mathrm{~min}$ in a cobalt nitrate hexahydrate $\mathrm{Co}\left(\mathrm{NO}_{3}\right)_{2} \cdot 6 \mathrm{H}_{2} \mathrm{O}$ solution (procured from Sigma Aldrich ${ }^{\circledR}$, Johannesburg, South Africa). The excess solution was removed using compressed air. The cobalt-dip-coated substrate was dried in an oven at $120{ }^{\circ} \mathrm{C}$ for up to $60 \mathrm{~min}$ and weighed. This was followed by calcination of the substrate in air at $450{ }^{\circ} \mathrm{C}$ for $4 \mathrm{~h}$, and ex-situ reduction at $350{ }^{\circ} \mathrm{C}$ for $3 \mathrm{~h}$ using $30 \mathrm{~mL} \cdot \mathrm{min}^{-1}$ of pure hydrogen. Thereafter, the catalyst was immediately weighed and configured in the discharge chamber of the reactor. The final catalyst was comprised of $6 \mathrm{wt} \%-\mathrm{Co} / 5 \mathrm{wt} \%-\gamma-\mathrm{Al}_{2} \mathrm{O}_{3}$.

The blank, $2 \mathrm{wt} \%$, and $6 \mathrm{wt} \%$ Co catalysts were retained in the reactor chamber for the entire duration of the pressure, current and inter-electrode gap variation investigations (exceeding 40 experiments). Thereafter, the pressure variation study was repeated at various pressures, especially at $2 \mathrm{MPa}$, thus ensuring experimental repeatability. The experimental repeatability indicates a relatively stable catalyst in the short-term-an expected benefit of this non-thermal plasma system is a shorter reaction time than conventional FTS. However, further research is required to confirm long-term catalyst stability. 


\subsection{Catalyst Characterisation}

Scanning electron microscopy (SEM), energy dispersive x-ray (EDX), transmission electron microscopy (TEM) and $\mathrm{x}$-ray diffraction (XRD) were used to characterize the $6 \mathrm{wt} \%$ $\mathrm{Co} / 5 \mathrm{wt} \%-\mathrm{Al}_{2} \mathrm{O}_{3}$ mullite catalyst.

For SEM imaging, the coated mullite substrate was fragmented into smaller pieces that were able to fit onto the SEM stage. Prior to analysis, the fragments were gold coated using a Quorum Tech Q150RES sputter coater (Quorum Technologies, East Sussex, UK). The catalyst was imaged using a Zeiss Ultra Plus FEG instrument (Carl Zeiss AG, Oberkochen, Germany) combined with the SmartSEM image capture software. Images were captured at a maximum magnification of 30 000. Elemental analysis was undertaken by coupling SEM with an EDX instrument-an Oxford X-Max 80 mm SDD instrument (Oxford Instruments, High Wycombe, United Kingdom) with Aztec analysis software.

The mullite coated substrate was milled into a fine powder for TEM analysis. The powder was mixed with ethanol to form a solution, which was then sonicated. The sonicated solution was dispersed onto an Agar 200 mesh copper grid for analysis by a JEOL JEM-1010 TEM instrument (JEOL Ltd., Tokyo, Japan). A final powdered catalyst sample was analysed using a Panalytical Empyrean x-ray powder diffractometer (XRD) fitted with a Co-K $\alpha$ radiation source (Malvern Panalytical technologies, Worcestershire, United Kingdom).

\section{Conclusions}

In this work, the influences of different cobalt loadings on the product yields and energy consumption for plasma-catalytic Fischer Tropsch synthesis (FTS) were explored. The blank, $2 \mathrm{wt} \%$, and $6 \mathrm{wt} \%$ Co catalyst systems produced $\mathrm{C}_{1}-\mathrm{C}_{3}$ hydrocarbons, with yields in the order: methane $>>$ ethane $>$ ethylene $>$ propane. The product concentration results indicated that the highest cobalt loading of $6 \mathrm{wt} \%$ achieved higher $C_{1}-C_{3}$ hydrocarbons yields than the other systems: $6 \mathrm{wt} \% \mathrm{Co}>2 \mathrm{wt} \% \mathrm{Co}>$ blank. In addition to higher yields, the $6 \mathrm{wt} \%$ Co also led to higher olefinicity, improved $C_{2}$ and $C_{3}$ chain growth, higher energy efficiencies (lower specific required energy (SRE)), and exclusively produced propylene and carbon nanotubes (detected using transmission electron microscopy (TEM)). Furthermore, TEM and scanning electron microscopy (SEM) showed that the $6 \mathrm{wt} \%$ Co catalyst provided a larger active cobalt surface area for synthesis, hence the higher yields. These findings suggest that syngas, apart from reacting in the arc core, also reacted on the $6 \mathrm{wt} \%$ Co catalyst surface. These catalytic surface reactions may have occurred via various reaction schemes: (i) the plasma (species) thermally activated the catalyst (without external heating), encouraging the adsorption of $\mathrm{H}_{2}$ and $\mathrm{CO}$ ground state molecules and/or (ii) plasma-dissociated $\mathrm{CO}$ (in the form of radicals and vibrationally-excited $\mathrm{CO}$ ) interacted with the catalyst at lower temperatures than that required in conventional FTS.

In contrast to the $2 \mathrm{wt} \%$ and $6 \mathrm{wt} \%$ cobalt-based catalysts, the blank catalyst led to significantly lower $C_{1}-C_{3}$ hydrocarbon yields than the other systems, which was related to the absence of cobalt and presence of $\mathrm{Al}_{2} \mathrm{O}_{3}$ and mullite in the catalyst leading to alternate reaction pathways. Due to providing the largest treatment volume, the interelectrode gap of $2 \mathrm{~mm}$ was the most effective operating parameter for improving FTS performance, trailed by current and pressure. At a gap of $2 \mathrm{~mm}$, using the $6 \mathrm{wt} \%$ Co catalyst-a combination that produced the highest yields in this work, the methane, ethane, ethylene and propane yields of $22424(2.24 \mathrm{~mol} \%), 517,101$ and $79 \mathrm{ppm}$, respectively, were $1.5,1.5,0.8$ and 4 times greater than the $2 \mathrm{wt} \%$ Co catalyst yields, and 558, 543, 436 and 2453 times greater than the blank catalyst yields. Additionally, at $2 \mathrm{~mm}$, the $6 \mathrm{wt} \%$ Co catalyst (SRE $=265 \mathrm{MJ} /$ molmethane, prod) used marginally higher energy than the $2 \mathrm{wt} \%$ Co catalyst (SRE $=224 \mathrm{MJ} /$ molmethane, prod), but $\sim 660$ times less energy to produce a mole of methane than the blank catalyst (SRE $=174451 \mathrm{MJ} /$ molmethane, prod).

Overall, the $6 \mathrm{wt} \%$ Co catalyst, the most effective catalyst, produced the highest yields and consumed relatively less energy at the following conditions: (i) $1 \mathrm{MPa}$ and $10 \mathrm{MPa}$, the latter pressure being the most favourable for $\mathrm{C}_{2}$ hydrocarbon production, 
for the pressure variation study at $10 \mathrm{~s}(0.5$ to $10 \mathrm{MPa}) ; 2 \mathrm{MPa}$ (most favourable for $\mathrm{C}_{2}$ hydrocarbon production) for the pressure variation study at $60 \mathrm{~s}(0.5$ to $10 \mathrm{MPa}$ ); (ii) $250 \mathrm{~mA}$ for the current variation study ( 250 to $450 \mathrm{~mA}$ ), due to this lower current generating a more non-equilibrium plasma; and (iii) the widest discharge gap of $2 \mathrm{~mm}$ for the inter-electrode gap variation study ( 0.5 to $2 \mathrm{~mm}$ ), as this gap produced the greatest discharge volume, which, in turn, interacted with a larger fractional area of the catalyst.

This study revealed the positive influence of tripling the cobalt loading (from 2 to $6 \mathrm{wt} \%$ ) on plasma-catalytic FTS, and provided evidence as to why the use of a mullite substrate coated with only $\gamma-\mathrm{Al}_{2} \mathrm{O}_{3}$ is not recommended for plasma-catalytic FTS. This merit the investigation of higher loadings in the range of conventional FTS, which is typically between 10 and $40 \mathrm{wt} \%$ [58].

Author Contributions: For Conceptualization, B.B.G. and S.A.I.; methodology, B.B.G. and S.A.I.; validation, B.B.G., S.A.I. and D.R.; formal analysis, B.B.G.; investigation, B.B.G.; data curation, B.B.G.; writing—original draft preparation, B.B.G.; writing—review and editing, S.A.I.; supervision, S.A.I. and D.R.; funding acquisition, D.R. All authors have read and agreed to the published version of the manuscript.

Funding: This research was supported by the Department of Science and Technology (DST) and the National Research Foundation (NRF) through the South African Research Chair Initiative for Fluorine Process Engineering and Separation Technology present at the University of KwaZulu-Natal, South Africa at the time of the study.

Data Availability Statement: The processed data that support our conclusions are contained in this article.

Acknowledgments: The authors wish to thank the Microscopy and Microanalysis Unit (MMU) at the University of KwaZulu-Natal (South Africa) for the SEM-EDX.

Conflicts of Interest: The authors declare no conflict of interest. The funders had no role in the design of the study; in the collection, analyses, or interpretation of data; in the writing of the manuscript, or in the decision to publish the results.

\section{References}

1. Fulcheri, L.; Rohani, V.; Fabry, F.; Traisnel, N. Experimental electrical characterization of a low-current tip-tip arc discharge in helium atmosphere at very high pressure. Plasma Sources Sci. Technol. 2010, 19, 045010. [CrossRef]

2. Rohani, V.; Iwarere, S.; Fabry, F.; Mourard, D.; Izquierdo, E.; Ramjugernath, D.; Fulcheri, L. Experimental study of hydrocarbons synthesis from syngas by a tip-tip electrical discharge at very high pressure. Plasma Chem. Plasma Process. 2011, 31, 663-679. [CrossRef]

3. Iwarere, S.; Rohani, V.; Ramjugernath, D.; Fabry, F.; Fulcheri, L. Hydrocarbons synthesis from syngas by very high pressure plasma. Chem. Eng. J. 2014, 241, 1-8. [CrossRef]

4. Iwarere, S.A.; Rohani, V.-J.; Ramjugernath, D.; Fulcheri, L. Dry reforming of methane in a tip-tip arc discharge reactor at very high pressure. Int. J. Hydrogen Energy 2015, 40, 3388-3401. [CrossRef]

5. Iwarere, S.A.; Lebouvier, A.; Fulcheri, L.; Ramjugernath, D. Experimental study on the formation of higher fluorocarbons from $\mathrm{CF}_{4}$ by a tip-tip electrical arc discharge at very high pressure. J. Fluor. Chem. 2014, 166, 96-103. [CrossRef]

6. Al-Harrasi, W.S.; Zhang, K.; Akay, G. Process intensification in gas-to-liquid reactions: Plasma promoted Fischer-Tropsch synthesis for hydrocarbons at low temperatures and ambient pressure. Green Process. Synth. 2013, 2, 479-490. [CrossRef]

7. Li, D.; Rohani, V.; Fabry, F.; Ramaswamy, A.P.; Sennour, M.; Fulcheri, L. Experimental study on plasma-catalytic synthesis of hydrocarbons from syngas. Appl. Catal. A Gen. 2019, 588, 117269. [CrossRef]

8. Akay, G.; Zhang, K.; Al-Harrasi, W.S.S.; Sankaran, R.M. Catalytic Plasma Fischer-Tropsch Synthesis Using Hierarchically Connected Porous $\mathrm{Co} / \mathrm{SiO}_{2}$ Catalysts Prepared by Microwave-Induced Co-assembly. Ind. Eng. Chem. Res. 2020, 59, 12013-12027. [CrossRef]

9. Govender, B.B.; Iwarere, S.A.; Ramjugernath, D. Plasma-Catalytic Fischer-Tropsch Synthesis at Very High Pressure. Catalysts 2021, 11, 297. [CrossRef]

10. Chu, W.; Wang, L.-N.; Chernavskii, P.A.; Khodakov, A.Y. Glow-Discharge Plasma-Assisted Design of Cobalt Catalysts for Fischer-Tropsch Synthesis. Angew. Chem. Int. Ed. 2008, 47, 5052-5055. [CrossRef]

11. Aluha, J.; Bere, K.; Abatzoglou, N.; Gitzhofer, F. Synthesis of nano-catalysts by induction suspension plasma technology (SPS) for Fischer-Tropsch reaction. Plasma Chem. Plasma Process. 2016, 36, 1325-1348. [CrossRef]

12. Aluha, J.; Braidy, N.; Dalai, A.; Abatzoglou, N. Low-temperature Fischer-Tropsch synthesis using plasma-synthesised nanometric $\mathrm{Co} / \mathrm{C}$ and $\mathrm{Fe} / \mathrm{C}$ catalysts. Can. J. Chem. Eng. 2016, 94, 1504-1515. [CrossRef] 
13. Aluha, J.; Gutierrez, S.; Gitzhofer, F.; Abatzoglou, N. Use of Plasma-Synthesized Nano-Catalysts for CO Hydrogenation in Low-Temperature Fischer-Tropsch Synthesis: Effect of Catalyst Pre-Treatment. Nanomaterials 2018, 8, 822. [CrossRef] [PubMed]

14. Hong, J.; Du, J.; Wang, B.; Zhang, Y.; Liu, C.; Xiong, H.; Sun, F.; Chen, S.; Li, J. Plasma-Assisted Preparation of Highly Dispersed Cobalt Catalysts for Enhanced Fischer-Tropsch Synthesis Performance. ACS Catal. 2018, 8, 6177-6185. [CrossRef]

15. Aluha, J.; Gitzhofer, F.; Abatzoglou, N. Application of Plasma Technology in Fischer-Tropsch Catalysis for the Production of Synthetic Fuels. Recent Adv. Petrochem. Sci. 2018, 5, 555657.

16. Rethwisch, D.G.; Dumesic, J. Effect of metal-oxygen bond strength on properties of oxides. 1. Infrared spectroscopy of adsorbed carbon monoxide and carbon dioxide. Langmuir 1986, 2, 73-79. [CrossRef]

17. Tanabe, K. Solid acid and base catalysts. In Catalysis Science and Technology; Anderson, J.R., Boudart, M., Eds.; Springer: Berlin/Heidelberg, Germany, 1981; Chapter 5; Volume 2, pp. 231-273.

18. Pines, H.; Haag, W.O. Alumina: Catalyst and Support. I. Alumina, its Intrinsic Acidity and Catalytic Activity. J. Am. Chem. Soc. 1960, 82, 2471-2483. [CrossRef]

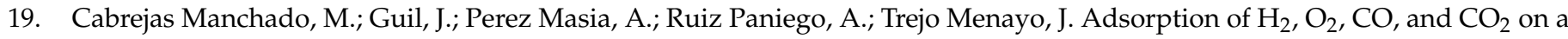
gamma.-Alumina: Volumetric and Calorimetric Studies. Langmuir 1994, 10, 685-691. [CrossRef]

20. Sun, H.; Page, M.I.; Atherton, J.H.; Hall, A. Kinetics of the conversion of methyl benzoate to benzamide by the alumina catalysed reaction with liquid ammonia at $120^{\circ} \mathrm{C}$. Catal. Sci. Techn. 2014, 4, 3870-3878. [CrossRef]

21. Liu, C.-j.; Vissokov, G.P.; Jang, B.W.-L. Catalyst preparation using plasma technologies. Catal. Today 2002, 72, 173-184. [CrossRef]

22. Roland, U.; Holzer, F.; Kopinke, F.-D. Combination of non-thermal plasma and heterogeneous catalysis for oxidation of volatile organic compounds: Part 2. Ozone decomposition and deactivation of $\gamma-\mathrm{Al}_{2} \mathrm{O}_{3}$. Appl. Catal. B Environ. 2005, 58, 217-226. [CrossRef]

23. Holzer, F.; Roland, U.; Kopinke, F.-D. Combination of non-thermal plasma and heterogeneous catalysis for oxidation of volatile organic compounds: Part 1. Accessibility of the intra-particle volume. Appl. Catal. B Environ. 2002, 38, 163-181. [CrossRef]

24. Roland, U.; Holzer, F.; Kopinke, F.-D. Improved oxidation of air pollutants in a non-thermal plasma. Catal. Today 2002, 73, 315-323. [CrossRef]

25. Morent, R.; Dewulf, J.; Steenhaut, N.; Leys, C.; Van Langenhove, H. Hybrid plasma-catalyst system for the removal of trichloroethylene in air. J. Adv. Oxid. Technol. 2006, 9, 53-58. [CrossRef]

26. Conner, W.C., Jr.; Falconer, J.L. Spillover in heterogeneous catalysis. Chem. Rev. 1995, 95, 759-788. [CrossRef]

27. Valero, M.C.; Raybaud, P. Cobalt Catalyzed Fischer-Tropsch Synthesis: Perspectives Opened by First Principles Calculations. Catal. Lett. 2013, 143, 1-17. [CrossRef]

28. Bhatelia, T.; Li, C.; Sun, Y.; Hazewinkel, P.; Burke, N.; Sage, V. Chain length dependent olefin re-adsorption model for FischerTropsch synthesis over $\mathrm{Co}-\mathrm{Al}_{2} \mathrm{O}_{3}$ catalyst. Fuel Process. Technol. 2014, 125, 277-289. [CrossRef]

29. Ogata, A.; Yamanouchi, K.; Mizuno, K.; Kushiyama, S.; Yamamoto, T. Decomposition of benzene using alumina-hybrid and catalyst-hybrid plasma reactors, Industry Applications. IEEE Trans. 1999, 35, 1289-1295.

30. Marques, R.; Da Costa, S.; Da Costa, P. Plasma-assisted catalytic oxidation of methane: On the influence of plasma energy deposition and feed composition. Appl. Catal. B Environ. 2008, 82, 50-57. [CrossRef]

31. Ma, W.; Jacobs, G.; Ji, Y.; Bhatelia, T.; Bukur, D.B.; Khalid, S.; Davis, B.H. Fischer-Tropsch synthesis: Influence of CO conversion on selectivities, $\mathrm{H}_{2} / \mathrm{CO}$ usage ratios, and catalyst stability for a Ru promoted $\mathrm{Co} / \mathrm{Al}_{2} \mathrm{O}_{3}$ catalyst using a slurry phase reactor. Top. Catal. 2011, 54, 757-767. [CrossRef]

32. Borg, Ø.; Eri, S.; Blekkan, E.A.; Storsæter, S.; Wigum, H.; Rytter, E.; Holmen, A. Fischer-Tropsch synthesis over $\gamma$-aluminasupported cobalt catalysts: Effect of support variables. J. Catal. 2007, 248, 89-100. [CrossRef]

33. Bukur, D.B.; Pan, Z.; Ma, W.; Jacobs, G.; Davis, B.H. Effect of CO conversion on the product distribution of a Co/ $\mathrm{Al}_{2} \mathrm{O}_{3}$ Fischer-Tropsch synthesis catalyst using a fixed bed reactor. Catal. Lett. 2012, 142, 1382-1387. [CrossRef]

34. Botes, F.G. Influences of water and syngas partial pressure on the kinetics of a commercial alumina-supported cobalt Fischer-Tropsch catalyst. Ind. Eng. Chem. Res. 2009, 48, 1859-1865. [CrossRef]

35. Van Der Laan, G.P.; Beenackers, A. Kinetics and selectivity of the Fischer-Tropsch synthesis: A literature review. Catal. Rev. 1999, 41, 255-318. [CrossRef]

36. Iglesia, E.; Reyes, S.C.; Madon, R.J.; Soled, S.L. Selectivity Control and Catalyst Design in the Fischer-Tropsch Synthesis: Sites, Pellets, and Reactors. In Advances in Catalysis; Eley, D., Pines, H., Weisz, P.B., Eds.; Academic Press: Cambridge, MA, USA, 1993.

37. Madon, R.J.; Iglesia, E.; Reyes, S.C. Non-Flory product distributions in Fischer-Tropsch synthesis catalyzed by Ruthenium, Cobalt, and Iron. In Selectivity in Catalysis; ACS Symposium Series; American Chemical Society: Washington, DC, USA, 1993.

38. Dinse, A.; Aigner, M.; Ulbrich, M.; Johnson, G.R.; Bell, A.T. Effects of Mn promotion on the activity and selectivity of Co/SiO 2 for Fischer-Tropsch Synthesis. J. Catal. 2012, 288, 104-114. [CrossRef]

39. Tavasoli, A.; Khodadadi, A.; Mortazavi, Y.; Sadaghiani, K.; Ahangari, M. Lowering methane and raising distillates yields in Fischer-Tropsch synthesis by using promoted and unpromoted cobalt catalysts in a dual bed reactor. Fuel Process. Technol. 2006, 87, 641-647. [CrossRef]

40. Komaya, T.; Bell, A.T. Estimates of rate coefficients for elementary processes occurring during Fischer-Tropsch synthesis over $\mathrm{RuTiO}_{2}$. J. Catal. 1994, 146, 237-248. [CrossRef]

41. Kuipers, E.; Scheper, C.; Wilson, J.; Vinkenburg, I.; Oosterbeek, H. Non-ASF product distributions due to secondary reactions during Fischer-Tropsch synthesis. J. Catal. 1996, 158, 288-300. [CrossRef] 
42. Eliasson, B.; Kogelschatz, U.; Xue, B.; Zhou, L.-M. Hydrogenation of Carbon Dioxide to Methanol with a Discharge-Activated Catalyst. Ind. Eng. Chem. Res. 1998, 37, 3350-3357. [CrossRef]

43. Li, M.-W.; Tian, Y.-L.; Xu, G.-H. Characteristics of Carbon Dioxide Reforming of Methane via Alternating Current (AC) Corona Plasma Reactions. Energy Fuels 2007, 21, 2335-2339. [CrossRef]

44. Nozaki, T.; Muto, N.; Kado, S.; Okazaki, K. Dissociation of vibrationally excited methane on Ni catalyst: Part 1. Application to methane steam reforming. Catal. Today 2004, 89, 57-65. [CrossRef]

45. Nozaki, T.; Muto, N.; Kadio, S.; Okazaki, K. Dissociation of vibrationally excited methane on Ni catalyst: Part 2. Process diagnostics by emission spectroscopy. Catal. Today 2004, 89, 67-74. [CrossRef]

46. Pietruszka, B.; Anklam, K.; Heintze, M. Plasma-assisted partial oxidation of methane to synthesis gas in a dielectric barrier discharge. Appl. Catal. A-Gen. 2004, 261, 19-24. [CrossRef]

47. Amouroux, J.; Cavadias, S.; Doubla, A. Carbon Dioxide reduction by non-equilibrium electrocatalysis plasma reactor. IOP Conf. Ser. Mater. Sci. Eng. 2011, 19, 012005. [CrossRef]

48. Nikoo, M.K.; Sharifi, M.A.; Amin, N.S. Carbon dioxide reforming of methane by catalytic-plasma reactor over $\mathrm{Cu} / \mathrm{Zn} / \gamma-\mathrm{Al}_{2} \mathrm{O}_{3}$. J. Teknol. Sci. Eng. 2011, 56, 75-86.

49. Chen, H.L.; Lee, H.M.; Chen, S.H.; Chang, M.B. Review of plasma catalysis on hydrocarbon reforming for hydrogen productionInteraction, integration, and prospects. Appl. Catal. B Environ. 2008, 85, 1-9. [CrossRef]

50. Wang, Q.; Yan, B.-H.; Jin, Y.; Cheng, Y. Dry reforming of methane in a dielectric barrier discharge reactor with $\mathrm{Ni}_{/} \mathrm{Al}_{2} \mathrm{O}_{3}$ catalyst: Interaction of catalyst and plasma. Energy Fuels 2009, 23, 4196-4201. [CrossRef]

51. Kappes, T.; Schiene, W.; Hammer, T. Energy balance of a Dielectric Barrier Discharge reactor for hydrocarbon steam reforming. In Proceedings of the HAKONE 8: International Symposium on High Pressure Low Temperature Plasma Chemistry, Puhajarve, Estonia, 21-25 July 2002.

52. Sobacchi, M.; Saveliev, A.; Fridman, A.; Kennedy, L.A.; Ahmed, S.; Krause, T. Experimental assessment of a combined plasma/catalytic system for hydrogen production via partial oxidation of hydrocarbon fuels. Int. J. Hydrogen Energy 2002, 27, 635-642. [CrossRef]

53. Li, M.-W.; Liu, C.-P.; Tian, Y.-L.; Xu, G.-H.; Zhang, F.-C.; Wang, Y.-Q. Effects of catalysts in carbon dioxide reforming of methane via corona plasma reactions. Energy Fuels 2006, 20, 1033-1038. [CrossRef]

54. Pham, M.; Goujard, V.; Tatibouet, J.; Batiot-Dupeyrat, C. Activation of methane and carbon dioxide in a dielectric-barrier dischargeplasma reactor to produce hydrocarbons-Influence of $\mathrm{La}_{2} \mathrm{O}_{3} / \gamma-\mathrm{Al}_{2} \mathrm{O}_{3}$ catalyst. Catal. Today 2011, 171, 67-71. [CrossRef]

55. Wallis, A.E.; Whitehead, J.; Zhang, K. The removal of dichloromethane from atmospheric pressure air streams using plasmaassisted catalysis. Appl. Catal. B Environ. 2007, 72, 282-288. [CrossRef]

56. Bodke, A.; Bharadwaj, S.; Schmidt, L. The effect of ceramic supports on partial oxidation of hydrocarbons over noble metal coated monoliths. J. Catal. 1998, 179, 138-149. [CrossRef]

57. Iglesia, E.; Reyes, S.C.; Madon, R.J. Transport-enhanced $\alpha$-olefin readsorption pathways in Ru-catalyzed hydrocarbon synthesis. J. Catal. 1991, 129, 238-256. [CrossRef]

58. Tavasoli, A.; Sadaghiani, K.; Nakhaeipour, A.; Ghalbi Ahangari, M. Cobalt Loading Effects on the Structure and Activity for Fischer-Tropsch and Water-gas Shift Reactions of $\mathrm{Co} / \mathrm{Al}_{2} \mathrm{O}_{3}$ Catalysts. Iran. J. Chem. Chem. Eng. 2007, 26, 9-16.

59. Yang, J.; Ma, W.; Chen, D.; Holmen, A.; Davis, B.H. Fischer-Tropsch synthesis: A review of the effect of CO conversion on methane selectivity. Appl. Catal. A Gen. 2014, 470, 250-260. [CrossRef]

60. Sinnott, S.; Andrews, R.; Qian, D.; Rao, A.; Mao, Z.; Dickey, E.; Derbyshire, F. Model of carbon nanotube growth through chemical vapor deposition. Chem. Phys. Lett. 1999, 315, 25-30. [CrossRef]

61. Kunhardt, E.E. Generation of large-volume, atmospheric-pressure, nonequilibrium plasmas. IEEE Trans. Plasma Sci. 2000, 28, 189-200. [CrossRef]

62. Staack, D.; Farouk, B.; Gutsol, A.; Fridman, A. Characterization of a dc atmospheric pressure normal glow discharge. Plasma Sources Sci. Technol. 2005, 14, 700. [CrossRef]

63. Fan, H.Y. The transition from glow discharge to arc. Phys. Rev. 1939, 55, 769. [CrossRef]

64. Van Durme, J.; Dewulf, J.; Sysmans, W.; Leys, C.; Van Langenhove, H. Efficient toluene abatement in indoor air by a plasma catalytic hybrid system. Appl. Catal. B Environ. 2007, 74, 161-169. [CrossRef]

65. Chen, H.L.; Lee, H.M.; Chen, S.H.; Chang, M.B.; Yu, S.J.; Li, S.N. Removal of Volatile Organic Compounds by Single-Stage and Two-Stage Plasma Catalysis Systems: A Review of the Performance Enhancement Mechanisms, Current Status, and Suitable Applications. Environ. Sci. Technol. 2009, 43, 2216-2227. [CrossRef]

66. Neyts, E.; Bogaerts, A. Understanding plasma catalysis through modelling and simulation-A review. J. Phys. D Appl. Phys. 2014, 47, 224010. [CrossRef]

67. Benilov, M.; Marotta, A. A model of the cathode region of atmospheric pressure arcs. J. Phys. D Appl. Phys. 1995, $28,1869-1882$. [CrossRef]

68. Benilov, M. Understanding and modelling plasma-electrode interaction in high-pressure arc discharges: A review. J. Phys. D Appl. Phys. 2008, 41, 144001. [CrossRef]

69. Bakhtiari, M.; Khorasheh, F.; Zamanian, A.; Nakhaeipour, A.; Irani, M. Preparation, Evaluation and Characterization of Monolithic Catalysts for Fischer-Tropsch Synthesis. Pet. Coal 2008, 50, 56-61. 
70. De la Pena O'Shea, V.A.; Alvarez-Galvan, M.; Campos-Martin, J.; Fierro, J. Strong dependence on pressure of the performance of a Co/SiO 2 catalyst in Fischer-Tropsch slurry reactor synthesis. Catal. Lett. 2005, 100, 105-116. [CrossRef]

71. Akay, G. Co-Assembled Supported Catalysts: Synthesis of Nano-Structured Supported Catalysts with Hierarchic Pores through Combined Flow and Radiation Induced Co-Assembled Nano-Reactors. Catalysts 2016, 6, 80. [CrossRef]

72. Cheng, D.-G. Plasma decomposition and reduction in supported metal catalyst preparation. Catal. Surv. Asia 2008, 12, 145-151. [CrossRef]

73. Cheng, D.-G.; Zhu, X.; Ben, Y.; He, F.; Cui, L.; Liu, C.-J. Carbon dioxide reforming of methane over $\mathrm{Ni} / \mathrm{Al}_{2} \mathrm{O}_{3}$ treated with glow discharge plasma. Catal. Today 2006, 115, 205-210. [CrossRef]

74. Zhang, Y.-P.; Ma, P.-S.; Zhu, X.; Liu, C.-J.; Shen, Y. A novel plasma-treated Pt/NaZSM-5 catalyst for NO reduction by methane. Catal. Commun. 2004, 5, 35-39. [CrossRef]

75. Jacobs, G.; Das, T.K.; Zhang, Y.; Li, J.; Racoillet, G.; Davis, B.H. Fischer-Tropsch synthesis: Support, loading, and promoter effects on the reducibility of cobalt catalysts. Appl. Catal. A Gen. 2002, 233, 263-281. [CrossRef]

76. Jacobs, G.; Patterson, P.M.; Zhang, Y.; Das, T.; Li, J.; Davis, B.H. Fischer-Tropsch synthesis: Deactivation of noble metal-promoted $\mathrm{Co} / \mathrm{Al}_{2} \mathrm{O}_{3}$ catalysts. Appl. Catal. A Gen. 2002, 233, 215-226. [CrossRef]

77. Abbaslou, R.M.M.; Tavassoli, A.; Soltan, J.; Dalai, A.K. Iron catalysts supported on carbon nanotubes for Fischer-Tropsch synthesis: Effect of catalytic site position. Appl. Catal. A Gen. 2009, 367, 47-52. [CrossRef]

78. Tavasoli, A.; Abbaslou, R.M.M.; Trepanier, M.; Dalai, A.K. Fischer-Tropsch synthesis over cobalt catalyst supported on carbon nanotubes in a slurry reactor. Appl. Catal. A Gen. 2008, 345, 134-142. [CrossRef]

79. Xiong, H.; Motchelaho, M.A.; Moyo, M.; Jewell, L.L.; Coville, N.J. Correlating the preparation and performance of cobalt catalysts supported on carbon nanotubes and carbon spheres in the Fischer-Tropsch synthesis. J. Catal. 2011, 278, 26-40. [CrossRef]

80. Trépanier, M.; Tavasoli, A.; Dalai, A.K.; Abatzoglou, N. Co, Ru and K loadings effects on the activity and selectivity of carbon nanotubes supported cobalt catalyst in Fischer-Tropsch synthesis. Appl. Catal. A Gen. 2009, 353, 193-202. [CrossRef]

81. Trépanier, M.; Tavasoli, A.; Dalai, A.K.; Abatzoglou, N. Fischer-Tropsch synthesis over carbon nanotubes supported cobalt catalysts in a fixed bed reactor: Influence of acid treatment. Fuel Process. Technol. 2009, 90, 367-374. [CrossRef]

82. Tavasoli, A.; Trépanier, M.; Abbaslou, R.M.M.; Dalai, A.K.; Abatzoglou, N. Fischer-Tropsch synthesis on mono-and bimetallic Co and Fe catalysts supported on carbon nanotubes. Fuel Process. Technol. 2009, 90, 1486-1494. [CrossRef]

83. Guczi, L.; Stefler, G.; Geszti, O.; Koppány, Z.; Kónya, Z.; Molnár, É.; Urbán, M.; Kiricsi, I. CO hydrogenation over cobalt and iron catalysts supported over multiwall carbon nanotubes: Effect of preparation. J. Catal. 2006, 244, 24-32. [CrossRef]

84. Bahome, M.C.; Jewell, L.L.; Padayachy, K.; Hildebrandt, D.; Glasser, D.; Datye, A.K.; Coville, N.J. Fe-Ru small particle bimetallic catalysts supported on carbon nanotubes for use in Fischer-Tröpsch synthesis. Appl. Catal. A Gen. 2007, 328, 243-251. [CrossRef]

85. Bezemer, G.; Van Laak, A.; Van Dillen, A.; De Jong, K. Cobalt supported on carbon nanofibers-a promising novel Fischer-Tropsch catalyst. Stud. Surf. Sci. Catal. 2004, 147, 259-264.

86. Eschemann, T.O.; Lamme, W.S.; Manchester, R.L.; Parmentier, T.E.; Cognigni, A.; Rønning, M.; de Jong, K.P. Effect of support surface treatment on the synthesis, structure, and performance of Co/CNT Fischer-Tropsch catalysts. J. Catal. 2015, 328, 130-138. [CrossRef]

87. Kumar, M.; Ando, Y. Chemical vapor deposition of carbon nanotubes: A review on growth mechanism and mass production. J. Nanosci. Nanotechnol. 2010, 10, 3739-3758. [CrossRef]

88. Meyyappan, M.; Delzeit, L.; Cassell, A.; Hash, D. Carbon nanotube growth by PECVD: A review. Plasma Sources Sci. Technol. 2003, 12, 205. [CrossRef]

89. Meyyappan, M. A review of plasma enhanced chemical vapour deposition of carbon nanotubes. J. Phys. D Appl. Phys. 2009, 42, 213001. [CrossRef]

90. Kuzmany, H.; Kukovecz, A.; Simon, F.; Holzweber, M.; Kramberger, C.; Pichler, T. Functionalization of carbon nanotubes. Synth. Met. 2004, 141, 113-122. [CrossRef]

91. Bell, M.S.; Teo, K.B.; Lacerda, R.G.; Milne, W.; Hash, D.B.; Meyyappan, M. Carbon nanotubes by plasma-enhanced chemical vapor deposition. Pure Appl. Chem. 2006, 78, 1117-1125. [CrossRef]

92. Hou, Y.; Tang, J.; Zhang, H.; Qian, C.; Feng, Y.; Liu, J. Functionalized few-walled carbon nanotubes for mechanical reinforcement of polymeric composites. ACS Nano 2009, 3, 1057-1062. [CrossRef] [PubMed]

93. Jeon, I.-Y.; Chang, D.W.; Kumar, N.A.; Baek, J.-B. Functionalization of Carbon Nanotubes. In Carbon Nanotubes-Polymer Nanocomposites; Yellampalli, D.S., Ed.; InTech: Rijeka, Croatia, 2011.

94. Prasek, J.; Drbohlavova, J.; Chomoucka, J.; Hubalek, J.; Jasek, O.; Adam, V.; Kizek, R. Methods for carbon nanotubes synthesisReview. J. Mater. Chem. 2011, 21, 15872-15884. [CrossRef]

95. Shi, H.; Barker, J.; Saidi, M.; Koksbang, R.; Morris, L. Graphite structure and lithium intercalation. J. Power Sources 1997, 68, 291-295. [CrossRef]

96. Nakamura, J.; Tanaka, K.-i.; Toyoshima, I. Reactivity of deposited carbon on $\mathrm{Co}_{-} \mathrm{Al}_{2} \mathrm{O}_{3}$ catalyst. J. Catal. 1987, 108, 55-62. [CrossRef]

97. Tan, K.F.; Xu, J.; Chang, J.; Borgna, A.; Saeys, M. Carbon deposition on Co catalysts during Fischer-Tropsch synthesis: A computational and experimental study. J. Catal. 2010, 274, 121-129. [CrossRef]

98. Keyvanloo, K.; Fisher, M.J.; Hecker, W.C.; Lancee, R.J.; Jacobs, G.; Bartholomew, C.H. Kinetics of deactivation by carbon of a cobalt Fischer-Tropsch catalyst: Effects of $\mathrm{CO}$ and $\mathrm{H}_{2}$ partial pressures. J. Catal. 2015, 327, 33-47. [CrossRef] 
99. Potoczna-Petru, D. The interaction of model cobalt catalysts with carbon. Carbon 1991, 29, 73-79. [CrossRef]

100. Lee, D.-K.; Lee, J.-H.; Ihm, S.-K. Effect of carbon deposits on carbon monoxide hydrogenation over alumina-supported cobalt catalyst. Appl. Catal. 1988, 36, 199-207. [CrossRef]

101. Deprez, N.; McLachlan, D. The analysis of the electrical conductivity of graphite conductivity of graphite powders during compaction. J. Phys. D Appl. Phys. 1988, 21, 101. [CrossRef]

102. Benilov, M.; Naidis, G. Modelling of low-current discharges in atmospheric-pressure air taking account of non-equilibrium effects. J. Phys. D Appl. Phys. 2003, 36, 1834. [CrossRef]

103. Kogelschatz, U. Atmospheric-pressure plasma technology. Plasma Phys. Control. Fusion 2004, 46, B63. [CrossRef]

104. Arkhipenko, V.; Kirillov, A.; Safronau, Y.A.; Simonchik, L.; Zgirouski, S. Self-sustained dc atmospheric pressure normal glow discharge in helium: From microamps to amps. Plasma Sources Sci. Technol. 2009, 18, 045013. [CrossRef]

105. Lebouvier, A.; Iwarere, S.A.; Ramjugernath, D.; Fulcheri, L. 3D magnetohydrodynamic modelling of a dc low-current plasma arc batch reactor at very high pressure in helium. J. Phys. D Appl. Phys. 2013, 46, 145203. [CrossRef]

106. Huang, H.; Ye, D.; Leung, D.Y.; Feng, F.; Guan, X. Byproducts and pathways of toluene destruction via plasma-catalysis. J. Mol. Catal. A Chem. 2011, 336, 87-93. [CrossRef]

107. Mizuno, A. Generation of non-thermal plasma combined with catalysts and their application in environmental technology. Catal. Today 2013, 211, 2-8. [CrossRef]

108. Whitehead, J.C. Plasma catalysis: A solution for environmental problems. Pure Appl. Chem. 2010, 82, 1329-1336. [CrossRef]

109. Kim, H.H. Nonthermal plasma processing for air-pollution control: A historical review, current issues, and future prospects. Plasma Process. Polym. 2004, 1, 91-110. [CrossRef]

110. Chang, M.B.; Lee, H.M. Abatement of perfluorocarbons with combined plasma catalysis in atmospheric-pressure environment. Catal. Today 2004, 89, 109-115. [CrossRef]

111. Yu, S.J.; Chang, M.B. Oxidative conversion of PFC via plasma processing with dielectric barrier discharges. Plasma Chem. Plasma Process. 2001, 21, 311-327. [CrossRef]

112. Chen, X.; Rozak, J.; Lin, J.-C.; Suib, S.L.; Hayashi, Y.; Matsumoto, H. Oxidative decomposition of chlorinated hydrocarbons by glow discharge in PACT (plasma and catalyst integrated technologies) reactors. Appl. Catal. A-Gen. 2001, 219, 25-31. [CrossRef]

113. Rueangitt, N.; Sreethawong, T.; Chavadej, S.; Sekiguchi, H. Non-oxidative reforming of methane in a mini-gliding arc discharge reactor: Effects of feed methane concentration, feed flow rate, electrode gap distance, residence time, and catalyst distance. Plasma Chem. Plasma Process. 2011, 31, 517-534. [CrossRef]

114. Rueangitt, N.; Sreethawong, T.; Chavadej, S.; Sekiguchi, H. Plasma-catalytic reforming of methane in AC microsized gliding arc discharge: Effects of input power, reactor thickness, and catalyst existence. Chem. Eng. J. 2009, 155, 874-880. [CrossRef]

115. Hilmen, A.-M.; Bergene, E.; Lindvåg, O.; Schanke, D.; Eri, S.; Holmen, A. Fischer-Tropsch synthesis on monolithic catalysts of different materials. Catal. Today 2001, 69, 227-232. [CrossRef]

116. Hilmen, A.-M.; Bergene, E.; Lindvåg, O.; Schanke, D.; Eri, S.; Holmen, A. Fischer-Tropsch synthesis using monolithic catalysts. Stud. Surf. Sci. Catal. 2000, 130, 1163-1168.

117. De Deugd, R.M.; Chougule, R.B.; Kreutzer, M.T.; Meeuse, F.M.; Grievink, J.; Kapteijn, F.; Moulijn, J.A. Is a monolithic loop reactor a viable option for Fischer-Tropsch synthesis? Chem. Eng. Sci. 2003, 58, 583-591. [CrossRef]

118. De Deugd, R.M.; Kapteijn, F.; Moulijn, J.A. Using monolithic catalysts for highly selective Fischer-Tropsch synthesis. Catal. Today 2003, 79, 495-501. [CrossRef]

119. Kapteijn, F.; de Deugd, R.M.; Moulijn, J. A Fischer-Tropsch synthesis using monolithic catalysts. Catal. Today 2005, 105, 350-356. [CrossRef]

120. Guettel, R.; Knochen, J.; Kunz, U.; Kassing, M.; Turek, T. Preparation and Catalytic Evaluation of Cobalt-Based Monolithic and Powder Catalysts for Fischer-Tropsch Synthesis. Ind. Eng. Chem. Res. 2008, 47, 6589-6597. [CrossRef]

121. Liu, W.; Hu, J.; Wang, Y. Fischer-Tropsch synthesis on ceramic monolith-structured catalysts. Catal. Today 2009, 140, 142-148. [CrossRef]

122. Avila, P.; Montes, M.; Miro, E.E. Monolithic reactors for environmental applications: A review on preparation technologies. Chem. Eng. J. 2005, 109, 11-36. [CrossRef]

123. Panneerselvam, M.; Rao, K. Novel microwave method for the synthesis and sintering of mullite from kaolinite. Chem. Mater. 2003, 15, 2247-2252. [CrossRef]

124. Chaudhuri, S.; Patra, S.; Chakraborty, A. Electrical resistivity of transition metal ion doped mullite. J. Eur. Ceram. Soc. 1999, 19, 2941-2950. [CrossRef]

125. Schneider, H.; Schreuer, J.; Hildmann, B. Structure and properties of mullite-A review. J. Eur. Ceram. Soc. 2008, 28, 329-344. [CrossRef]

126. Liguras, D.K.; Goundani, K.; Verykios, X.E. Production of hydrogen for fuel cells by catalytic partial oxidation of ethanol over structured Ni catalysts. J. Power Sources 2004, 130, 30-37. [CrossRef]

127. Zhao, X.; Cong, Y.; Lv, F.; Li, L.; Wang, X.; Zhang, T. Mullite-supported Rh catalyst: A promising catalyst for the decomposition of $\mathrm{N}_{2} \mathrm{O}$ propellant. Chem. Commun. 2010, 46, 3028-3030. [CrossRef]

128. Schimmoeller, B.; Schulz, H.; Pratsinis, S.E.; Bareiss, A.; Reitzmann, A.; Kraushaar-Czarnetzki, B. Ceramic foams directly-coated with flame-made $\mathrm{V}_{2} \mathrm{O}_{5} / \mathrm{TiO}_{2}$ for synthesis of phthalic anhydride. J. Catal. 2006, 243, 82-92. [CrossRef] 
129. Villegas, L.; Masset, F.; Guilhaume, N. Wet impregnation of alumina-washcoated monoliths: Effect of the drying procedure on Ni distribution and on autothermal reforming activity. Appl. Catal. A-Gen. 2007, 320, 43-55. [CrossRef]

130. Holmen, A.; Venvik, H.J.; Myrstad, R.; Zhu, J.; Chen, D. Monolithic, microchannel and carbon nanofibers/carbon felt reactors for syngas conversion by Fischer-Tropsch synthesis. Catal. Today 2013, 216, 150-157. [CrossRef] 